


\section{UNIVERSITY LIBRARY}

\section{UNIVERSITY OF CALIFORNIA, SAN DIEGO}

from the collection of

Professor Koppel S. Pinson 


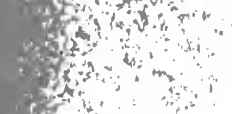

t)

$x+$

(n)

tis

Nes.

40

$\therefore$ की

ist?

46

30

of

करt?

3 ing

is:

$=\sin$

$\therefore$ ard

"Son"

soris

Sons.

$3 x^{3}$

$\because \mathrm{ket}$

$\therefore$ ate

$-4 x^{2}:$

48

tis

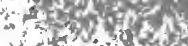

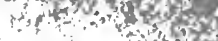

$$
\text { . }
$$$$
, ; \quad \text { insto }
$$

.

-irestos.

* $\quad \because 40+2$

the

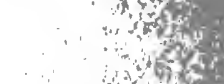

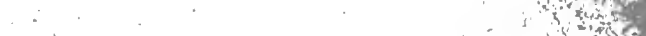

5 pinge

की

1.

ring

$\therefore \rightarrow t^{2}<$

a, inter.

$\therefore$,

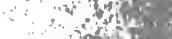

4 कर St

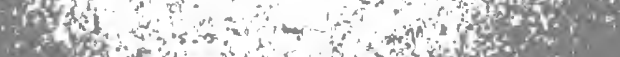

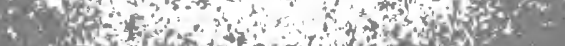

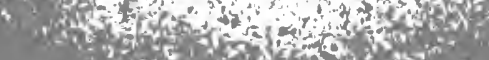
250. 
is

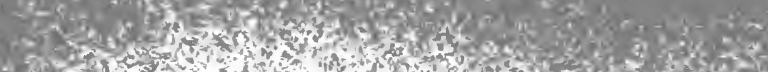

32 (2)

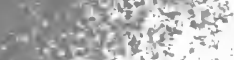

B.

a

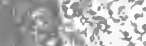

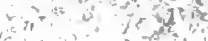

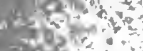

$+1$

201

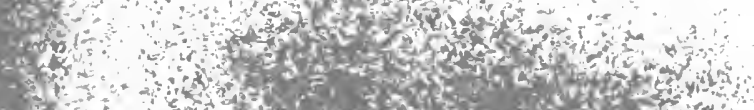

201

$1+30$

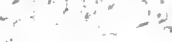

(n)

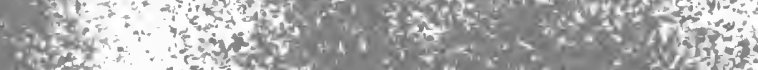

Ootez

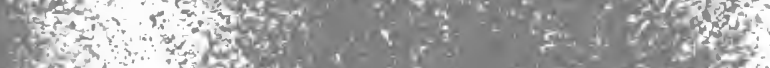

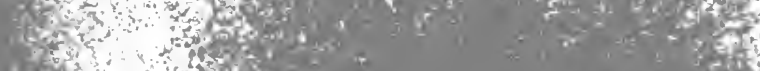

$x^{2} x^{3}$

andegs:

aris

2. $5, y^{2}=$

ats

B:

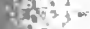

(5)

(a)

(5)

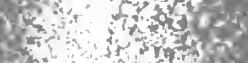

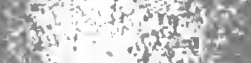

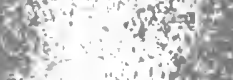

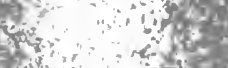

indiv

150

and

Zef

tots

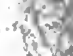

6

tin

और

$\rightarrow$

$\because 8$

- 9 की

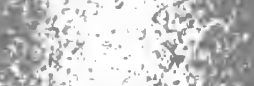

ofis

करेक

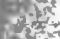

intor.

tion

ind $x^{-1}=0$

stists.

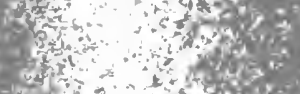

- dt

Ofy

of

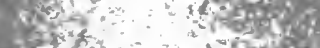

atsing

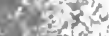

- oxstin?

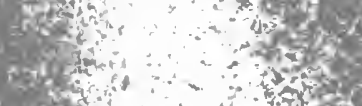

$+x y_{0}$

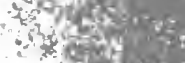

in. 


\section{THE PSYCHOLOGY OF NATIONALITY AND INTERNATIONALISM}


Digitized by the Internet Archive in 2007 with funding from Microsoft Corporation 


\title{
THE PSYCHOLOGY OF \\ NATIONALITY AND \\ INTERNATIONALISM
}

\author{
BY \\ W. B. PILLSBURY \\ PBOFESSOR OF PSYCBOLOCY, DIRECTOR OF THE PSYCHOLOGICAL \\ LABORATORY, ONIVERGITY OF MICHIGAN. AUTHOB OF \\ "Essentlals of psychology," "AtTention," AND \\ "THE PSYCHOLOGY OF ReasoNiNG"
}

\section{APPLETON AND COMPANY NEW YORK \\ LONDON}

1919 


\section{Copyright, 1919, BY D. APPLETON AND COMPANY}


TO

M. M. P. 


\section{PREFACE}

THIs book was suggested by contact that I had with the American Greeks returned to Greece to fight in the Balkan War. That raised for me a number of problems which I have tried to answer and in part have answered to my own satisfaction. On the more theoretical sides much has been suggested by the writings of Graham Wallas and his school.

The position taken appears, now that the work is finished, to be a compromise between the position of MacDougall, with his great insistence on immediate instinct, and that taken by Trotter who finds all social phenomena explained by the fear of the individual for the social whole, with the consequent dominance of convention. I have shown that the social responses are in part due to each of these forces. They begin in a rudimentary way as instincts and are then determined by conventions and ideals developed through experience and imposed upon the group by the "herd instinct." It also seems necessary to insist that the result of the action of these forces is not unvii 
worthy. One obtains the impression from reading Trotter, at least, that the action of man in the mass is altogether deplorable, that all of his conventions lead to undesirable results. One forgets in this view that reason itself is nothing more than a control of action and thought by wide experience and tradition, and that while conventions at times enforce an ultra conservatism, they also prevent unconsidered action on impulse, as well as thinking by uncontrolled association. This is an instance of a general tendency in ethics and psychology, to forget that a process when analyzed is the same process as that with which one started.

I desire to thank my colleague, Professor Reeves Dow, for reading certain of the later chapters, and for suggestions he made in connection with them, without, however, holding him responsible for the doctrines themselves or for any errors that may have escaped me. I also desire to thank my wife for help with the proofs. 


\section{CONTENTS}

CHAPTER PAOE

I. The Problem of Nationality * * • • . 1

II. The Nation as a Psychological Unitm-Social INSTINCTS . . . . . . . . . . . 21

III. Hate as a Social Force . . . . . . . 63

IV. Nationality IN History . . . . . . . 90

V. Nationality in the Process of Naturalization 126

Vi. The Nation and the Mob Consciousness . . 164

ViI. The National Mind and How it Thinks, Feels, AND ACTS . . . . . . . . . . . 186

VIII. The Nation as Ideal . . . . . . . . 224

IX. Nationality and the State . . . . . . . 249

X. Nationality and SUPER-nationality as ExPRESSEd in A LEAGUE OF Nations . . . 278 


\section{The \\ Psychology of Nationality and Internationalism}

\section{CHAPTER I}

THE PROBLEM OF NATIONALITY

Probably no word has been spoken more often in the political discussions of recent years than the word "nation" or "nationality." No principle has been more frequently referred to by all sides in arguing for right and wrong than that each nation is entitled to settle its own affairs. One may assert that there has been many a declaration of independence for nationalities that corresponds to the American Declaration of Independence for the individual, that each nation has a right to life, liberty, and the pursuit of happiness in its own right just as the individual American claimed that right for himself. We are assured over and over again that the next peace must be based upon the principle 
of nationality. This means apparently that each nation, however small, must be permitted to manage its own affairs, without interference from any outside nation. All of these discussions presuppose an agreement as to what a nation is and the existence of definite criteria for deciding conflicting claims between peoples that believe a group of people to belong to its own rather than to another nation.

That these criteria are not altogether clear in different cases is evident from numerous discussions. Both France and Germany claim Alsace and Lorraine, one on the basis of language and the desire of the inhabitants, the other on the ground of formal connection earlier in history, and community of race. In Ireland the same dispute exists in another form. Are the Orangemen to be regarded as Irish when they prefer to be English, or shall they determine their own affiliations? Here the question is different since it turns on whether a discordant element in a community is to be regarded as part of the community or as independent. The problem of criteria presents itself at many points on the borders between the central and eastern and southeastern peoples. Are the inhabitants of the Dalmatian Islands Italian because they speak the language and because their land formed part of the Roman and, later, part 
of the Venetian Empire? Are the people of Dobrudja Roumanians or Bulgarians? Is the Macedonian, Serb or Greek or Bulgarian? Are Little Russians really Russian or are they a separate people because of their different religion and slightly different language? These and rnany similar problems must be settled before the world can be properly partitioned and made safe for democracy or guaranteed a permanent peace. But before any one of them can be solved or even given a basis for adequate discussion, we must decide what a nation is and discover suitable criteria of nationality.

Many suggestions have been made as to what constitutes a nation, and most are accepted in greater or less degree in the popular discussions. Most extended, perhaps, of the characteristics regarded as essential is language. It is felt by many both among the uninstructed and the more scientific thinkers that nationality is measured by the presence of a common language. We feel that the man who can speak our own tongue is much nearer to us than the man with whom we cannot converse. Many of the authorities on nationalization insist that all citizens should be compelled to speak the language of the nation if they are to be regarded as citizens. One group of scientists implies, if it does not assert, that language is the best test of 
descent in doubtful cases, and some incline to the view that descent and language must always go hand in hand. The second criterion of nationality is this line of descent. Not infrequently do we find it implied that nation must have some close connection with race-that common physical descent is essential or atleast highly desirable if a nation is to be a unit in the best and fullest sense. The statement is frequently made that the wonderful resistance of France to what seemed to be overpowering force was due to the purity of the race, to the absence of alien elements in the race. That the racial feature is important in our own thought in popular discussions is seen in the prevalence of race prejudice. If one assigns an individual to another race, he is willing to accept that as an explanation of many shortcomings and will be suspicious of the probable motives or capacity of that individual until he has had considerable experience with the individual or with the race. Any popular political discussion will bear evidence of this tendency. Probably language and race are the elements most frequently accepted in current discussions as criteria of nationality.

In discussing the problem of nationality in general, distinction must be made between the nation and the state, between the consciousness 
of communal solidarity and the accepted political organization. For many purposes the two ar identical. A form of government usually rests upon the willingness of the governed to regard themselves as part of the social whole; and $\lambda$ successful government of a mass of people will frequently develop in them a national unity. For our present purposes we must distinguish between the terms no matter how ready we are to recognize their points of resemblance. By a naiion we mean a group of individuals that feels itself one, is ready within limits to sacrifice the irdividual for the group advantage, that prospers as a whole, that has a group of emotions experienced as a whole, each of whom rejoices with the advancement and suffers with the losses of the group. The spirit of nationality may be defined as the personification of this unity. As opposed to this the state would be merely the system of government, a unity for the sake of making and enforcing laws. It rests upon a feeling of community in most cases, but frequently the recognized unity extends beyond the bounds of the state and still more often the edicts of the state may be enforced upon individuals who do not feel themselves a part of the national group. For our purposes, the distinction must be closely drawn. Nationality is the mental state or community in behavior. 
This characterizes the nation, and this alone concerns us.

The most widely accepted theory of the state and of the nation, in so far as state and nation are confused, is that the nation is an enlargement of the family, and the state a development of the paternal authority. We find this theory so far as it affects the state definitely formulated by Plato in his Laws and it has been repeated in different forms by most writers on the development of society from his fime on. If this theory be accepted it would explain why both racial descent and language have been adopted as the criteria of nationality. Were the human organization to have developed from the family, all members of the nation would speak a common tongue and all would be blood relations, would be descendants of common ancestors. One could expect to trace the members of the nation by the physical similarities as well as by the similarities in speech. The nation would be a real biological unit. On the mental side, one might think of the nation as united by an extension of the family ties. The solidarity would be an extension of the family solidarity and the social instincts would be the racial instincts in a wider application.

In all primitive communities there is some evidence for identity between the family and 
the narrower political units. Kindred and clan are recognized among all of the races of Northern Europe until well down into medieval times, and traces can be found in remote districts until within two centuries. The system of land holding in early England shows many traces of the original family connections, and still more strikingly, the system of money payments to kindred for slaying a member is conclusive evidence of the solidarity of the kindred in all the Teutonic peoples. Here we seem to approach the condition demanded by the theory that the children of one father form a single group and these are united for purposes of receiving and paying the weregild or blood money into larger groups or kindred to the fourth and sometimes to the eighth or ninth degree of relationship. The kindred or clan was an administrative unit as well as a group bound by ties of friendliness, a social unit. From the clan various groupings are made in different lands, but in all alike the larger groups are aggregations of clans. Whether the lines of descent are recognized in the larger groups is not so clear. Certainly there is evidence that new groupings of clans that do not recognize degrees of blood relationship may be made in an emergency, and that in ordinary circumstances the degree of blood relationship, if the unit extends beyond 
the clan, has little to do with the system of organization.

That this closeness of blood relationship is not the only factor in the development of the notion of a social whole and may be in a measure opposed to it and even need to be overcome before the larger allegiances can be fully developed is clear from a number of circumstances of the organization, both in the ancient Teutonic peoples and in the modern primitive. First we have good evidence that the notion of kinship is in some degree symbolic, that while the family is thought of as a group descended from a single father, this is not necessarily true in a strict sense. In the first place the relation was never quite restricted to blood relationship. The practice has grown up almost everywhere of tracing the connection only on one side, through one parent. In most of the Teutonic and Celtic peoples only the relationship on the male side was accepted in the constitution of the clan. While the maternal relations might at times be recognized as in the weregild, the degree of their contribution was always less than that of the paternal and in many of the duties the contribution of the maternal kin was voluntary. ${ }^{1}$ Obviously the ties of emotion, which are as strong on one side as on the other,

"Phillpott: "Kindred and Clan." 
were not the basis of the connection of the kindred. It was rather a convenient form of political organization.

The symbolic character of the clan is evident, too, from the fact that a man might be adopted into the group and have all of the rights of the natural members. In many of the savage tribes some symbol of adoption may be more important in determining the relationship than the known paternity. Among the Todas of India a son known to be the offspring of another man may be accepted as the son by a ceremony performed at the birth, and where the ceremony and known facts are at variance, the ceremony is the deciding factor. The limitations of blood relationship are evident among the many peoples who measure relationship by totems. The members of the totem are restricted to descendants through the male side. That kinship as such cannot be regarded as the only measure of the tribe appears from the requirement that marriage must always be with a member of another Totem. At this stage, race and kindred, as measured by the possession of the same Totemic symbol, must be distinct, since the marriages are usually restricted to members of the same tribe, but to those that belong in another immediate family. Even in the Teutonic peoples other wider systems of organization develop 
that are recognized as distinct from the family or kindred. The chief is not the mere hereditary head of the tribe or group of tribes but frequently seems to derive his authority from some other source. Early, the leadership of the manor, of the war chief, and later of the church seemed to compete with the tie of kinship to its ultimate destruction. It is this wider community from which the modern nation has developed rather than from the tribe.

Granted then that the relationship of the family is the one from which the relationship of the nation developed in the beginning, it must still be admitted that sufficient departures appear later to make the nation a different entity and differently derived from the family as an expression of mere kinship. Either, when the kinship becomes remote, the tribe or clan takes on a symbolic character that changes it essentially from the family proper, or new relationships develop which are different in kind and in the emotions that they express from those of the family. In either case the nation raises a new problem in group psychology, and the questions that arise with reference to what a particular nation may be cannot be answered by tracing the lines of descent. We have, then, in the discussion of the nature of the nation or of nationality to ask one by one a series of questions 
that grow out of the assumption that the nation may be an outgrowth of the family, and of the different theories that oppose or limit this theory. First, how far are nation and race identical and the nation merely a group of individuals of similar descent with consequent physical and mental characters. Second, how far may one develop the mental qualities that constitute the nation in individuals of a different race.

The first question is particularly important in the light of the widespread belief in the importance of race which the victims of the discrimination regard as race prejudice and the supporters as a necessary means of keeping the race reasonably pure. The extreme upholders of this theory insist that no real nation can be developed from mixed blood, or, at least, that the more pure the blood of the nation, the stronger and more unified is that nation. Opposed to this is a group equally positive in its belief that only a mixed race may be strong, although few go to the extreme of insisting that the greater the mixture the stronger the race. In these popular discussions, even in race congresses there is frequently more prejudice than reason. The members of the races that are regarded as inferior always point to the accomplishments of the best of their race as evidence 
of what they might accomplish were they given a chance, while the believers in the superiority of one race or group of races emphasize what the worst of the lower races have done or failed to do and forget the lower individuals in their own or the worst acts of their best.

It cannot be denied that at present clear evidence of racial capacity is lacking. At the extremes no one would assert that all the races are equal, on the other hand no one can grade the races with respect to their intelligence. Standards of accomplishment are absolutely different. Tagore denies that one can measure ability by business capacity or attainments in pure science. He insists that artistic appreciation is quite as important. Others insist that race prejudice and natural environmental conditions have prevented the backward races from getting a fair chance and that they are backward because of that rather than from lack of capacity. I suppose that until they have their chance and really succeed this would not prove capacity, however much it may complicate the discussion or the possibility of asserting equality. It is not sufficient to say that the negro has not done more because prejudice prevents him from being accepted as an equal in the professions. It may in part explain the failure, but individuals of other races overcome prejudices 
and no one can say whether these prejudices are greater or less than those under which the negro labors. This makes it a question whether it is of any advantage to have a nation all of one race, whether in fact any emphasis at all is to be put upon the line of descent. We need not settle this problem if we could; suffice it for our purpose to indicate that race, could one know it with certainty, is not necessarily final in determining capacity.

The strongest advocates of the theory hold that race and nation are or should be identical, believe that races are distinct physical entities which may be discovered by measuring the members of the race. The anthropometrists of the last generation worked on the assumption that it was possible to discover a group of characteristics that went together, which when known would characterize the race. The signs upon which they insisted most strongly were the size and shape of the skull, the shape of the nose and other features, stature, and pigmentation. Some of them seem to believe that one could measure the skull of an inhabitant of the British Isles and determine whether he was descended from the pre-Celtic primitive, from Celt, from Saxon or Norman. While it cannot be said that this theory is definitely wrong, recently accumulated evidence tends to discredit 


\section{THE PSYCHOLOGY OF NATIONALITY}

the more extreme views. Many of the characters regarded as fixed seem to be open to change under the influence of environment. One of the most striking facts in favor of the statements is the well authenticated series of changes in some German emigrants who settled in 1817 among the Georgians near Tiflis. Originally fairhaired, blue-eyed, with coarse features, in two generations they have developed dark hair and brown eyes with a "noble oval face." This was without inter-marriage with the natives. The change is ascribed to climate and general environment alone. ${ }^{2}$ Boas found a marked change in the cephalic index of Russian Jews and Italians in America in only one generation. The Jews became markedly more dolichocephalic, while the long-headed southern Italians became considerably broader-headed. Why this change should take place Boas does not pretend to say, but it is apparently because of food and environment. As the cephalic index or ratio between length and breadth of the head is made the cornerstone of race by many anthropometrists it is especially significant that it should prove so variable. Evidence of the change in mental characters is also apparent in the change of status of the immigrant in America and in other cases of widespread race migrations. If

"Keane: “Ethnology," p. 203. 
one add the two reasons for skepticism together, it would seem that it is impossible to detect race except by tracing the history of the descent, a history which is lacking in most cases, and if the physical and mental characters change with environment, it would make little contribution to the problem of race could we succeed. Descent has little influence in determining the character of the individual over long periods of time and hence can have little effect upon the nation.

Could one determine the race and did race have all of the significance that has been ascribed to it, we would be little farther ahead in the discussion of the nature of the modern problems of nationality. All of the modern European nations are mongrel, are compounded of numerous elements and many of them are composed of much the same elements in a slightly different combination. If we compare the nations that were aligned on opposite sides in the great war we find that they had quite as many common elements as those that were fighting together. In each nation wave after wave of conquering peoples has settled and been absorbed by mixture with the conquered. The original primitives were probably absorbed in the conquering Celts, affecting only a few of their customs, the Celts in less degree by the Romans, 
themselves a much mixed race, and the more or less Romanized Celts by the Teutons in the west and by the Slavs and Mongols farther west. If one follow Keane ${ }^{3}$ in a classification the English would be Celto-Teutonic; the French, IberoCelto-Teutonic; the Italians, Liguro-CeltoItalic; the Russians, Finno-Slavonic. The central powers would be made up of Germans who are Slavo-Celto-Teutonic, the Prussians, LettoTeuto-Slavonic, the Austrians would add various Slav and Mongol elements, the Bulgars and Turks would add new complexes which were as remote from one group as from the other. The ethnic composition of the opposing groups offers no explanation of the alliances. The elements that are mixed are much the same and the proportion of the different components does not differ sufficiently to explain the lines followed by the alliances. The nations are not racially pure, nor do they approximate purity. The components were found on each side in the alliance and approximately as many on one side as on the other. Possibly a few more Celts on the side of the Allies, a larger percentage of Teutons on the other, but in no sense was it a race war. In the determination of national lines in general, race is no more important. There is no pure race in any nation. In the race mix-

"Keane: "Ethnology," p. 201. 
tures that constitute nations, it is not the numerical predominance of one racial group which determines the character of the nation. For that we must look to more subtle causes.

The prevailing language of a nation may offer a somewhat less uncertain criterion of the racial descent than the physical measurements. One at least can say what the language is and can trace the elements that have entered into its composition in the development of the peoples. But language is probably no more accurate than physical measurements as an indication of the racial components of a nation or of community of spirit of its inhabitants. The language of a nation varies with its racial components, but one can be sure neither of the numerical nor political dominance of the races by the languages. Sometimes the conquering race may impose its language as the Romans did on Gaul when the race contribution was comparatively slight. Again the conquered persist in their original speech practically unaffected as did the English at the Norman Conquest. Community of language does not mean community of spirit or the reverse. The Irish will not admit that they are English although they speak the tongue nor do the Swiss follow the linguistic boundaries in their feeling of nationality. The German Swiss is as much Swiss as the French, 
the Italian as the German. While the sympathies of the communities in the great war seem to have followed the speech of the district in some degree, it was not sufficient to endanger at all the national unity. On the whole it seems that a common language may be either a result of national unity, or it may be a sign of the historic development of the peoples. When a national spirit develops as among the Irish, a national language may be fostered to give it strength or serve as a symbol of that unity. In that case it is rather a symbol or effect of that community of spirit than its cause. We must not deny that a common speech is an important element in furthering the national spirit. All that is intended is to assert that it is not a sine qua non,- - that language and language alone does not measure and indicate the nationality.

In this brief survey we have developed a formidable list of negatives. We have found many elements that might and are frequently assumed to furnish a criterion for nationality which obviously are either without influence, have less influence than one is inclined to believe at first sight, or are impossible of application. Physical descent cannot be used as a criterion. For, in the first place, it cannot be traced with accuracy over a sufficiently long period to settle disputed points. Where it can be traced in historic 
periods we find it does not correspond accurately to the present political boundaries. Large nations that have remained in their territory for a long period may change their allegiance. When large numbers of descendants leave the mother country they may or may not carry with them the essentials of their native land. Americans ceased to be English in a few generations, Alsatians ceased to be German in an equally short period. Where individuals move from one country to another they tend to change their allegiance, and frequently in the second generation are by no means to be distinguished from the people among whom they live.

Granted that physical descent were a basis for determining nationality, it cannot be discov-. ered by other than historic methods. The physical features which might be regarded as marking nations or even races are not sufficiently certain nor sufficiently permanent to be an aid in deciding the question. Historical evidence shows that nearly all races are mongrel, and that where the lines of division can be traced at all the mixtures are not markedly different for any of the countries of Western Europe. Anthropometry cannot solve the problems that history leaves in dispute. Were a commission to be given power to sort the individuals in the Balkan Peninsula into ethnic groups and then to as- 
sign boundaries and rearrange the population so that all people of similar physical characteristics were in the same communities, it is safe to say that the confusion in the Balkans would be increased rather than diminished, and that the result would not make for the happiness of the individuals. Even the more readily discovered speech, while ordinarily following racial lines, is not an absolute guide. It is an indication of the probable allegiance, but neither a necessary cause nor an effect of national spirit.

For the final deciding factors, the final explanation, one must look not to these physical or fixed mental characteristics and habits but to purely mental qualities, or to mental qualities based upon physical characteristics. The national characteristics are to be discovered not directly but only through the responses of the individual and through the responses that betray his emotional and intellectual activities. If you are to know to what national group an individual belongs the simplest way is to ask him, and while his answer cannot always be trusted, but must be interpreted in terms of his general behavior, it is, if he speaks the truth, a better criterion than history, or racial descent, or physical measurements. Nationality is first of all a psychological and sociological problem; only indirectly can it be determined by anthropometry or even by history. 


\section{CHAPTER II}

THE NATION AS A PSYCHOLOGICAL UNIT-SOCIAL INSTINCTS

To have discovered in the last chapter that the nation cannot be explained from physical laws alone does not free us from attempting to discover what laws do control it. For the psychologist believes that man's so-called mental nature is controlled by laws that are quite as assured if somewhat more difficult to discover than the laws of his physical organism. If we cannot believe that a nation originates by the gredual accumulation of offspring from common progenitors as a coral island grows, we are not therefore absolved from all attempts to determine what the laws are that govern the common action of groups and explain the fact that certain individuals unite into a group, accept as proper the acts and desires of the other members of the group, and refuse adherence to the ideals of other groups. In fact, we must endeavor to learn why, when the groups have been formed, each has many of the aspects of a single individual and acts toward other groups 
very much as if that were a rival individual. One may reduce many of the acts to common terms and find in these many points in which the nation as a whole resembles the activities of individual animal or man.

In the explanation of the acts of social wholes as of an individual the most striking single fact is the divergence between the motives and forces that the individual himself assigns to his acts and the explanation which seems to the scientist the real explanation. One can place little reliance in the statement that the agent gives of his motives or of the forces that he believes to control him. It is the privilege of the scientist to arrogate to himself omniscience as to the causes that impel the actions of the mass. This may be only for effect and is frequently far from being accepted by the agent or by other scientists as final. At the worst, our knowledge is sufficient to indicate that many of the acts that seem to us simplest are really the effects of changes wrought in the nervous system in some remote period of evolution. It is the duty of the psychologist to trace in every way the present responses to their causes in early formed habits, and in the predispositions of the organism at the birth of the individual. This can be done only by study of the behavior of the individual or of the society under differ- 
ent conditions, and by comparing the action of individuals and societies that have been subjected to those different conditions. The results of all of these studies have been combined in a number of different theories of social groups. One theory, which is perhaps most fundamental, would explain the social group as the embodiment of instincts. A second finds the closest analogy for the action of a nation, even when the individuals are so numerous and so remote that they may communicate only by the press and through representatives, in the action of a crowd and would ascribe to the crowd certain peculiar qualities that render it different from a mere group of individuals and much different from our ordinary conception of a crowd. A third endows the nation or any social group with a self in addition to the selves of the separate individuals, finds in its action evidence that it thinks, feels, and acts as a unit apart from the thoughts of its component selves. The first theory may be regarded as analytic. It distinguishes different phases of the action of the social unit and finds similarities for each in the action of individual animals and men. The last two are more general analogies, are satisfied to point out similarities between well known phenomena and the action of the nation, and re- 
gard that analogy as an explanation. Each may be discussed in order.

Since Darwin there has been a growing tendency to explain the acts of man and of the animals in terms of instinct. This means that most. of the acts are made for some reason that cannot be understood by the individual, in the case of man, or by an observer unless one assumes that they are an expression of innate dispositions,--dispositions that have survived because they were essential to the existence of the organism. Many of these acts which we call instinctive are performed in advance of any opportunity to learn them, and in certain cases the organism in question would be better off if they did not appear. The infant takes nourishment at the first opportunity and with movements almost as perfect at first as after frequent practice. The first nest of a robin is as well made as the last, and the beaver needs no practice to cut a tree in the most approved fashion. These instinctive movements are evidently not rational as they frequently are performed in every detail under circumstances in which they are of no value. Thus a squirrel will give a perfect imitation on a carpet of the actions used in burying a nut, and James cites an instance of a dog that carefully laid down a bone in a room, and after making movements as if scraping dirt over it, 
left it in full sight. Many of the fears of man are absolutely valueless, probably a detriment in the environment in which most of us now live. Fear of snakes in the city dweller or in the North European, fear of the dark, fear of open places, as we find them in certain of the neuroses, have no value in protecting the individual and no chance to develop through habit. Still they appear in the most unexpected places and in the most rational of men.

One might think of these instincts as inherited habits, activities acquired by progenitors which have been transmitted to the present generation. This explanation is accurate save for the method of origin. The modern biologist objects to the assumption of an inheritance of the characters acquired during the life of the individual. Instead he insists that instincts, like all changes in structure, arise through some chance change in the germ plasm, the cell set aside at the first stage in the development of the parent and remaining in the body of the parent unchanged until it begins to develop into the individual in question. This reproduces the general type of the race, but may undergo variations of slight amount in the new individual. No two are quite alike, and occasionally very wide divergencies from type present themselves. Some of the changes may be due to the 
mating of unlike parents, others seem to be owing to chemical changes in the cell, which occur for an unknown reason. When they occur, the changes in structure or the acts induced by these changes may be beneficial and increase the chances for survival of the individual, or they may be harmful and cause him to act in a way that shall result in his death. Thus, if some change in the nervous system cause the new member to like and eat a food that is abundant and nourishing, but which has been instinctively disliked by the race up to that time, the probability of survival will be increased. If, on the contrary, the change produce an appetite for a poison of frequent occurrence in the environment, the individual will be speedily eliminated. Similarly any new instinct of caring for the young will cause the survival of a greater number and so be self-perpetuating. The race that develops that instinct will soon outnumber and may crowd out the others that fail to develop it. An appetite for its own young would result in the elimination of the race in which it appeared. One might picture this process of development of instincts by natural selection as an enormous game of chance in which the stakes are life and death for the individual and increase or decrease in numbers for the race. The chance lies in the appearance of the changes in 
the germ plasm, the stakes are won for the race provided the individual lives long enough to propagate his kind, and the degree of success is measured by the number propagated and the number that survive.

Most acts that are essential to the survival of the individual and to the propagation of his kind are instinctive. They cannot be left to learning and so are insured by being established in the nervous system at birth. They have been essential to the life of the ancestors and so have been retained when they appeared by chance. These individual and racial instincts express themselves in two ways. The simpler are acts which are performed at once when the stimulus or occasion arises. Taking nourishment, sleep and exercise, movements of withdrawal from dangerous stimuli are of this character. The second form is marked out in the rough and is controlled in detail by the feelings. Most instinctive movements that serve to approach or retain objects are pleasant; those that constitute acts of withdrawal are unpleasant. In the more complicated acts only the pleasantness of attainment of ends that are beneficial and the unpleasantness that attaches to the presence of harmful stimuli give evidence of instinct. The movements are not mechanical, are not prescribed, but again may be regarded as chance 
responses, in which pleasure or displeasure decides whether they shall be made, or the results accepted or rejected. Thus a chick will peck at any bright object at first and, when it takes into its mouth a bitter tasting worm, will at once reject it. The movement is not discriminating. The final test is the pleasure or displeasure of the taste. A youth selects his mate on the basis of the instinctive pleasure aroused by her features or form; we judge the consequences of our acts and plan our future activities in terms of the pleasure or satisfaction they are likely to produce. In general, then, our most important acts are prescribed at first by instincts, and all through life the instinctive feelings of pleasure or satisfaction and discomfort or dissatisfaction serve to select and guide our movements.

Many of the fundamentals in human nature that make social life possible and agreeable are also instincts. The pleasure in association with others, the responses of features and voice to the looks and remarks of friends constitute the simplest, least active processes. At the other extreme stand the incentives to coöperate, the impulses of self-sacrifice for the social unit upon which depends the formation of nation and state. In this discussion we must distinguish the coöperative from the antagonistic so- 
cial instincts. The first serve to hold the group together and further the interests of its members. Opposed to these are the instincts of cooperative defense and aggression, instincts which unite the members of one whole against another for the sake of advancement at the expense of the other. The one makes possible the organization of the peaceful society, the other the organization for war. The second in a measure depends upon the first, but contains elements of self-sacrifice that are not required for it. The one presupposes life together in the absence of hostile tribes, the other is a development of a life of conflict between rival groups. It is probable that the second may have been the first to develop-that only when there were dangerous rival tribes was it necessary to form a larger social grouping. However this may be, it is certain that at present we can see traces of each. We may begin with a treatment of the coöperative or intra-social instincts or forces and pass on later to the instincts of hate and conflict, the inter-social.

The fundamental instincts upon which cooperation is dependent may be reduced to two; sympathy for the other individuals, and fear of the social group or of other members of the group. Upon these two develops a system of ideals and social concepts which constitutes the 
fabric of the social system. These ideals when fully developed seem to have many of the positive features of law. The instincts of sympathy. are among the most definite of the social responses. When one observes the suffering of another one suffers with him in the literal sense of the Greek original. One cannot read of eyes gouged out without a strain of discomfort in one's own eyes. Observation of the effects of hunger or of blows may similarly induce a localized pain. The pain or the discomfort is apparently an immediate instinct. The localization in one's own body is probably largely due to suggestion. Whatever the neurological connection, the fact is obvious and verified every day. The suffering is very real and can be escaped only by relieving the suffering of the other or forcing one's self to forget it. The former is usually the easier method. This instinct is probably the strongest incentive to charity; it makes charity not an intellectually or morally motived activity merely, but a necessity for the individual's immediate comfort. Its ramifications in the social life are wide; most unselfish coöperation depends upon it. When strongly aroused it passes over into resentment and becomes a strong factor in the exercise of the criminal law.

The instincts of the second class are more ef- 
fective in keeping discipline within the group. They are the instincts of fear or of respect for the group as a whole or for its members. These vary from the paralyzing effect of youthful bashfulness, through stage fright, to respect for the opinions and feelings of others just because they are expressed or exhibited by others. In its strongest manifestations bashfulness suggests a pathological fear. It is most intense in childhood and weakens later to increase in adolescence. Even in the adult, only long practice will enable a man to appear before a large audience with complete composure, and the most experienced are subject to embarrassment when put in a new position or before a strange audience. It appears when reason gives every assurance that there is no danger. In the crowd this fear enables the group to establish its dictates against the better judgment of the individual. He does what others do because he is uncomfortable when he does not, he is in many cases actually afraid to assert his opinions against the crowd. The fear may be overcome by a strong man who is confident that he is right, but the weak man does not assert himself and the strong man yields on points that seem to him relatively non-essential rather than undergo the discomfort of self-assertion. This in the crowd assures coöperation and is one of the 
factors that make the crowd approach a unity. It is a powerful agent in the enforcement of standards in groups of individuals who are in communication only through the indirect means of the press and hearsay. The individual tends to subordinate his opinion to the social group's. Why he acts as he does, why he feels uncomfortable when face to face with a crowd, the individual does not know. The instinct expresses itself only in the acts and in the feelings; it is not revealed to consciousness in any other way. The actor knows only that he acts, and that he would be uncomfortable if he failed to act as he does.

This fear of the group, or of society as a whole when at a distance, makes possible what is perhaps the most important concrete factor in the development of society and in the development of the individual as a member of societythe development of ideals and the enforcement of ideals upon the members of a social group. The ideals themselves we may take for granted as the gradual development of a standard of action or of thinking that has proved valuable for the group. They certainly do not arise from rational considerations. When they do appear, ideals constitute the most essential element in determining the life of the individyal and of the community. Success in attaining 
these ideals gives most of the pleasant emotions, failure to attain them many of the most poignant sorrows. In the present state of industry and the use of machine tools the absolute needs for food, clothing, and shelter might be satisfied by working a few hours a day. The rest of the time is devoted to satisfaction of what might be satirized as the "showing off" instinct. No one, of the gentler sex in particular, is content with comfort in clothing; one must have something that shows on the face that it is difficult to procure. As if to make sure that garments are not carried over from year to year, the styles change with frequency, and the most elaborate gown that bears the marks of an earlier season must be discarded. The current styles emphasize the statement that neither protection nor comfort has much weight in the minds of the designer, or in the thought of the wearer who selects or accepts his product. How little can be made of the development of these standards is evident from the way the styles develop. There is no official dictator, but a changing group of designers who feel that their success depends upon their ability to please the public. The public on the other hand accepts what it believes to be supplied to the best people. Probably the public and the designer both are guided to some slight extent by instinctive apprecia- 
tion of beauty, however little beauty there seems to be in many of the styles. More depends upon the prestige of earlier successes, obtained in ways and for reasons that cannot be clearly determined.

Less clearly, but none the less unmistakably, the manner if not the materials of eating is determined by these social standards. One eats in places to be seen of men, or if one lives at home, has accessories of the table that shall carry conviction of the social status of the family. Less obvious are the manners that are acquired by or forced upon the children as a sign of descent from a superior stock, minutiæ which have no raison d'être aside from giving the distinction of being different. The size and adornment of the house is chosen rather to impress and serve as a sign of power or possession than for the comfort of the inmates. Many of the real conveniences are introduced because they are proper rather than because of their accepted utility or hygienic value. All of these features of life derive their vogue from the fact that they are approved by the group. They are a sign of the material success of their possessor, or of his social position. The pleasure that they give is largely derived from the effect that they are supposed to have upon others rather than from their inherent satisfaction. 
The owner does not feel that he is observed of men, nor does he feel that he is strutting with the peacock, but take the element of social approval away and he loses interest in many of his most treasured possessions. Change the nature of social approval and the things desired change their character. One can imagine that in a national struggle for life and death when everything was needed to save the nation itself, abstinence might become enough of a virtue to have men rejoice in rags and plain living. In the late war we approached this sufficiently to appreciate how much the ordinary scale exceeds the level of minimum necessity and sometimes even of the minimum comfort.

These standards are set not only for the creature comforts and material necessities, but for the matters of the spirit as well. What shall be the accepted doctrine in politics, in religion, even in science and philosophy is determined from generation to generation, even from year to year, by the social whole. Apart from its truth or philosophy the divine right of kings had a vogue before the French revolution that has been entirely lost since the downfall of Czar and Kaiser. Belief in hell had a long run of popular favor that seems to have pretty well passed at present. The dominance or passing may be in part explained by the experience of a 
society of a given age, and may be a reasoned belief for the select few, but for the great mass these fundamental beliefs are almost as much matters of fashion as the cut of a coat. It either is or is not the thing at a given time and in a given circle and is accepted or rejected accordingly. Certain men, the leaders, can give a reason, if not the reason, for a particular belief; some contrary-minded individuals are spurred to skepticism by the prevalence of any doctrine, but the great majority accept their beliefs from the parson, from the latest book, or from a fashionable lecturer just as they take their hats from the best milliner. The attitude might be rationalized by saying "if all the best people accept it, it may be right, at least it saves thought, for after all nobody knows and it is as well to be in good company."

The readiness to accept these ideals and beliefs from society is probably one of the most important factors in the development of social life in any form. It holds not merely in the smug, best society, but even more strongly for the common people and the dregs. It holds as well for the workingman or man who is disinclined to work who believes that a socialistic state will provide the utopia, as for the capitalistic believer in protection and large armaments as a specific for all industrial evils. The social- 
ist orator is as ready with his "it is universally agreed" or "all the best minds who have examined the social position of the laborer assure us" as is the orator in Congress. Each is as ready to rest upon the authority of a generally recognized man, and much of the general recognition accorded to certain men arises because their opinions suit the many who give them great praise, because they desire to believe their statements. In the last analysis many such statements mean merely that it is good form in my set to accept this opinion. Seldom does any one either in the high or in the low levels of society attempt to go farther when talking for public effect. When the honest independent thinker does reach conclusions at variance with orthodox or accepted opinion, no matter how thorough his investigation, it is very difficult to have them considered, and it is almost impossible to convince the masses even when the evidence in their favor is the best possible.

These ideals depend for their existence upon two factors: (1) the existence in the individual of an instinctive respect for the opinion of the whole akin to the fear of the group, and (2) upon a traditional growth of a conventional standard. To accept the opinion or the standard of the group is instinctive, but the opinion or standard itself is not immediately instinc- 
tive; it is the product of experience, of separate instincts and of the tradition in the society. If one consider the ideals of success of the contemporary American, one finds that what he strives for are things that appeal to the primal instincts, and are on their material side desired instinctively by all men. The degree and form in which they are desired are determined primarily by the conventional standards of each community. Wealth in any of its forms is in some degree instinctively desirable. The horses of the steppes or the buffaloes of the Todas satisfy the instinctive demands by providing food and clothing in addition to being beasts of burden. When the wealthy chief obtains more than he can use they are of prime value as a medium of exchange, may, as with the buf'faloes of the Todas, become connected with the religious worship, and in any case obtain their main worth as a sign of the success and consequent importance of the possessor. Probably gold and silver and precious stones developed their place in the scale of values in the same way. Satisfying first the instinctive æsthetic desires, their rarity gave them an established status as a medium of exchange. They were first an immediate means to the satisfaction of all needs and, secondly, a symbol of power, They then became conventionalized as a meas- 
ure of the degree of social approval and hence the end of all attainment. When thus established they are the accepted ideal of the particular group. One never questions why one should strive to attain them. They seem to be an end in themselves.

The standardized ideals of other kinds follow the same course. All men are curious. From this develops love of knowledge, from that, in turn, respect for knowledge. From this series of instincts is derived the social respect, so far as it exists, which attaches to the scholar's career. In a measure, the appreciation sets up rewards and standards of attainment in positions in connection with learned institutions, memberships in academies abroad and what not, that in a measure atone for the small financial returns. That financial rewards are of the same order as social approval is seen in the lower levels where the girl of superior intelligence will take the smaller wage of the department store rather than the higher of the factory, and either rather than better paid household service. The ideal for attainment in these cases consists in the name of the profession. Society gives greater esteem to the lawyer than to the locomotive engineer of the same earning power, to the physician than to the veterinarian, to the clergyman than to the riveter. 
These are in part symbolized in the dress. Any calling that permits wearing a white collar and having moderately clean hands seems to stand higher than one which is too dirty or too rough for the better clothing. This may be due partly to the pleasure in the dress, and partly to the fact that the dress is merely an indication of the respect in which the calling is held and of the type of man who seeks to enter it. Certain it is that these "white collar" callings have a more general esteem; men are willing to submit to longer training in preparation for them and to receive smaller rewards in them than in others of less difficulty and in themselves no more disagreeable. Success in none of them is measured by the financial rewards and in some measure they compete with business on this basis. In some of them, the attainment is measured rather by the standing in the profession itself, by the number and value of the books written, by the pictures hung and the prizes received rather than by the financial reward. There is in artistic circles a tendency even to look upon financial rewards as vulgar even though they are never spurned. The reward is conventionalized; but it is a different, perhaps a contradictory, ideal from the ordinary monetary reward.

When we turn from these standards of appreciation to the ideals of conduct we find that 
in general outline the process is the same. In morals the standards have been formulated so definitely that they may be reduced to codes, although frequently the actual legal codes are not identical with the standards approved by society. The incentives to live up to the ideals are approximately the same as for the attainment of success, except that more emphasis is put upon the punishment for failure than upon reward for success. The acts interdicted are those that would be harmful to the social whole, and most would, if permitted, render the group less likely to survive. As in the preceding instances the standards or ideals are firmly established, although it is easier to say when they have been departed from than exactly what they are. The moral as distinguished from the religious among the ten commandments are specific, but they are given latitude in interpretation. The less fundamental features of moral behavior are quite as rigidly enforced, although not so clearly formulated. All may be said to be instinctive in their fundamental character, given a particular form or content by convention and tradition, and then enforced by the instinctive fear of the dictates of the social group.

Ideals for the vaguer relations of states illustrate the same laws. One may say that all modern states have an ideal of freedom for the in- 
dividual. This ideal is somewhat peculiar in that it is in large part a reaction against the older social conventions, but has become establishod in its turn through social approval. The content varies from nation to nation in the shade of meaning that is given it, and even from one social group to another. For the allied group of nations the term means in general freedom from interference by the government, and in less degree by social opinion, with the details of the thought and action of the individual. Even in the different members of the alliance the meaning varies from nation to nation. In England freedom of speech in political matters is much more prominent than in any of the others. In the United States we emphasize more right to vote and perhaps the abstract notion of freedom with little practical application to personal freedom in conduct or in speech that affects matters of established government or general political belief. In France personal freedom is much more in evidence. The Puritanical restraints of both England and the United States would be irksome to the Frenchman. There is probably, too, less or at least a different subordination of the individual to the state where personal pleasure and state interests come into conflict. In all three countries the interpretation of the ideals varies from time 
to time, under the stress of circumstances. During the war many of the most cherished features of the American constitution have been put aside by popular consent because they stood in the way of winning, and even the highest courts have found a way to justify their temporary abrogation. In all of these countries liberty is restricted in its application by the accepted needs, by the conventionally accepted greatest good of the greatest number. In all of these countries rights are tempered by duties. In the Russia of the Bolshevists alone is there complete freedom, with no restriction by convention. The result is license and, to the distant observer, a condition that resembles the earlier autocracies, with the complete dominance of the physically powerful.

The ideal of personal liberty is very different from the national ideal in either of the Central Powers. There the doctrines of a century have succeeded in reducing the freedom of the individual to the exaltation of the State. The State is accepted as a real person with the rights and joys of a person and the educated German at least has accepted it, has become content to share the glory of its greatness as a substitute for his own more personal emotions. The less intelligent are bribed by good wages and living conditions to accept an existence with a mini- 
mum of personal freedom, aside from the freedom to gratify his more fundamental instincts in his own way. How far this condition will survive the wreck of the war is still to be seen. What strikes one most forcibly in the rapid changes of the war period is the quickness with which one ideal may supplant another and the completeness with which the material conditions change with change in the ideals. Russia is made over or destroyed, as one will, by the general acceptance of an ideal held before the revolt by a small but noisy minority. France is reborn with the vivifying of an ideal that many had assumed before the war to be accepted only. as a form. Whether the well disciplined and conservative German has a latent ideal that shall transform Germany in the same way is still to be seen.

These ideals constantly cross the racial and the individual instincts and may easily be confused with them. One frequently speaks of an instinct of cleanliness, but study of different races and the evolution of the small boy show that much of the dislike of cleanliness depends upon social ideals. Imitation has been frequently spoken of as an instinct, but it is probably only one form of the socially enforced acquiescence in the standards of the community. The forms of the constructive instinct, of the 
acquisitive instinct, of the instinct of curiosity, if not the acts that are ascribed to the instincts, are frequently derived from the social standards or ideals. As opposed to the immediate instincts, these ideals obtain only their general content and the incentives and warrant from instinct. Their content comes from learning. As compared with the individual instincts, too, they reveal themselves by feelings rather than by acts. One is guided in the decisions by the emotions that attach to the contemplated act, or by the empirically known results of the act rather than by the immediate compulsion of the acts themselves. In effect they are no less strong than the immediate instinct, as is evident from the result when they come into conflict with the individual and racial instincts. Many a sensible woman will give up food or comfort for a gown that will win social approval, and many an ambitious youth sacrifices health that he may succeed in a profession. The birth-rate is low in the higher classes, for children are incompatible with the best garments, with automobiles and other material signs of social standing.

Of particular importance in all discussions of social psychology, because of the large place that has been assigned to it by Tarde, ${ }^{1}$ Bald-

1Tarde: "Laws of Imitation." 
win $^{2}$ and others is the relation of imitation to the instincts. Tarde and others who make most of it regard imitation as a simple instinct, and assume that any act made by one man will be imitated by others about, just because this act is observed. What observations we have on the simpler forms of imitation indicate that such an instinct does not exist. Imitation seems rather to be the result of a number of instincts and to be closely dependent upon the general social instincts we have been considering. We may distinguish at least three different senses in which the term is used: first, the imitation of simple movements that have not yet been learned; second, of simple movements that have been learned and made at other times by the individual who is to imitate; third, complicated acts, purposes, or institutions which are adopt- . ed by one people from another. The experimental evidence both in animals and men for the influence of imitation of the first sort is negative. An unknown movement is learned no more quickly when a model is furnished by another than when the animal or child is left alone, provided only some incentive for the movement is given. Cats get out of boxes no more quickly, monkeys learn to pull bananas near them with a cane no sooner if they are shown than if they

'Baldwin: "Social and Ethical Interpretations." 
are left to try by their own efforts. The acts as made by another may provide an incentive to attempt to make them, where that is otherwise lacking. Thus the child learns to speak, apparently, because the sound he hears sets a model that he tries to repeat. When that sound comes by chance from his own vocal organs he is interested in it and will repeat it. Even this is not a separate instinct but is only one expression of the instinctive interest in others of his own species which impels him to notice the sounds they make.

The movements which have been learned already will, of course, be repeated when another is observed to make them. This has fundamentally the same explanation. The general social instinct leads the actor to observe the movement of other men, and, when that movement is seen, the sensation evokes the movement by what we know as idea-motor action. It should be observed, too, that the movement will not be made unless the results appeal to the individual as desirable. Whether they shall or shall not be desirable is also dependent upon instinct and experience, with social convention as an element in deciding. The same may be said of the third more complicated form of imitation-the adoption of styles, of ways of thinking, and of social or legal institutions. Seeing them or knowing 
of their existence may suggest the adoption, but whether they shall be finally adopted depends upon who exhibits them, the emotional reaction that they arouse, and their success in practice. In short, imitation in none of these forms is an instinct, but like all other acts it is in part dependent upon instincts. At the most it is the expression not of one instinct alone but of many divergent ones. Most of the social instincts, particularly social pressure, combine to induce imitation in each of the senses in which the term had been used. We shall have several occasions to discuss the third form.

The development of social instincts is explained by the same principles as the development of any instinct. The higher animals survive as groups, packs, or herds, rather than as individuals. The beasts of prey are more effective in the pack than alone, the herd of deer or of cattle is more likely to survive than separate individuals of the same species. Assume two species of wolf in the same region, one with the instinct of hunting in the pack, the other without it. The former would survive in greater numbers and the others would in time be eliminated. Where game is scarce or large animals predominate, the survival of those that hunt in the pack would be more pronounced, the elimination of the others more rapid. Similarly, 
where predatory animals abound the non-social Herbivora would quickly be eliminated.

The specific forms of the social instincts are also to be related to survival value. The tendency to self-sacrifice would subserve the interests of the species since if the males alone are killed there are always enough to preserve the fertility of the group. Were the herd to scatter on attack, more individuals would perish and they would be the young and the females upon whom survival mainly depends. The instinct of the deer to gather in a circle with the males on the outside, then, favors survival. The social instincts, like the individual and the racial, can be regarded as tendencies or dispositions that have developed by chance and which persist because the individuals in whom they have developed survive while those who fail to develop them are eliminated or survive in smaller numbers. The fear of the group would tend to make for discipline. In man, at least, one can trace the effects clearly, and possibly in the higher animals one may imagine an instinctive fear of the group that would force the male to the outside of the herd, as it shames a coward to the attack. The more tender emotions of sympathy seem little if at all in evidence among the animals, although they appear in the lowest men.

In man the social instincts are more impor- 
tant than in any of the animals. Man is less fitted to survive alone, more dependent upon the care of parents at birth, and he alone, apparently, is aided by knowledge and the possession and use of instruments that can be developed only gradually through the course of generations rather than found ready to hand. It can be seen at once that no great numbers of men could survive did they not gather into groups and coöperate for defense against the more powerful beasts and in the pursuit of the animals which provide them with food. The question has been raised by MacDougall whether we need to assume more than the maternal instinct to explain the social phenomena of sympathy. $\mathrm{He}$ asserts that when the family instinet is extended, as it is bound to be, the social instincts are certain to arise. If we accepted the development of society from the family the extension of the maternal and paternal instincts would naturally follow, weakening as we find them to do, with remoteness of relationship. We have seen reason to doubt whether the nation developed quite in this way, whether, at least, the feeling of kinship was not extended so far before the nation developed as practically to cease to exist. We have also reasons to believe that loyalty to the social whole contains some elements that are different in kind from family affection. 
They certainly are more readily developed and transferred, and have no relation to the nearness in blood. Graham Wallas ${ }^{3}$ is probably right in insisting that the social instincts are distinct from the maternal and paternal. Even if they are not distinct in origin they are distinct in application which is all that we need to contend for our present purposes.

All the social instincts must have been effective in developing the primitive communities at a time when the formation of groups of individuals was necessary and not optional. One may assume on the one hand that individuals who spoke the same language or were of the same general physical structure and had common interests might be drawn together from mere gregariousness. They instinctively liked to be near others of the same kind. The exchange of ideas, if we assume them to have reached the stage of being able to speak and of having ideas, might of itself be sufficiently pleasant to bring them together. However disagreeable man in the mass may be when one is in the midst of the mass, there is a hunger for society that approaches the strength of a physical appetite when one has long been alone. The avidity with which the sheep herder on the mountain range hangs on the words of the pass"Graham Wallas: "The Great Society," pp. $146 \mathrm{ff}$. 
ing stranger, even if he can with difficulty or not at all understand the language, seems due to this gregariousness alone.

More utilitarian, even if no more pressing, is the mutual aid from coöperation. Even at the stage of the huntsman with no fixed habitation, many tasks are possible for the group that are impossible for any individual of the group alone. Large game falls more readily to the group than to the individual, requires more than one for its preparation and transportation, and will supply a small group for as long a time as it will remain edible. As the development proceeds the advantages of working together become more pronounced, and the stages above the simplest agricultural would be impossible without it. Where division of labor becomes the rule, as in all complicated societies, the advantages are obvious. In fact, the modern state could not be approximated did it not exist. Whether the results for the individuals with the rougher, harder tasks are such as would be willed in cold blood by those members of society were they free to choose and saw all the results of the choice, as compared with the simpler, less organized primitive existence, is a question that we have no means of answering. Certainly those who live under the more primitive conditions on farms and in simply organ- 
ized villages are moving to the great cities in ever-increasing numbers and few'return. Whether the total result for the individual be a gain or a loss, the average individual is bound to desire coöperation and the social group develops from the advantages that lead men to draw together.

In the original state the desire for protection, the desire to escape the greater at the expense of the lesser evil, is also strong. As soon as tribes come into conflict, as soon as the range is restricted or game is scarce in a given region, men must voluntarily draw boundaries for the country over which each tribe or each family may hunt. Granted that hostilities result, the tribe must draw together for protection or to wreak vengeance upon the other group. At this stage the impulses of the gentle cohesive type are replaced by the aggressive class. The common affection is replaced in emphasis by the common hate of the outsider that would eat the grass from his range, or would kill and drive away the deer that have fed in the valley and on the mountain where he has hunted. This common hate or common anger obviously implies increased unity in plans for the destruction of the intruder. The small community appreciates the advantages of the common action as it may never have done before. 
The slight bitterness over the brother or neighbor who has offended in some of his own hunting expeditions, who has finished the deer that the individual in question wounded, is forgotten in the greater dislike of the common enemy. The tribe becomes united in spirit as it never has been since the occasion of the last common struggle. Very much of the primitive union of tribes would be traced to this and similar common offensive reactions, the community of spirit of the pack rather than of the defensive reactions of the herd of deer or the mere gregariousness of the oxen. All three need to be considered if we are to know why men gather into communities or feel together as nations. To assign the relative importance of each may offer difficulties, but it is a problem that we may keep in mind as we go on.

The development of social ideals is a different problem. In some cases they, too, may have developed by chance and been selected by the survival of the nations in which suitable ones had developed. The respect for ancestors and the consequent ideal of many progeny to worship those now living when they become ancestors, which has developed in China, certainly has been a factor in the survival or great increase in population; while the ideal of thrift and consequent race suicide threatens to depopulate 
France. In other cases, however, selection of the ideal seems to be due to the pleasing result of action in accordance with the ideals, or the instinctive respect for the ideal itself. The universally extended ideal of freedom has little survival value, but does contribute to the enjoyment of life in the society that accepts it. The ideal of accumulating goods against a time of misfortune makes both for greater comfort and, originally, was a factor in survival. The greater comfort alone is sufficient reason for its development and persistence. The failure of some codes of morals that depart from tradition and convention, such as the failure of the numerous free love communities, seems to be due rather to the emotional reaction to the results of the practice when tried than to the elimination of the communities that have tried it. The practice is abandoned before time is given for a test of its survival value. The emotions evoked are themselves instinctive, so that one might say that ideals arise in part from instinct, that the acts which initiate them are instinctive and that in part the emotional reaction which determines whether they shall be accepted or rejected in advance of trial is instinctive.

How the standard actions or the actions which become standard and the theories or beliefs which become ideals should develop at first 
is a different and more difficult question. Some we may explain as we have the origin of instincts, as due to chance. Movements are constantly being made, some of which are successful, and these develop into habits. Of these the better are adopted and taught to the next generation. In the course of time many acts become standardized that are of no great superiority to others that are rejected. Here belong table manners, methods of pronunciation, and many others that will occur to the reader. They are passed on as signs of class or caste and have value as one element in a complex rather than for themselves. Beliefs and ideals, too, seem to originate at times in much the same way. New theories are constantly occurring to individuals in society. These are propounded to the group, are tested by their instinctive appeal and by their harmony with experience. Some seem promising and are tried in practice and those which prove useful or give pleasant results are accepted. After they have been accepted for a time, they acquire a prestige that makes them difficult to overthrow; man no longer questions them. Even when circumstances change in a way to make the old ideal no longer valuable, it still persists. It is this that makes tradition an incubus on progress at the same time that it gives a conservatism to society which provides 
a necessary stability. After ideals have once been established they may be propagated by the conquest of other peoples by the race in which they have developed, as Greece and Rome imposed their civilization upon the world. On the contrary, ideals may, by their own inherent strength, survive a conquest, as Rome imposed her language, laws and religion upon her conquerors, and China is said always to have absorbed her conquerors without herself changing. At other times ideals spread as suggestions to other peoples through their own worth, or because of the general prestige of the nation in a particular respect. Parisian styles conquer the world now as the political ideals of the French did before and after the Revolution. In some of these instances ideals are imposed and physical conquest is the cause of the acceptance of the ideals ; in others the ideals are merely suggested and win because of the superiority of their appeal.

As instinctively developed, we may look upon the nation as an outgrowth first of the social instinct which makes the mere presence of other individuals pleasant, the fundamental gregariousness that may be regarded as bringing the units together. Further coöperation is imposed by the instinct of sympathy which makes it impossible to see another suffer with comfort to 
one's self. More general in its effect is the instinctive respect for the opinions of others, which rises at times to a fear of man in the mass which enforces the ideals of all upon each individual. More important than either, but definitely dependent upon the latter for its existence, are the ideals which each nation has developed-some for all individuals in a group, some for separate classes. These are taken from the society in which one lives. The child accepts the ideals and standards of the family in which he grows up, of the teachers in his school and of the companions in his shop. To a certain extent he may pass upon the adequacy of the standard, particularly when he changes from one environment to another, but for the most part he accepts them without question. This choice is made in terms of the instinctive pleasure or appeal of one or the other, or in terms of the probable benefits as judged from earlier experience. For the most part they are accepted without thought, because of the social forces, the fear of society, and the instinctive discomfort which attaches to its real or imagined disapproval. This gives the ideals or the standards of the society in which the individual chances to live the effect of a primitive instinct. The individual thinks of the standard not as a social imposition but as an ultimate 
law; its dictates are the dictates of his conscience, of the proprieties or of good taste. As a result of these instincts and the acceptance of these ideals, the nation is for each individual in it something more than an abstraction, he identifies himself with it as a part of himself, he suffers pain when it is diminished, he rejoices with it as it thrives, it becomes almost as much a center of his emotions as is his self.

Assuming as we may and must that every individual is born into the world with a full equipment of social instincts, we must still recognize that these instincts are relatively closely limited in their application. It is this limitation that is at work in the development of a national feeling. One is bound in virtue of the instinct to act in a certain way toward other individuals of society. One must feel sympathy when they suffer. One must help them when they are in trouble, one subordinates one's self to their demands and accepts their ideals without question, or with relatively little question. One may be willing to die to win the approval of the group or to prevent it from being destroyed or from being subjected to undue hardship. What is most striking for us in the whole application of the social instinct to the formation of nationality is that the instinct is strictly limited in its expression to the individuals who belong 
to one group, to the group recognized as one's own. A member outside of the group receives the benefit of these instinctive responses in constantly diminishing amount as he is farther removed from the immediate circle. When outside he has no effect upon our opinion, his ideals are ridiculed rather than accepted, he has no influence in restraining our individualistic responses, he receives but a limited sympathy, and, at the extreme, we may rejoice at his suffering and even join with pleasure in inflicting pain upon him.

It is the fact of the formation of these limited groups within which the social instincts may be applied that is at the basis of the whole problem of nationality. Were the instincts to be limited to the immediate family or were all men without distinction to be included in their application we would not have this problem. The one word instinct would answer all questions. As it stands, our coöperating impulses extend beyond the immediate family and still do not involve the whole range of humanity. The problem of nationality is primarily one of determining the limits of the instinct. One feels or may feel the social response of friendliness or of helpfulness toward any individual of the accepted group, but what shall constitute the group is settled rather by convention or by cus- 
NATION AS A PSYCHOLOGICAL UNIT 61

tom than by instinct. The problem would be simple were the group determined also by instinct. If one were born to love one group and to have or to be indifferent to another group, then all that would be needed to decide where to draw the national boundaries would be to discover the limits of application of the instinct. If long-headed individuals would with pleasure live with all other long-headed individuals and dislike all broad-headed ones, evidently one could, by cranial measurements, form nations that would insure an ideal of fellowship. It might be asserted by overzealous advocates of the importance of physical signs of race that the future wars will be between groups who differ by a few degrees in cephalic index. Or were the common heredity to determine the reactions and responses, one need but to determine the degree of kinship to divide and subdivide the human species into appropriate groups and classes. As has been seen, the real lines of division do not follow along the same lines as physical differences, and slight observation even of one's own likes and dislikes show that nearness in kin provides no criterion of community of spirit.

As the matter stands, one must admit that, while man is endowed with many social instincts the range of application of the instincts is rela- 
tively little determined, may in fact be regarded as undetermined. The decision as to who shall be regarded as coming within and who as standing without the field of its application constitutes the real problem and this seems to depend more upon the conditions of the life of the individual, upon habit and training, than upon instinct. In practice this means that one may select whom one will to constitute one's community, or at least that the limits of one's community are not drawn by inheritance or by evolution. If one is to solve the problems of nationality one must study the conditions that determine the particular groupings of individuals as well as the general fact that all men desire to live together and are forced to coöperate with each other by their inherited dispositions which not only make another course impossible but make the only alternative pleasant. 


\section{CHAPTER III}

HATE AS A SOCIAL FORCE

WE have been emphasizing in the last chapter the kindly, sympathetic instincts that hold society together, that further coöperation and promote all of the gentler virtues. But there is another side. Society originated in conflict and one of the strong incentives to the development of a primitive society was protection against other tribes, and, on occasion, aggression against others. This meant that instincts and emotions must develop in the individual which would insure his taking part in any conflict that was necessary to the survival of the group to which he belonged. These emotions are not different from those aroused by the individuals with whom he comes in contact, but they are intensified if not extended by the other members of the group. If the instincts have developed through their value for survival it would be the instincts that were dominant during periods of stress that would appear and persist through the survival of the animals who show them. Only, dangers from without need drive 
the herd together, only acts of aggression would require the pack to gather. The emotions and instincts appropriate to these situations are anger and hate, the anger that steels for resistance and nerves for the attack.

If one took as one's thesis that societies are formed through opposition to outside forces, one might find an analogy from studies which were made by Jennings of the tendencies of a unicellular organism that he studied, the paramecium, to gather into groups. The paramecium lives in colonies which may be transferred to the slide and studied under a microscope. The animal is a single shuttle-shaped cell that moves by the strokes of a row of ciliæ, small hair-like processes which grow on two sides. At first sight the paramecia seem to be of a marked social disposition. No matter how scattered they may be they soon all assemble in one small group. Were they men we would incline to explain this by saying that they liked each other's society or that they had a social instinct, at least the instinct of gregariousness. Careful study of their movements and of the way they gather indicates that the process is very much more mechanical. In the first place, the only reaction that they show is a negative one. When certain stimuli affect them they will reverse the movements of the ciliæ and move away from it. 
They make no response whatever when the stimulus is what we would call pleasant. It is this same negative reaction that causes them to come together. They always attempt to avoid an alkaline solution, or to avoid going from a mildly acid medium to one that is more alkaline. About each small group of cells there develops a solution of carbon dioxide, from the respiration of the group. Whenever a member of the group swims to the limit of this acid, it makes a sudden reversal movement of the ciliæ, a series of back-strokes that makes it return to the more acid medium. When one from outside the group chances to swim into the acid medium, it is imprisoned, for when it approaches the boundary the back-stroke is induced and again it is forced to turn and swim back. Soon all are trapped in the small area of acidulated water. In short, what seems to be a fondness for other's society proves in the paramecium to be merely a mechanical impossibility of escaping from the water about the group that has been made acid by the excreted carbonic acid of the group. If we generalize this, it would mean that society develops not from a liking for society but from a dislike of the surrounding medium. That which drives the individuals together is the dislike of the outside forces 
rather than any fondness for the company of which they are members.

As we turn to the most developed stage, we can find instances and phenomena in the human organization and forms of human emotion which indicate that many of our human acts, some even of those that seem most worthy, are the outcome of hate rather than of love and the more positive altruistic sentiments to which they are sometimes ascribed. Were one to take a militaristic view of the world it would be possible to argue that it is hate of the opposition that furnishes all of the real incentives of life, that if war and hating were to stop, all progress would stop and we would drop down to a monotonous stage of little endeavor. All progress, on this view, has been derived from conflict, and when conflict ceases there will be little incentive to endeavor. One need not go so far as this to see that the emotion of hate and the instincts of opposition are important, and that it is hard to exaggerate the part which they play in the control of modern life, even if one should attempt to avoid special pleading. I remember hearing a distinguished scientist, a resident of an eastern city, say at the beginning of the war in 1914 that he had never before known the joys of unrestrained hate, particularly of unrestrained hate in unison with others. 
He added that he thought he had known something of it in his hatred for the members of certain old and prominent families of his community for whom he had great contempt, but that that was nothing in comparison with the gratification which came with the joys of the newer and freer emotion. This is probably an avowal that few would be honest enough to make, if true, and probably that few feel in such an intense degree, still it is not so far removed from the general attitude, as the mildest of us would like to believe.

We can see the effects in the individual reactions to war and the choice of sides or at least the distribution of sympathies in America when the European war broke out and before we were engaged. In many cases that came under my observation, the alignment was determined by resentment against one side or the other rather than by fondness for the side favored. One, a Russian who had been exiled, and who had spent most of his life in America with study in Germany for one or two periods of a year or so each, felt first a bitter hatred of Russia that aligned him against the Allies; then, when Belgium was invaded and England came in, his hatred of the German began and continued. This grew stronger when we entered the war. Another man, a Swiss, hated Germany and 
found his sympathies with France and Russia until England came in, when his dislike for England, much stronger than for Germany, drove him back to a neutral position; as he put it then, he did not care much so long as Switzerland could remain neutral.

In the attitude of the native American to the war, one was struck by the vastly greater effect of hate and resentment against the cruelty of the German than of sympathy with the victims. If we divide Americans into the two groups: those who knew enough of European politics to follow the war intelligently and the great mass who heard of the conflict as one might of an eruption in Java or in Mars, we can see the effect in the same form but different degrees. The first felt a rush of horror at the fact of war at all and then anger or indignation at the individuals and nations that started it, that brought them definitely to take sides for one or the other of the contestants. It would be fair to say that, at the beginning, sentiment in this class was fairly evenly divided. Many of the group were familiar with both sides; some of the more highly educated had studied in Germany, others were German by birth or descent or had come under the influence of the extended preaching of German ideals that had been so extensive in the preceding decade. There were 
certainly as many admirers of Germany as of England. The affliations as determined by sympatnies in the preceding wars were either neutral or were opposed to the Entente. Opinion was lostile to England in the Boer war and had been on the whole bitter. There were few Americans cf this class who would not have been glad to see the British whipped at that time. This was probably more than enough to overcome the effect produced by England's action at Manilla in the Spanish war, particularly as English. men as a whole had been inclined to side with Spain during that war. Sentiment in America had always been hostile to Russia because of her form of government and the tales of punishment inflicted on political prisoners-an attitude that had been intensified by sympathy with Japan during the Russo-Japanese war. Between France and Germany they would have been neutral, as the outcome of the war of 1871 had generally been regarded as deserved. On the whole, sentiment was quite as friendly towards Germany as towards the entente when the war began in 1914, but it developed rapidly against Germany, really against Germany and not in favor of the Entente. This began with the note of the Chancellor von BethmannHollweg, in which he referred to the Belgian treaty as a scrap of paper, grew with the vari- 
ous atrocities in Belgium and reached a climax with the sinking of the Lusitania. If one will re-read the speeches and letters to the papers, not to mention the editorials that demanded that we enter the war, one will see that the emphasis is always upon the punishment of the guilty, seldom that we should save the afflicted.

With the less educated the process was much longer, but followed about the same course. The first effect was slight in many parts of the country. Sympathy, if there was any, was in favor of the Entente, or at least against Germany. Where German propaganda had been active opinion was nearly evenly divided; where only the American newspapers were responsible for the information, the Entente was favored. In any case interest was not so vitally aroused as would seem necessary as one looks back upon it. The great mass was opposed to intervention, where the question had been raised at all. It was believed that it was not our quarrel. Some even tried to shut out all knowledge of the war on account of the suffering they were caused in sympathy. This attitude was sufficient, when sympathy for the Allies increased, to induce many to echo the arguments of German propagandists, rather as an excuse for our remaining neutral than from any fondness for Germany. Their neutrality 
was overcome by increasing knowledge of German atrocities. Her acts in Belgium were sufficient for some to change toleration into hate; the sinking of the Lusitania and the attacks of the submarines on American ships and the cold blooded ferocity of the German warfare in general brought the nation gradually to the culmination of hate, with the feeling that war was our duty.

In the whole experience, one is struck by the great predominance of hate and anger over sympathy. The Belgian refugees aroused sympathy, of course, and the great mass were sorry for the victims of the war on all sides, but punishment and vengeance were the active forces in bringing us into the war. The eye was kept first upon the harm that could be done to the German-the prevention of suffering was incidental. One may have a fair monetary measure of the two influences in comparing the contributions for relief with the expenses for war. We were proud of the amounts that were collected for Belgian relief, for French orphans, and for the other victims of the war in minor states, but these, large in the aggregate, amounted to less than a dollar per person, and were nothing compared with the billions that were readily spent in preparing for war, in expressing hate rather than sympathy. To be 
sure, expenditures by private individuals are always more modest and more reluctantly made than are expenditures by the state. But even this is not sufficient to explain the entire difference, the thousand-fold increase in the wealth poured out for war as compared with the few millions per year that were given for relief of suffering.

Many other lessons of the war indicate the dominance of hate and anger, or the active unpleasant emotions or instincts, over fear and the passive unpleasant instincts or emotions. The Germans, as is well known, advocated the doctrine of frightfulness even in the manual that they prepared to direct the acts of their commanders in the field. This is based upon the assumption that a people if sufficiently abused, if treated with the greatest atrocity, will be cowed and give in and sue for peace. The psychology is that accepted by some animal trainers towards an animal, that you can by pain and suffering break him and prepare him to do what you will. All the experiences of the war showed that this is a mistaken psychology. Instead of causing foar such acts always caused hatred and anger; instead of breaking the temper of the people they angered and nerved them to renewed effort.

If we run through the list of illegal acts, we 
find no single one that really paid. The frightfulness in Belgium, perhaps, came nearest it. Kellogg ${ }^{1}$ asserts that the Germans boasted that one man captured Charleville in France as a result of the stories of the way the Belgians had been treated. Even this effect was but local. While the men in the immediate neighborhood of the advancing Germans fled and left the cities deserted, the men out of reach rallied to the colors. It may have had an effect in reducing the number of franc-tireurs, but it increased very greatly the number of soldiers in uniform, and strengthened the resistance of the conscripts. The Belgians and the French of the occupied region may have offered less overt resistance at the time, but the secret resistance was increased ten-fold. It might be said that this was only annoying and had no effect upon the outcome of the war, while if the Germans had been compelled to keep an army corps in Belgium it would have cost them the war, but this seems a marked exaggeration. All of the Belgians left could not have done very much by irregular warfare, and showed no great inclination to such illegal acts; if they had, very few men would have been necessary to deal with them. The exciting effect of the

"Vernon Kellogg: “The Capture of Charleville": Atlantic Monthly, vol. 122, p. 289. 
atrocities and the letters of Cardinal Mercier, among others concerning them, served to arouse the Belgians and all others of the Allies as they would never have been had the Germans respected the laws of war as generally recognized.

Each of the other violations of the rules of humanity had the same effect. Bombarding open towns and air raids in which non-combatants were killed were said to be the greatest stimuli to recruiting in Great Britain in the days before conscription was introduced. Later the murder of Captain Fryatt and the drowning of the crews of the vessels sunk by the U-boats had no effect in preventing the ordinary sailor from going to sea; the merely angered him and spurred him to greater effort in ramming or in otherwise attacking the Uboat. The execution of Miss Cavell, together with the others mentioned above, had a marked influence on neutral opinion, and these with the sinking of neutral ships, probably, by bringing in the United States, were the final forces in losing the war for Germany.

Certainly the war as a whole constitutes a definite refutation of the German doctrine of frightfulness. The Germans entirely mistook the psychology of the human race at large. Frightfulness arouses not fear, but hate. It 
does not break the will of the victim, but merely spurs to new effort to obtain vengeance. If the German had been even as humane in the conduct of the war as the Turk, when not indulging in religious prosecution, the outcome might have been different. As, it is, she is paying in harsh treaty terms for the indignation she aroused as well as making restoration in kind, so far as that is possible, for the damage that she actually inflicted. Whether this will arouse the Germans in turn or will be accepted as just retribution is still to be seen. It is possible but not probable that the Germans were correct as to the effect of frightfulness on themselves although mistaken as to the rest of the world.

It would not require any overemphasis of the facts to argue that even religious organizations and religious creeds have been developed more from dislike of the opposing belief, of the men who hold them, or of their practices, religious or personal, than from any consuming belief in the doctrine that was accepted. The history of the various heresies and heterodoxies of the early church is one of quarrels over nonessentials, usually of quarrels whose real occasion was not the one mentioned, but some disagreement on personal points, or on racial dislikes. The early controversies turned on points too slight to be apparent to any but the most 
hair-splitting mind. So trifling were the differences that one cannot believe that the disputes were more than a symbol of the real difficulties, probably rooted in class or racial controversy. Certainly the bonds that held together the opposing parties were not the fondness for the timeless or the temporal explanation of the relation of father and son. They can hardly have been an intellectual repugnance for the opposing doctrine; rather must we find them in some deep-seated personal or class antagonism between the individuals concerned. We have more knowledge of the Great Reformation of Luther and his fellows and here can trace the profound hatred for the immoral life and grasping financial system of the older clergy on the part of the reformers and their flocks. The theological issues of transubstantiation and similar questions were but incidental to the personal and financial.

That hate of the opposing groups rather than affection for the principles and love for the persons of the groups accepted is an important element in the development of the religious sect or community is evidenced by the ferocity with which heretics were dealt with in ancient times, persisting until the beginning of the eighteenth century. Why an innocent woman should be burned for doubting that the communion bread 
was part of the very body of Christ, or a scholar for believing that it was his privilege to think for himself in ways prescribed by the brain and mind with which he had been created, cannot be explained from affection either for the creed or for the organization. If these forces are the first occasion for the combination they are quickly replaced by the much fiercer emotion or instinct, the hatred of those without. Religious organizations flourish just so long as there is definite opposition; when the opponents vanish, the vigor of the group lessens and may disappear. Even to-day, the active organizations are those with a personal devil who may be hated, and forces of evil that may be given definite embodiment. The evangelist and the Salvation Army orator have the widest appeal when they preach against definite and if possible personal opponents rather than when they preach the beauties of resignation and the joys of fellowship. As religion has become more universal, and the differences in doctrine have become fewer, particularly since the principle of toleration of religious belief has been generally accepted, religious enthusiasm has lessened. A vigorous heresy seems important if not essential to the persistence of a strong faith. When the devil was a real person he was an important aid to religious organization. The 
impersonal evil or sin, or the universal evil in our own desires, is not a satisfactory substitute.

Nor is this influence of a common hate in uniting individuals in large masses confined to hates between definitely organized groups. In the relations between individuals in every day social intercourse one may trace the same feeling. Dislike of the mass holds many a small clique together, and plays a not unimportant part in the development of the universal system of social levels. Political parties, schools of thought in science and philosophy, and even in religion, are certainly guided by contempt for the members of the opposite party quite as much as nations. At times, to be sure, the dislike may start from the thwarting of one's own desires. The populist movement and the free trade movement soon ceased to be mere matters of political theory and became resentment for injuries feared or actually suffered at the hands of a supposed conspiracy of the rich. The answer of the conservative parties is again not so much that the system defended is good for the laborer or the farmer, but that the pauper labor of Europe will, if not prevented, steal the markets and force our citizens into bondage. In the same way, the favorite answer to the socialist is an appeal to the man who has little that 
that little may not be taken from him by the man who has nothing. Dislike for great wealth is met by preaching hatred against the multitude pictured as marauders rather than as mendicants. In either case, appeals to self-interest are overshadowed in effectiveness by appeals to hates.

In the field of charity and criminology the same instincts are prominent. A cynic might well argue that most charity develops from hatred of somebody or of something. Many bequests for charity or education are made not from any particular love of the institution benefited but from hatred of the heirs who might otherwise obtain the money. What proportion this is one could learn only from revelations of trustees and of witnesses. Many of the charity workers themselves start from a desire to help the victims of poverty and misfortune, but end with hatred of the system or the individuals that are responsible for the existence of the condition. When this hating or fighting attitude is aroused, the worker doubles his efficiency. The whole relation of the criminal to society and of society to the criminal revolves around the emotion of hate. The criminal is likely to be guilty of his first offense under the influence of a sudden resentment. Once he has been convicted he becomes an object of fear 
and distrust that leaves him no alternative but to hate society, and there are no means of livelihood that are not at its expense. He may see the error of his ways and long for the opportunity to reform, but as long as society is suspicious and, as he believes, unfair, he cannot avoid hating nor the actions that result. Society cannot escape the suspicion based on a knowledge of the strength of habit as long as the man is assigned to the class of the professional criminal. The exceptional man may rise to the heights of pitying or even of admiring the man who attempts to reform, but this seems hopeless for society as a whole, while it is ruled by the theories accepted at present and these are rooted in the instinct of mankind to hate all who are likely to be dangerous.

The socialist in particular has developed to the full the principle that you can arouse people by appealing to hate and anger, where you leave them untouched by appeals to sympathy or cooperation. The foreign language and other radical newspapers are filled with denunciations of capital and capitalists who have fattened on the suffering of the toiler for all the ages. The call to unitary action for the good of the laborer appears at times, but that receives less space than the call to fight, the cry of hate. Even the opposition to war that they preach is not an 
altruistic or sympathetic one; it is not that war is a source of suffering that disturbs them, but that it is an instrument of the capitalistic class, devised to keep the laborer in subjection by killing some and reducing the others by taxation. Meantime, they argue, the excitement will distract the laborer from his sufferings, will make him forget his own interests in the emotions of patriotism.

In the development of nations hate is highly important. A writer, ${ }^{2}$ sympathetic to the confederacy, brings out very clearly the influence of hate in the development of the attempted secession. The Southern States were united primarily against what they regarded as the aggression of the North. Their primary objection was to the interference with their institutions and personal freedom, but there were no common ideals which held them together. When the secession had been effected, even in the midst of the conflict when common action usually serves to unite a group, they became conscious of the differences between them, and these seemed to many too important to be neglected even to win the war they were actually engaged in. Those who favored slavery as an institution came into conflict with those who re-

'N. W. Stephenson: "The Confederacy, Fifty Years After." Atlantic Monthly, vol. 123, p. 750. 
garded it merely as a symbol of Southern independence, and these with the consistent upholders of the doctrine of States Rights. The one group was not willing to abandon slavery nor to arm the slaves with promise of freedom if they won; the others were not inclined to accept a strong central government, however essential that might be to coördinated effort. The confederacy came near splitting on these points on numerous occasions, because they seemed almost if not quite as important as did the main controversy with the North. The lesser hates grew almost to equal the greater; and there was no common constructive ideal strong enough to unite them firmly and there were too many minor differences to drive them apart. Had the Confederacy been victorious in that war it would undoubtedly have gone to pieces soon on other issues, unless, of course, fear and hatred of outside forces had been sufficient to unite it.

We can see the same tendencies in the development of alliances of nations through treaties. Lichnowsky ${ }^{3}$ has said that nations only make treaties of alliance against some other nation or group, never merely for the mutual benefit through coöperation of the nations

'Lichnowsky: "The Future of Germany." "Die neue Runschau"; Tr. Littell's Living Age, vol. 301, 1919, p. 580. 
that combine. He made the statement in warning against a treaty of alliance of Germany with Russia, on the ground that it would be assumed to be and would really be a combination against England and would be provocative of future wars. The implication can be readily justified by a study of the treaties that have maintained the "balance of power" in Europe in the last century. Whenever one nation is strong enough to threaten others, alliances are formed against her; when she loses her position and another comes up, the alliance shifts to have another group ready to counter her possible attacks. The dread of Napoleon united Europe against France. Fear of Russia followed, a fear that even brought England to support the Turk and kept him in Europe for half a century after he would naturally have been expelled. As Germany became strong and began to preach her doctrine of war for aggression, England and Russia came together and the Turk found a champion in the Triple Alliance. The alliances are always against a common danger and that fact brings many strange partnerships.

Similarly a common hate is one of the most frequently effective factors in making or uniting a nation. The United States was made by anger at Great Britain, or more truly at a 
king and his ministers, Italy by hatred of Austria and the Pope, Germany by the hatred of Napoleonic rule. Bismarck consciously made use of wars and the hates that wars engender to remake the German Empire. The league of the Balkan nations was the outcome of a common hate, a hate that ceased to be common almost before the war was won, with a consequent new direction of hate and war between the earlier allies. In the Great War, as in all wars, it was primarily hate or fear rather than prospect of gain or mutual sympathy or admiration that bound the allies together. Barring Germany and possibly Roumania and Italy, no country seems to have had any notion of gain in entering the strife, and even Italy was governed in some part by her traditional hatred of Austria and of modern German methods and of individual Germans who came as tourists and business men. Austria was moved by hatred of Serbia and fear of Germany, Germany in part by fear of the Russia that she thought was to be, France by fear and by the hatred left from the earlier war. Both France and Russia were given the final impetus by the insulting ultimatum of Germany, while the people and probably the government of Great Britain were stirred to the point of war by the anger aroused by the invasion of Belgium. 
These hates are not fixed but fluctuate in intensity from moment to moment in very much the same way, certainly quite as quickly, as do likes and also with as little apparent reason. Re-alignments on the basis of hates can be traced in national as in intra-national groups. The change of partners in the last Balkan war furnishes one of the best instances of the former. The split between Greece and Servia on the one side and Bulgaria on the other could be seen to grow from the moment Greece captured Salonica. It was carefully repressed until peace was made or was on the point of being made with Turkey and then suddenly flamed out in the war that enabled Turkey to regain a considerable portion of her losses and established the enmities that have determined the alignments of the Balkan states in the present conflicts. Still more striking is the conflict of hates in Russia that so profoundly changed the whole aspect of the war on both fronts. Here the conflict of dislikes is between the internal and the external. The Russian peasant or artisan may dislike the German, but this paled into insignificance beside his hatred of the wealthy and of the system that enables differences in social and industrial condition to exist.

The utility of combinations through hate and the vigorous common action induced by it are 
obvious from the evolutionary considerations. Societies are primarily means of defense against outside agencies. They apparently survive as units in the original savage state and both the organizations and the hates are an expression of the needs of survival. If hate, then, is an instinctive response against an injury or a threatened injury, coöperation of the individuals subject to injury is an effective if not an essential agent in common defense. Unlike the lower animals, in whom the response is aroused only by direct stimulation by pain after the injury, man undergoes the emotion when he hears of injury or has reason to believe that injury is to be suffered. His sufferings are largely mental and his responses are to imagined or foreseen injuries rather than to real injuries. On the whole this prevents the actual harm, but in the highly organized civilization with its overkeen imagination and openness to suggestion it may cause as much mental anguish as it prevents of bodily injury. In no few cases it generates unnecessary wars, wars on suspicion of injuries that are not intended. One nation becomes suspicious of evil intent in another, and prepares to meet the assumed danger. The second sees the preparations, assumes that some offense is intended against it on the initiative of the other nation, and begins 
its own preparations. Each suspicion breeds new suspicions, each preparation new preparations, until what starts as a protective measure, becomes an actual cause of the act that was dreaded. The instinct that was an instrument of advancement and even a necessity for the survival of the original primitive society has become in the complex modern civilization one, and probably the most important, of the agencies of destruction. Although it must be granted that once a nation becomes the victim of a war of aggression hate is still the most important factor in national defense.

One miglit question whether, if hate is an important element in making possible the development of a nation or a feeling of nationality, there is chance for a disappearance of the unpleasant group of emotions without corresponding loss of national feeling or effective coöperation-whether one must choose between the era of good feeling and a loss of all the virile if not vital forces. We may turn back to our original analogy with the paramecium. While the group was held together at first by a dislike of the outside medium it was found that as the group kept together the area impregnated with $\mathrm{CO}_{2}$ gradually extended until it filled the entire microscope slide. Then the bond was broken and the members could go anywhere. 
If man is similar we might expect that as the different groups increased in size by the absorption of new races, a process that has gone far already, we might hope to find in time that all nations would amalgamate into one so far as common emotion goes and leave no one outside to hate. This condition is in sight if the League of Nations succeeds.

When we are studying the forces in man's nature that are important for the development of society we must not forget the warlike emotions of hatred and anger. Human association was born of conflict and the instincts made necessary by conflict were the most certain to develop and survive. Even the gentlest, most altruistic emotion has its harsh side. Pity or sympathy is always likely to be linked with hatred of the person responsible for the situation that appeals to one's sympathy, and on the whole the reaction against the offender is stronger and more immediate than that which would remove the pain. An appeal to hate is always more effective in an argument than any other. The Bolshevist mob robs and murders the rich or the relatively rich before it considers means that shall prevent suffering by the poor or the workman. The socialist, in the street corner orator form, at least, is perfectly ready to overthrow and destroy before he has 
carefully worked out a plan for rebuilding. In one's own reaction to political events and in the pages of history one sees hatred and love mingled in the reactions of the individual and of society. This tendency means that nationality thrives on opposition, that any attempt to crush nationality results in its increase or a new birth. This statement is illustrated by every attempt that has been made in history to discourage or destroy nationality by force or by law. A nation is strongest when fighting, whether on the offensive or the defensive. Nationality is a two-fold sentiment, of helpfulness towards all within the group and of distrust of all that is without. While it is not true that had there been no war or if wars were to cease there would be no nationality, it is certain that coherence is emphasized when there is opposition. 


\section{CHAPTER IV}

\section{NATIONALITY IN HISTORY}

WE have seen reason to believe that nationality is fundamentally an expression of the social instincts modified and elaborated by habit and learning, which, in turn, come to constitute tradition and custom. As phases of the social instinct we distinguished the liking for the mere presence of fellow men, whether friend or not, the instinct that brings men together; sympathy, the suffering that comes with knowledge that another is suffering, which impels to much of effective coöperation, and finally, fear of others which enforces upon the individual respect for the opinions and conventions of the group. Upon the basis of these instincts, which may be called the immutable laws of human nature, ideals and standards develop and come to have the force of laws. The instincts cannot be changed but the ideals have arisen in the course of human association and may change with conditions and the progress of knowledge. They may arise through the chance suggestion 
of some thinker, but are tested by experience, and are transmitted by tradition. Because of the instinctive respect for the opinions of others, they have, when once established, almost absolute power and they are often mistaken for instincts because of their universal acceptance.

Before we go farther in the discussion of theories we may to advantage consider how these principles and ideals have developed and how the national allegiance may change at the present time. These changes and developments affect only the ideals or standards; the instincts we must regard as the same everywhere. From these studies we may secure suggestions of other laws and can at least obtain a body of facts which may be used to test theoretical conclusions. Within our limits we can do no more than find instances of the way in which nations have developed, so far as it can be determined from readily available material. A complete treatment would require volumes.

Where and when the first nation developed we do not know. The same laws, working at different places, must have brought men together into societies very early, certainly before recorded history begins. Nowhere do we find at present a people so primitive that there is not some approach to a national organization, or at least to some wider than the family, and 
from no time in the past, aside from the doubtful records of the Bible and the myths of the Greeks do we have evidence of a merely family organization. There are remnants of the tribal elements in the early records of all nations, in the early law and tradition of the Norseman, in the traditions of Greece, as well as in the records of the Old Testament, but they are remnants of an earlier stage and exist side by side with other forms of organization. We can nevertheless trace the principles by which wider national units were formed out of smaller, and the principles which guided the development of nations out of fragments left over from decaying or disintegrating groups.

The Jew from the earliest day to this has had a distinct notion of nationality, marked by pride in his institutions and in his history and his heroes of ancient times, in his accomplishments and in his laws which still persists as pride of race since his dispersion over the surface of the earth. In the biblical times it was thoroughly tinged with religion. One of the national perquisites of the Jew was to walk and talk with God, part of his pride was in having a just God as almost his peculiar privilege. As in many other cases it is difficult to determine whether nation or religion comes first. Sometimes one obtains the impression that God 
was great because he was the God of the Jews rather than that the Jews were a marked and peculiar people because of the closeness of their relation to God. If one were to trace the feeling to its origins, it is probable that one would find that God had grown into the affection and respect of the race because He was the Grod of the ancestors, because of His connection with the triumphs of ancient Israel, and because $\mathrm{He}$ served as a convenient means of formulating and personifying the ideals and standards of the race. Religion and race were closely connected. On a relatively small scale the Jews had a nation, something for which they would sacrifice themselves, and which was superior in its appeal even to the family relationship, although there was always in it something of the tribal or family element.

The development of nationality among the Greeks is none the less clear in spite of the fact that it takes a different form and develops different ideals, or perhaps embodies its ideals in different materials. We may trace in the literature the development from the tribal organization of the Homeric age, through the city state of Athens or Sparta, to the empire under Alexander. We can trace the abandonment of private vengeance in favor of a law of the state, we can trace the development of a willingness 


\section{THE PSYCHOLOGY OF NATIONALITY}

to fight for the nation as a whole rather than for the individual or the tribe. The national ideals take a different form in Greece from that which they had in Israel. There is more of unity of the individuals themselves, a sense of the strength of an organization as self-dependent, as opposed to the reliance upon a king or a priest. The ideals of the Athenians stand out most clearly in the funeral oration of Pericles. They were, first, pride in the attainments of their ancestors; second, pride in the justice of the laws and the dependence of the nation upon the intelligence and virtue of the citizens and the willingness of each to sacrifice himself for the whole, and, finally, pride in the beauty and wealth of the city itself and in the opportunities the. $t$ it offered for pleasure and profit. The Greeks also made less of their religion. The gods were numerous enough to permit them to be measured by human standards-if they failed to measure up to the ideals, they might be discarded. Justice and the other ideals were not altogether personified in the gods but existed independently as ideals in the minds and hearts of the people. The Greeks in this sense had passed from religion to philosophy, from personification to abstraction. One form has the same effect as the other, they are but dif- 
ferent expressions of the same fundamental principle. ${ }^{1}$

We can see clearly, too, in the Greek world the expression of the different allegiances with their balanced loves and hates, their tendencies to combinations of different sizes and on different principles. In Sparta and Athens at their prime there seems to be little within the city state that conflicts with the allegiance to the group as a whole. There is some division along the lines of wealth or occupation. The dweller on the land at times felt drawn to others who made their livelihood in the same way, and at times we can detect opposition developing between the dweller in the city and the dweller by the shore. On the whole there was probably less of class interest and fewer lines of division into smaller groups than we find in the modern nation. Even the family affiliations were carefully subordinated in Sparta, and in Athens the tribe seems to have been intentionally and successfully replaced by the national interests. The wider allegiance among the Greeks as a whole fluctuated greatly. There seems to have been a feeling of solidarity with other Greeks as opposed to the barbarians, but only at times of great danger did this become pronounced enough to lead to effective combination. It was

'Zimmern: "The Greek Commonwealth." 
at its best during the Persian war, but quickly broke down under the influence of rivalry between Athens and Sparta. When it develops again in the empire, the real national solidarity is gone. External force, pride in a great leader, and the desire for the loot that came with successful war take the place of earlier national cohesion. These were not sufficient to sustain the empire any length of time. Only when the state was destroyed and the nation existed as a purely ideal or spiritual unity did Greece regain true unity.

In Rome we see an equally well developed sense of national unity, developing over a much wider area, and based upon rather different ideals. If the Jew may be said to have lived for his God, the Greek for his city or state and the ideals of justice which it fostered, Rome had an ideal of order and economic prosperity. Subordinate to this and a means to it was a just rule over all, but it was justice for the sake of the quiet and consequent prosperity, rather than justice in the abstract. The Roman roads and Roman laws are equally significant of the ideals which ruled the state because they had become rooted in the beliefs and in the habits of the people. ${ }^{2}$ They dominated during all forms of government from the early kings

"Marvin: "The Living Past." 
through the republic to the emperor. When they began to fall before ihe difficulty of applying them under different local conditions throughout the broad extent of the empire where they came into conflict with the traditions of conquered tribes, the empire itself began to disintegrate.

At no time has so large a proportion of the earth's known extent been united under one common rule over so long a period as under the Romans. Certainly at no time before and at no time for centuries after that had there been such complete recognition of the equality of man, or, to speak more truly, of equality of privilege to all men as under the Roman rule. True, there were distinctions between master and slave, between Roman and non-Roman, but the differences could be obliterated by proved ability. While the Athenians boasted that they gave rights to foreigners, the other Greek states were much more exclusive. The Roman seemed always ready to incorporate the desirable features of any tribe or nation within their own system and were quite ready to leave undisturbed the local institutions that worked well. Roman citizenship was within the reach of any one who proved worthy, and the line between slave and free man was one that could be readily passed by all who proved exceptional abil- 
ity. While the Roman legions were an important factor in introducing and maintaining the Roman peace, the common ideals and the common opportunity for sharing and profiting by them were the real forces in extending and perpetuating the Roman nation and the Roman influence. In spite of its catholicity of taste in modifying its laws and customs to meet the needs of subject peoples and even in accepting better practices into its own code, the Roman ideals always dominated, the supremacy of Rome was always accepted, the Roman state was sufficiently virile to absorb and still to rule. "We find, then, that the ideal of justice which developed in a narrow plain in central Italy, was sufficiently strong to bind together the few thousand original inhabitants, nerve them to resist numerous aggressions and to extend itself through their efforts over the greater part of the known world. As it conquered it absorbed, so that the final body was not merely ruled from above but the whole mass of citizen and subject alike was united by common respect for the Roman ideals as embodied in Roman laws and Roman political institutions. These ideals and laws outlasted the Roman state and still control large numbers of individuals, and in less degree the modern civilized world.

After the fall of the Roman Empire the stage 
is very dim, the story of actual historical happenings is not always clear and we have little record that throws light upon the motives of the great body of individuals. On the whole it seems that with the eruptions of the northern barbarians, the central organization gradually broke down and the world dissolved into small units with only local affiliations. The center of reference was not now the tribe, but the local chieftain or feudal baron. The loyalties that remain are personal, to the local leader first and he to the greater and so on up. At times, as when certain of the Holy Roman emperors are in the saddle, there is a reorganization on something that approximates national lines, but these groupings are only transitory and when they exist the loyalty is to the man rather than to the state. Only the intellectual and religious affiliations extend beyond the local boundaries. The intellectual is not very strong, learning is restricted to a very few and they, because of their use of Latin, came into slight contact with the masses. Even the church tended to be something apart from the mass of common individuals. Religion no longer was for man, man existed for religion. Its doctrines were imposed from above and were their own justification. At times, as in the crusades, the common religion would unite mankind everywhere 
for a common end, but these ends were temporary and when the expedition was over the organization disbanded. In short, it seems safe to say that the national organization disintegrated in the medieval period, and that only very gradually did nations begin to arise afterwards.

When the new nations did begin to appear, they took on a sligintly different character from that of the ancient time. The modern nation always began as a combination to resist oppression, and to establish an ideal. If we regard the feudal system with its personal allegiance as typical of the medieval state, the modern is characterized by a revival of the notion of a social group as a definite entity, with loyalty to the group and its peculiar ideals. The modern state is different from the ancient also from the fact that in the former the ideals of the nation, on the whole, grow up within and may be said to be a product of the nation, while the modern nations are often new or revived outgrowths or embodiments of ideals. In the one the nation came first, the ideal later, in the other the ideals were first and the nation appeared later to establish it. This is more natural than it seems at first sight for when ancient civilizations went to pieces as states the ideals still survived; they were cherished by. 
many men and when physical hardships became too great, they were revived to form the basis of new organizations and to justify the instinctively organized revolts. Many of the modern states, most of the very modern, are embodiments of these ideals, although it must be granted that the ideal alone did not suffice to produce a state until some practical need or anger against oppression drove a group to struggle to realize it.

While the state first fully develops according to this principle in the late eighteenth century we can see anticipations of it on a small scale here and there in the medieval period and from then on. Some of the Italian cities approach it from time to time on a small scale, and the Netherlands of the sixteenth century exhibit it in full measure.

This course of growth is seen very clearly in the development of Switzerland, one of the earliest to appear as a distinctly national unit, the first certainly in which there is little trace of loyalty to a leader as the basis or starting point of the organization. Switzerland, too, has had a purely democratic form of government for the longest time. If we may believe the tradition, the men of the original four cantons were driven to unite in the revolt by the heavy taxes and cruelty of the Hapsburgs. The 
revolt itself was justified by an appeal to the general principle of liberty. After the original revolt was successful, pride in the deeds of the men who had struggled and won, of Tell and of Arnold von Winkelried, added enthusiasm to the union and coöperation of the descendants. The common tradition, pride in ancestors, and the continued necessity for protection against strong and dangerous neighbors sufficed to continue and to strengthen the bond. Even when with the growth of the nation new groups were added, some with different languages, and when religious differences made their appearance, the national unity triumphed. Switzerland may safely be said to be the first of the modern nations to have developed through a desire for liberty. As such it was a place of refuge for those seeking freedom all through the modern period. As in most of medieval history many of the heroic events and even the motives for the original organization may have been a construction of later origin. But they nevertheless reveal the ideals of the people who originated and accepted the myths, the Swiss of the fifteenth and sixteenth century. They indicate that with the renaissance we had in Switzerland a real nation, held together by ideals of freedom and strong enough to maintain its position. It is probable that it is in Switzerland 
we have the strongest national consciousness that has persisted for the longest period of any in the modern world.

In other countries the course of the development is more obscure. England certainly had a gradually increasing consciousness of being a distinct people from a very early time. It is the more difficult to determine in what it consisted because it developed so gradually and never had occasion to burst forth into any single expression. As everywhere, it increased during periods of external conflict and was subordinated to class and religious allegiances during periods of internal strife. It may be said to have had its first marked development during the aggressive campaigns of the Hundred Years' War and was especially strong during the threat of the Spanish Armada. England most nearly approaches the ancient Romans in the nature of the national consciousness, in that that consciousness has been closely connected with the development of the practical institutions. The ideals most firmly impressed were the ideals of justice, which were respected in fact, in spite of marked theoretical differences in privileges between the orders of society and even the degrees of education. The most distinctive characteristics of the nation are its laws, which were accepted as superior 
to the authority of the king in the Magna Charta, and have been supreme for all ever since with constant growth through adaptation to the changing ideals of the people. About this develops the sacredness of the person and of the home of the common citizens, and an ideal of civil liberty that is equaled in few other countries. Together with this has gone a gradual perfection in the organization of business and manufacture, and an ideal of business success that reminds one of the Roman organization and ideals. At times in the later years it is probable that this ideal has been permitted to dominate the other ideal of the personal rights of the individual in a way that has been unfortunate for the lower members of the social order, perhaps in even greater degree than in the other commercial states.

The development of the spirit of nationality in England is particularly important since the spurs to that development so prominent in most other nations, resistance to an aggressor or oppressor, have been singularly lacking. England has never been conquered since it was England and seldom seriously threatened by a foreign power. It gives evidence that the spirit of nationality may develop to the full in a people who have usually been moved by the desire to coöperate, by the sympathetic instincts, rather 
than by the more active protective or aggressive impulses. While the ideals have seldom come to full consciousness, and the nature of the nation is therefore rather more difficult to trace, no one would deny the existence in the Englishman of a strong national consciousness. And that, too, in spite of the fact that the lines between the classes and between different forms of religious beliefs are more rigidly drawn and society more conventionalized than in other modern states.

In France, loyalty to the nation as a whole has alternated with adherence to the local group. In the early years the local allegiances were much stronger than loyalty to the central authority, and since the central authority was the king, loyalty was a personal loyalty, rather than loyalty to the nation as such. A man was less a Frenchman than a follower of Louis or of Henry. At times, as when Jeanne d'Arc stirred the nation, the national spirit is brought to the fore. All are French and will fight to the death rather than be subjected by the hated Englishman. On the whole, however, in medieval and modern France to the death of Louis XIV, the consciousness of unity is a common dependence on the reigning family. This varies from time to time with the popularity of the monarch, and on the whole there is a pro- 
gressing national spirit, an allegiance to the whole people as a group or entity. A man becomes gradually more a Frenchman than a Breton or a Norman, or Provençal, and more a citizen and less a subject.

Of Germany and Italy little is to be added to what has been said of Europe in general. Both had such checkered careers from the fall of the Roman Empire to the time of Napoleon, or really until the period of the universal blossoming of the national consciousness in the middle of the last century, that it is impossible to say at most times whether there is a nation or only a group of principalities, and, if both exist, whether the whole or the part is the object of the individual's allegiance or loyalty. During the greater portion of this period it is fairly clear that in Italy the sense of a common nationality was at a low ebb. Undoubtedly the common language, and at times the recognition of the Pope as the head of the church with claims to temporal power made many individuals count themselves as Italians when there was no common state to which they might belong. This was certainly true of many upon whom Dante had an influence, both his immediate successors and his intellectual disciples through the centuries. If one were to choose whether he were Italian or French there would 
be no question, except in the region of Savoy, but if the question were raised as to whether one were Florentine or Italian, or Venetian or Italian, the answer would not be quite so easy. Here, too, the consciousness of nationality was stimulated at times by the conflicts with the German Holy Roman emperors, to lapse again. when no outside force threatened.

In Germany the problem is still more diffcult and the situation varies more from time to time. The personal allegiance is, as in France, the most important element. If we regard the Holy Roman emperors as the rulers of Germany, we may say that when a strong man is on the throne, there is a sense of unity and a recognition of a common authority; when a weak man succeeds, the empire dissolves into its constituent parts. Through the empire even when divided politically there is probably always some recognition of a wider Deutschthum. How much, it is particularly difficult to say, for since the modern revival of the empire, German historians have undoubtedly exaggerated the unity of earlier periods for political effect upon the present generation. When Luther organized his revolt against the Church a national spirit was aroused which was strengthened by his translation of the Bible and the consequent general literary use of the German 
language. In neither Germany nor Italy was there a nation in the sense that we find one in Switzerland, in Holland, in England, or even in France, although in both many of the mental or social forces essential to the development of a nation are operative.

It is not until the latter part of the eighteenth century that we first find full recognition of the nation as an organic unity, a whole with the action of the parts determined by the parts instead of from without or from above. Before that the picture of the state was of a mass of individuals dominated by superior authority. Even when the warrant for the organization really came from the ideals of the individuals who composed it, the rules were justified by reference to some higher power, human or divine. From the Greeks down men had sought the best means of securing justice and of giving each man his rights, but in theory the standard of justice was always derived from a lawgiver, from God or a god, or at the best from some immutable and logically deduced principle which was only recognized by man, not made by him or derived from his nature and rights. When, as happened not infrequently in the middle ages, appeal was taken from the king or pope it was always to the law of God rather than to the 
rights of man. Man was made for the state or for the law or for the nation, not the state or the law or religion for man. It should be said that most of the early theories of human society follow Plato in considering the political organization of the state as primary and in deriving justice from theoretical principles rather than from the nation as a social body, developed by natural laws.

With the last half of the eighteenth century the emphasis is shifted fairly suddenly to the problems of the nation as such and of the ways in which peoples might have developed states for themselves. The assumption gradually gains acceptance that, if there were no central authority or divine warrants for a social or political organization, one must have developed because of the nature of mankind. This way of looking at the problem was a natural outcome of the skeptical and naturalistic attitude of the philosophers from Descartes to Condillac, Lamettrie and Hume, but it found more definite expression in the very popular works of the Encyclopedists and Voltaire. It took the form that exercised a profound influence on political and social theories in the writings of Montesquieu and particularly in the contrat social of Rousseau. Rousseau's insistence on the natural goodness of mankind in a state of 


\section{THE PSYCHOLOGY OF NATIONALITY}

nature, and his belief that government arose and must have arisen from the very character of human nature by the spontaneous union of men into groups appealed strongly to the imagination of the western world and became the political bible of the epoch. It is not within our province to trace the origin of Rousseau's theory. It is probable that other men were expressing the same theory; certainly the current philosophy led rather easily to the conclusion expressed. As happens so frequently it fell to the lot of Rousseau to crystallize and formulate what had been previously only suggested, and he is given credit, whether deservedly or not, for a radical departure in political theory.

Beginning with the American Revolution the history of modern times has seen one nation after another develop a vigorous and very often an aggressive democracy which embodies in some degree the same fundamental principles. In each instance the change in the form of government has followed approximately the same course. There was usually some definite abuse or discomfort; efforts were made to remove or to reduce it and in the process the movement went farther than was at first intended. In the first two cases, too, political ideals have been adduced to warrant or to justify the po- 
litical change, but these theories have been brought in to excuse or to advance the change. They do not originate the movement. It chanced that the most immediate cause for complaint in each of the peoples was that the taxes were unfairly imposed. It was not so much the burdensomeness of the taxes, although in France they were burdensome, as the way in which they were levied that aroused the ire of the masses. In America the exactions were not sufficient to produce any real suffering or to take any undue proportion of the total income. The resentment was against the injustice, the mental rather than the physical anguish. Probably the resentment started because the taxes were of a new kind and the language of the decree that assessed them was not altogether tactful. This led to seeking an excuse for not paying them. Partly they came after the stress of a successful war when the colonies felt that the mother country should have been grateful for their services and shown increased generosity rather than have added an unwonted burden. The objections to the taxes were not much greater than were those of the Englishman at home to the corresponding imposts, the cider tax, for instance.

Before the taxes were imposed, the attitude of the colonists towards England had been as 
friendly as could be desired, more friendly than the relation between the different colonies themselves. There was less in common between the Puritans of New England and the Cavaliers of Virginia or the Catholics of Maryland than between any of the colonies and England. The political theories of each of the colonies were represented by a certain group or class in the old country, while they were absolutely antagonistic among themselves. In fact one of the members of Parliament who favored the imposition of the new taxes argued that the differences between the colonies would prevent them from uniting for common defense. Even after the temporary repeal of the stamp tax in 1766, the colonies gave over all opposition to the king and celebrated his birthday as loyal and friendly subjects. Once the attitude of opposition had been taken, however, it grew on both sides. The colonists were less concerned about the money loss than the principle, and the king was anxious to compel the colonies to pay, not so much because he needed the revenue-he was in danger of spending more than that amounted to in the cost of collection-as because he would not be defied. What strikes one most is the suddenness with which the storm breaks. It is not a case in which there had been a long period of irritation that suddenly 
rose to unendurable force. Rather, all had been harmonious and the best of relations had existed. Then with the passage of a single bill opposition came at once and went comparatively quickly to the point of action.

When the dispute begins, the feelings grow constantly stronger on both sides. As usual, the instinctive resentment was quickly justified by theory. As John Morley has said, the feeling or the act is instinctive, only later is a rational explanation and, in case of need, a justification given for it. The reason alleged may or may not be the real cause of the resentment. In this instance, we find after the resentment arose that a large number of beautiful theories were developed or revived to prove that taxes should not be paid and to arouse the more lethargic to opposition. Some of these theories, such as the argument that there could be no taxation without representation, were derived from pure English sources. Others were modifications of Rousseau's principles of natural rights. The appeal to liberty, with little attempt to define what was meant by liberty and with shades of meaning that varied from man to man, was the most common. What had been accepted without question before the great cause of irritation had been given was now a violation of the sacred principle and 


\section{THE PSYCHOLOGY OF NATIONALITY}

must be eliminated at all cost. These furnished the ideal element that was accepted after the fact as the reason for the outburst and all of the resistance that was offered. If objection to taxes, the objection to the remarks of the new government in England and probably, too, dislike of the more prosperous colonials who as a rule arrayed themselves on the side of the government, really produced the emotions; the cause assigned was the more presentable doctrine of liberty and the infringement upon local freedom of government. That the resentment would have been felt if the way had not been prepared by the theories of liberty and other liberal political theories everywhere in the air, is not probable. That the ideals of liberty and self-government alone would have produced the revolt in the absence of anger at a disturbance of the regular course of life is still less probable.

After the issue had been drawn and the majority of colonists had been united in opposition, the common hate and the combined action against the enemy brought almost at once the sense of community that constitutes the essence of nationality. Differences in political theory, in social organization, in religion were all forgotten for the time being in the prosecution of the great purpose. After peace had been made, 
the necessity for continued coöperation and the memory of common deeds and the common sufferings of the struggle continued to hold all together, until the spirit could be embodied in written law and in accepted practice, which constitute the state. When all was peaceful in foreign relations, the older differences in theory and in temperament became more prominent and for the first quarter century it was now and again a question whether the instincts that divide or the instincts that unite would dominate. In the second war with great Britain and the period that preceded, the dislike of one section by the other very nearly overcame the cohesive forces, and it was not until the period of prosperity which followed that war that the nation was assured. During the disruption of the nation in the Civil War the bonds between the people were completely severed; only the forces of the state, the political rather than the emotional union, survived.

The laws that control and the course of the changes in France are very similar. The occasion for the commotion was objection to taxes; the revolution was not intended when objections were first made, and after the break had been made the accomplished acts were justified in terms of Rousseau's theory and of the theory of the American Revolution. Each step 
taken was also discussed in advance and the principles of the rights of man and human freedom advocated in the Assembly. But the series of moves made towards increasing democracy came suddenly and seem never to have been intended by the responsible leaders, if any of the leaders could be regarded as responsible. Thus we find an Assembly called to discuss improved methods of levying taxes spending its time discussing more or less fatuously almost every other problem of government, and finally ending by being compelled by an outside force, the Parisian mob, to limit the powers of the monarchy. The king gave way to the Assembly, the Assembly to the Convention, the Convention in reality to a few leaders and to the mob. Absence of the local self-government and lack of a foreign enemy to force internal cohesion, that had been present in the American Revolution, led to a constant increase in anarchy. The old régime dissolved, but no new organization appeared sufficient to take the necessary responsibility for the simplest acts of goverument. Each man in authority was ready to execute any one that he feared might be an enemy lest he himself should be a victim later. While the ideals of liberty and of love were upon the lips of every one, each became a petty tyrant when he had a chance and pas- 
sions of hate were very much more in evidence than deeds of kindness.

Striking, too, was the fact that the armies of the Revolution at the first excuse started out on the paths of conquest, and while the words and songs of freedom and the spirit of independence inspired them with an unwonted courage and effectiveness, their attitude towards the conquered was the same as that of the older autocrats except perhaps that they were even more cruel and overbearing because of the belief that the new freedom gave them a great superiority over their less progressive neighbors. Of the three watchwords introduced by the revolution and still the motto of France, "liberty" came to mean merely license to oppress every one who was weak, "equality" was for the public while the leaders successively prescribed elaborate forms of servility for all who approached them, and "fraternity" was reserved for men of the same party or at the most of the same nation. The whole course is a striking illustration of the fact that the tender and aggressive instincts, love and hate, are present in nearly equal measure in every individual. When freed from the restraint of habit, particularly of habit and convention as embodied in institutions, the opposed instincts alternate in such rapid succes- 
sion that social life is at best uncertain, and is almost sure to become frightful. The Russian chaos offers, if we may trust reports, further evidence of the same laws.

Not the least instructive part of the French Revolution is its far-reaching effect upon the spirit of the world. Although it ended in a riot of internal disorganization, which made its strongest supporters enthusiastically welcome a dictator as a relief, it is the most important single influence in the remaking of the states of Europe into nations. Its principles, which failed absolutely in practice, persisted as accepted theories during the succeeding régimes of the Empire and of the new monarchy and, as they were adopted by states which were sufficiently organized to repress the excesses of the uncontrolled conflicting instincts and emotions, became the guiding influence in each of the new free nations. While the first failure made the Revolutionary govermments abhorrent to the French themselves and to the enlightened world, the ideals from which the Revolution grew, or which justified it to the populace, were unaffected. In the French nation itself they have remained the watchwords of the people, and have sought embodiment in institutions whenever opportunity offered. Even under Napoleon they served to unite the people 
and to nerve the armies to conflict. Common acceptance of them was an important element in the spirit of unity that has made the French people a nation from that day to this, in spite of temporary departures from freedom in the form of government.

There has been an exuberant growth of nationalities in the nineteenth and in the early years of the twentieth centuries. As we stand now at the end of the war it seems that many more will be born or embodied in states in the next few years. The development of these modern nationalities has followed a course more like that of the American than of the French Revolution, while one, Germany, has a law all her own. One of the striking cases is the development of modern Italy. The Italian sense of unity persisted, or was at least sporadically reawakened at intervals after the fall of the Roman Empire. It is probably safe to say that the common people had been united in aspirations to a certain extent from the time of Dante, but had been prevented from realizing that union by the heads of states. On the whole the strictly Italian consciousness had been subordinated to the local allegiances and to the religious devotion to the Pope. Dante had attempted to rearouse it and had left an abiding reminder of the possibilities and an eloquent 
appeal for their attainment. Still the emotional response was mild, there was little embodiment of it in institutions and the love of a united Italy was largely Platonic.

The end of a united Italy with a single political organization was realized in the usual way. Mazzini furnished the ideals, or at least vivified to every Italian the ideals of the century. The Austrian, the Pope, and the King of Naples furnished the more painful and immediately stirring incentives of oppression, cruel punishments, over-taxation and suppression of free speech. Not the least important was the statesmanship of Cavour. Finally the enthusiasm and generalship of Garibaldi touched off the material prepared for the conflagration, and provided the heroic figure that inspired any hesitating patriot. The pride in the early history and the appeals of Mazzini, reënforced and advertised by the failure of the earlier revolts and the cruelty that was used in suppressing them, had prepared the way and, when leadership was provided, the spirit of nationality flamed forth and an independent state was born. It is interesting that the rallying cry of Mazzini, the atheist, pro popolo e deo, should have contained the religious element. This must have seemed to the followers of the church most ironical, and the ultra-sceptical mind of Maz- 
zini himself must have given it a peculiar interpretation. One might argue from this that the ideals which are used to warrant a revolt need not express its real cause - that the rallying cries need not be taken literally. Any watchword will arouse the people, provided only it obtains sufficient vogue. Not its meanings but its emotional association is important.

In the nations that are now just coming into political recognition or are being revived, the Ukrainians, the Czechs, the Slovenes and JugoSlavs, the Poles, one may see the same elements. Each has a common and peculiar language, an ancient history and in some cases an ancient literature in which they have taken a gradually increasing pride. All have been impelled to seek an independent political existence by the oppressive form of government to which they have been subjected, and now that the great powers that have been holding them in check are weakened or dissolved they are ready to develop the political independence that their national existence has long demanded and deserved. The ideals are fully accepted; all that is necessary is a chance to give expression to them. The new states they are establishing will give an opportunity to test at once the virility of the national spirit, and the capac- 
ity of the people for political organization and coherence.

- The development of German unity is of particular interest from the fact that the instinctive bonds that brought the various parts of the Empire together are very different from those that were effective in the other states of the western world. The first impulse came from the long and uncertain but finally successful struggle against Napoleon. After some centuries of fighting against each other and in various combinations against foreign foes, the northern German states found themselves united at that time against a common enemy, an enemy that on several occasions had an opportunity to prove his capacity as an oppressor. Coupled with this there had been a literary and philosophical awakening that had developed a system of inspiring ideals, and had emphasized the community of the German people and revived a memory of the ancient glories. Kant and Hegel, Schiller and Goethe provided the ideals, the successes of Stein after the period of subjection stirred the spirit of the people. This part of the development of the German nation follows the general rule as observed hitherto. There is first a development of ideals in the people as a whole, then some occasion is found for sacrifice in a common cause to attain a de- 
sired end. This brought the northern German states into a certain degree of unity of spirit, partly sealed in the political organization.

After the Napoleonic period we find a new tendency and a turning of the ideals into a new form. The scientific development added new glories to the continued philosophical and literary activities and the pride in race and language increased constantly. Aside from the theories of the leaders in the abortive revolution of 1848, the dominant note in the speeches 'and writings of the German political theorists was the supremacy of the state over the individual and the necessity for a strong state in the struggle for existence, not as in other parts of the western world, emphasis upon the principles of freedom and popular rights. The state was exalted as the unit for survival and its exaltation became the aim of every true citizen. This ideal seems to have been as thoroughly rooted in the governing class as were ever the notions of Rousseau in the minds of the French populace, and it echoed in less definite form through the lower classes. The state was made a super-person with an existence almost as real as that of the individual person. It was given a divine warrant and a personal devotion was developed towards it that seemed to equal in many cases the devotion towards immediate 
relatives or to the church. The series of wars engineered by Bismarck increased the patriotic emotion by their successful outcome. The first in 1864 and the second in 1866 united northern Germany, and the French war, given the form of a defensive war by Bismarck's cunning, united all by the glow of common deeds and the participation in the benefits of the indemnity.

This development of the German state is important for our theory as it is one of the few instances in modern times in which a national consciousness has been aroused on any other ideal than liberty or freedom. With Germany, the ideal was the aggrandizement of the state at the expense of the neighbors. It was justified by the assertion and apparently by a general belief that the Germans were a superior people, that their state had a superior civilization and by virtue of that superiority was entitled to rule the world of lesser states and of inferior men with inferior attainments. This was furthered by an appeal to selfishness. The citizens were to be rewarded, not merely by the pride they were to feel in membership in an allconquering body, but they were individually to be better fed and cared for, to receive better wages and thrive at the expense of their weaker neighbors. The union was cemented by a suc- 
cessful war, but it was a war of aggression rather than of defense. The war was started under the pretense of a defensive war which gave the government a stronger position with the people and with the world outside. Once started it continued as a war of aggression, and the official political theory of modern Germany recognizes the necessity for war, even an aggressive war, for the furtherance of the ends of the state. As we have viewed the nation in the light of evolutionary analogies we have found hitherto that the instincts that were prominent in the development were the instincts of self-protection, the people were as deer herding together for common defense. The origin of the German nation represents the pack of wolves gathering for a united foray. It seems that either will suffice for the development of a common consciousness, whatever moral judgment we may pass upon the method and the result. 


\section{CHAPTER V}

NATIONALITY IN THE PROCESS CF NATURALIZA. TION

Ar the end of the first chapter we had come to the tentative conclusion that nationality was the expression of a mental attitude and the product of experience based upon a fundamental instinct, that it was acquired rather than innate. The best evidence for this statement is found in the fact that national affiliations change. A study of the conditions of this change and of the process itself should give a knowledge of the nature of the mental state and of many problems connected with it. Any nation in which the population is compounded of immigrants from many countries would furnish a laboratory for this problem. Undoubtedly, the most favorable conditions for study are provided in the United States. In no other country is the population so mixed, and in no other has the process of transferring allegiance been so long continued and on the whole so complete.

This method of studying our problem is not 126 
altogether free from objections. In the first place the facts obtained are individual rather than statistical in character, and in consequence their interpretation is bound to be open to prejudices due to the experiences and heredity of the individual who passes judgment. The only available statistics of the sentiments of immigrants are furnished by the number of naturalizations, and these are open to many interpretations. Some are naturalized for pecuniary and social advantages, some even for the protection it will afford them in the native land, without undergoing any real change in attitude, any change of heart. On the other hand we are often inclined to mistake a difference in political theory for differences in national allegiance. Many foreigners are socialists and so have a very weak affection for any form of government of the present type, and at the same time may be American in national spirit, or at least be more nearly a member of this community than of any other. Many of the native stock have accepted these theories without thereby being eliminated from the American nation. We must not expect more of the foreign born than we do of our native citizens.

Other prejudices of similar nature are likely to becloud the interpretation of the facts. One of the most important is race prejudice. No 
one can count himself free from this, because when he is deeply affected by it he does not regard it as a prejudice but as an accepted fact. Through family and community environment every one has a fondness for his own race and coupled with that a firm belief in the inferiority of all others. When present, this prevents complete national amalgamation. Nevertheless we do find that race prejudices are, for certain purposes, overlooked in the nation,that several nations are composed of races, each of which looks with distaste upon the others and yet work together for national ends. The negro in America constitutes such an element, the Jew, wherever he is found, another. In the one case the feeling that one is inferior is held by one alone, but in the other it is mutual. The social prejudices are equally strong and in many cases hold towards the same peoples as the racial prejudices. Any of my readers will admit without question that he dislikes men who are too poor, or too dirty, or who speak ungrammatically and use tooth picks in public. Many on the other hand feel the same distaste for the men with too much money or those too fastidious in dress, perhaps even for those too fastidious in language. The Montana ranchman meets the condescension of the eastern visitor, whether real or suspected, by calling 
him a dude. These objections to people of different wealth, different education, manners, or even of trades and professions, which fuse to constitute social differences, give rise to a common emotion in which the elements are not distinguished. In coming to a decision whether a foreigner is or is not a member of the American nation, it is necessary to determine whether the feelings that separate him from the observer are the product of his national or of his social or of his political attitudes.

Study of the question whether a particular individual is an integral member of a nation may be approached from two sides, from the attitude of the individual towards society and from the attitude of society towards him. Usually the individual regards himself as a member of the nation before the other members of the social group are willing to accept him fully. If one follows the process of amalgamation, one finds that it begins with a belief on the part of the individual that he is one with the community in which he lives in aspirations and desires while he is still looked upon by the members or by many of them with suspicion or aloofness. He is content with a very platonic affection. Gradually he is accepted as a member of the state for business and political purposes, but is not regarded as a social equal. 
Slowly and grudgingly he may be admitted to some degree of social intimacy, but not to the most complete intimacy-he will be invited to the house but marriage with a daughter would be looked upon with aversion. In the final stage, all consciousness of race is lost and he is accepted without question as friend and equal. For the man himself and others he is at this point a part of the nation in the full sense.

Historically, it is easy to trace the various stages in this development. Numerous races have passed through it. The Irish, the German, the Swede, each in his own region has been first a complete outsider, the object of poorly concealed scorn or ridicule; then he is tolerated and his good qualities recognized; finally he is completely accepted and intermarries with the oldest stocks without question or hesitation on their part. If one traces the history of the attitude of any small or medium sized New England manufacturing town to the successive waves of immigration, these different degrees of acceptance of each race can be seen in succeeding stages. From the comments of grandparents and from books one can reconstruct the course of the Irish. In the grandmother of the middle class, whose reaction was determined in the forties, there is still sufficient explanation of the shortcomings of a neighbor in the Irish 
name. You can expect nothing of a Murphy. This attitude is brought out now only when some fault or misfortune is to be explained or understood, but is general. It is a remnant of the original attitude of half a century ago. The son shows signs of suspicion or distaste; the grandson can little understand either, unless the race is also coupled with adherence to a religion or a political party objectionable to the speaker.

I have myself seen somewhat the same change in the case of the French Canadian. As a boy visiting a New England factory town I was repeatedly told by an intelligent native of the disagreeable qualities of the French. They were dirty, were given to drink, constituted for some not well defined reason a danger that made it necessary to shun them for one's moral and physical salvation. They were represented as coming in swarms to this country, where large families all worked together in the mills, lived in squalor and saved money enough to go back home and buy a farm. As in most instances of race prejudice the faults were hinted at rather than specified, and the very vagueness of the statements added to the distaste produced. I remember that it was said of a close fisted, aggressive native real estate speculator that when he wanted to buy a piece of 
property he made the owner an offer and if it was not accepted he would buy a house on either side, fill it with French and in the expressive colloquialism of my informant "stink him out."

After twenty years' absence I happened to make some comment to this same man about the ways of the French, quoting as literally as I could remember them his own statements of an earlier visit and was surprised to have him deny that they had any of the qualities assigned. They were a sober, clean, industrious people, in fact were altogether American. I found that the natives were mixing with them on terms of equality and with no repugnance towards their manners or morals. That the change had not been altogether in the habits of the French became clear when I talked with men who had had more intimate dealings with them in the earlier period. A member of the same man's family, who had as employment manager to look up the reasons for absence from work in the homes of the operatives, reported that they had always been neat and law abiding, a statement that harmonizes with what one knows of their life in their home environment. When the new immigrants are regarded as outsiders all their peculiarities are exaggerated, the habits of the few are ascribed to 
all, and many traits are attributed to them which have absolutely no foundation. When accepted, the estimate becomes more just. The French Canadian has been accepted as the Irish before him, and now the Greek and the southern Slav is taking his place as the outsider, the individual scarcely human.

You will find that the man who has this prejudice, as who has not, will find a reason for it in the inferiority of the race of the new and unaccepted group. He will tell you that the earlier Irish knew the language, are of our own stock. The French lived in a democracy: before they came into this country and so on throughout the list. There may be much or little of fact in these statements, but they suffice to satisfy the prejudice and that is all that is needed. The enthusiast for the community of mankind assures you that they will amalgamate as have their predecessors; the cynic sees in them, as did his predecessor of three quarters of a century ago in the Irish, a menace to the purity of the race and to our free institutions.

It may be objected to this statement that newer arrivals have amalgamated only with the lower classes, that these people have not been admitted into the highest circles, but only into the fellowship of the middle class. Their names do not appear in the list of those present at im- 
portant social gatherings in the big cities. Admit this and you need say only that the list does not include members of the native stock of similar wealth and opportunities. Not infrequently this list is based on descent and on the time that the family has been a resident. They are accepted socially by individuals whom they know in trade and shop. Men of the race of special training, lawyers and physicians, are accepted by the native stock and marriage with them is not looked on askance by the native group. The exceptional man who gains wealth and education does appear in all but the most exclusive homes and on the most intimate occasions in the most select circles.

The process of amalgamation on the part of the immigrants follows much the same course. Most of those admitted are fleeing from something worse, and, hard as their lot may be here, they have suffered and escaped from a harder. They come ready to be assimilated and thankful to be accepted as a part of the community, even a humble part. That on the whole they become amalgamated in spirit cannot, I think, be denied in spite of a few exceptions and in spite of the long time required in many cases. For the most part they are more concerned with being accepted into the nation and its life than with the question of its advantages.

Only 
as they obtain a place and know more of the life do they become critical of American ideals or of American practices. Even then they are likely to take the avowed political ideals as a basis for the criticism of life and practice as they actually find it. Several recent critics among the foreigners and even some native Americans claim that the ideals of Americanism persist only among the recent immigrants, while the native stock is devoted to the worship of mammon and lost in the marshes of racial prejudice and intolerance.

What it is that makes an individual change his allegiance can be determined in a measure from a study of the reports available in the records of the individuals who have changed, and of the influences which statistics and observations show to produce the change. First, one must assume that there is the social instinct common to all men. This has identified the individual in emotion and ideal with his older community. One may readily distinguish two groups of individuals in this respect. The man of education or position or both is moved largely by ideals. $\mathrm{He}$ has not infrequently accepted the ideals of the nation before he comes and if then he finds only a moderately friendly reception from the citizens he is likely to change his allegiance fully by such slow de- 
grees that he will hardly know himself when or how the process takes place. As one reads the "Reminiscences" of Carl Schurz, for example, one discovers little or notbing of the forces at work in the change because apparently he accepts citizenship and is accepted altogether without question. He passes from the distinguished guest to the respected citizen with practically no intermediate stage. This is partly due, no doubt, to the fact that he at once becomes an active worker against slavery in common with a large number of older residents. He finds that he holds ideals in common with them and fights in a single cause.

Opposed to this, one may see at times an educated man who looks at the new always from the standpoint of the old civilization, who accepts the customs and values of his former residence as standard and passes upon all things and peoples in terms of them. Such a man will remain essentially a foreigner no matter how long he may live in the community. It is true that when he returns to the country of his birth he may find that it is as far different in reality from what he had pictured it in his memory as is the new. In that case our carping critic either returns more ready to change his allegiance or remains without definite affiliations in spirit with either country. What is 
lacking here is usually the willingness to accept the ideals of the new community or inability to work in harmony with its citizens for a common cause. One can find numerous examples of each class among educated foreigners resident for longer or shorter periods among us. The difference between them is partly in age, the one usually younger and more tractable, the other older and more fixed in standards; and is partly personal. The one is willing to learn, the other assured, perhaps even conceited, in his own opinion. On the whole, however, a man of this training who has united with a group of the native born in the pushing of some ideal, who makes common cause on any point with the citizens of the community, quickly becomes in essentials a true member of the nation. On certain points he is bound to retain his old beliefs, to be a critic rather than a partisan of the new country. In this he is, of course, in no different position from any intelligent citizen. One can decide whether he has or has not changed his allegiance from his whole attitude rather than from his attitude on one point alone.

The factors and forces that make for the naturalization and nationalization of the uneducated or unintelligent mass are of a different nature. These must always be the great 
majority and constitute at once the greatest problem for the nation and the most interesting material for investigation on the nature of the feeling of nationality. The intelligent men are few and are moved in greater part by rational considerations. The real reasons for their becoming citizens are more nearly the reasons alleged. At least they are more open to observation and more capable of reporting than are the great mass. The latter constitute the real nation. In them the instinctive and habitual processes run their course less influenced by the pale cast of thought. We may study in them the forces that are really effective rather than those the theorist thinks should work.

Before discussing the influences that produce the assimilation of immigrants, it may be well to admit that there is a question as to how far that assimilation is really possible among the lowest classes and those who live together in the poorer neighborhoods in great cities, in isolated rural communities, or in the colonies of unskilled or partly skilled laborers in villages devoted to a single industry. Undoubtedly we can find striking instances of complete amalgamation under the most unfavorable of these conditions. It is also true that most of the members of families in the third generation 
are really assimilated and in many cases are not to be distinguished from descendants of first settlers of English stock. The exceptions are to be found in the relatively few isolated communities which have been transplanted as a whole from the old country, and have retained its language and customs.

In estimating the relative importance of the different influences, one may probably put first the desire for the better social standing and higher degree of physical comfort enjoyed by the native. That the superiority of wealth and ordinarily of education is an important factor in inducing the amalgamation, becomes evident if one thinks what the probable course would be were the immigrant to go among an inferior people. It has been the history of the settlement of countries inhabited by inferior races that they were merely driven out or exterminated. Where the native and immigrant aro more nearly on a level or the natives are strong enough to hold their own, as in China and in certain of the more backward Latin American countries, either the races live entirely apart or the two fuse into a new race to which each contributes its share.

Many of the altruistic social workers and Zimmern among the theorists have criticized the American people for assumption of superi- 
ority and for their contempt of the foreigner. It must be admitted that it has no defense on theoretical or moral grounds. One must admit that the American is full of conceit as to his superiority and that the conceit is largely based on ignorance. In every city there are undoubtedly many men who are passed by with contempt, or more likely never noticed at all, who, by their training and ability, are entitled to a high place in literature or art or political theory. This attitude is taken not by the superior Americans but by the ordinary man, very much inferior in every respect to the men he is looking down upon. Much as we may deprecate the unfairness of the American in this respect and lament the opportunities that he misses on account of it, we must still grant that by it the process of naturalization is hastened. The unreasoning race prejudice which shows itself in repugnance toward the strange speech, customs, and standards of the immigrant is one of the strongest forces in compelling him to be absorbed. How the opposite course of accepting all as equals, with manners and clothing and standards that were merely different but just as good, would work, we cannot say because it has never been tried. Probably one would find that if the newcomer was not repressed he would dominate and soon 
oppress. At the best he would not be assimilated. Whatever its ethical value, even its logical truth, race prejudice is one of the most important forces in the amalgamation of the stranger.

It is, of course, granted that the more independent minds among the newcomers see the injustice of the native attitude, the more selfreliant resent it. The prejudice accounts in part for the strong socialistic and anti-governmental political beliefs among them. The great majority, however, feel the steady pressure of implied inferiority that meets them on every side and in every field. They respond to it both in essentials and non-essentials. Their costume may be affected first. The native dress is discarded as soon as possible. The women are ashamed to be seen without a hat; the native costume, however attractive in itself, soon becomes a mark of inferiority and a matter of reproach. All of the external manners and customs yield in the same way. The methods of salutation, habits in connection with the toilet and table are gradually given up or modified to meet the prevailing American usage.

Many of these are superficial and unimportant in themselves and serve only to indicate the way in which the assumed superiority of the 
new compels the change in old customs. In the more essential respects the same forces are at work. Between manners and hygiene there is a close relation. The reason for abandoning overcrowding in sleeping quarters, unhygienic food and personal habits is usually the social disrepute in which they stand rather than any rational consideration. To be able to receive friends in a room not used as a bed room, to say that the wife does not keep boarders, is a mark of social distinction, or a plea for social recognition quite as frequently as it is an acceptance of rational hygiene or a consideration of the well-being of the wife. Even the possession of a bath room is frequently, among the lower circles, more a mark of social superiority than a means of cleanliness. When the change, whatever its nature, has been introduced as means for the attainment of social distinction, habits develop that have a hygienic value. Cleanliness in its different forms becomes essential to comfort and cannot be easily dispensed with.

Frequently the change has been worked with slight recognition on the part of the individual. He may still look back with fondness to the good old ways. It is only when he tries a return to the old that he appreciates his change and the advantages of the new. I remember a 
relatively young Greek at Patras, who had been recalled for service during the Turkish war and had gone .back to the shepherd's life of his parents while waiting for induction. Before his return he had looked back upon the shepherd's life as idyllic, even as ideal. When he experienced it, the hardships, particularly the dirt, were insufferable. After a few weeks he gave up the life and came to Patras and worked as porter about a hotel. Even there he could not endure his accommodations but rented a room at his own expense to obtain the cleanliness that had become essential to him. Once the standard of comfort has been raised by the social forces, the new habits and the emotions that develop with them prevent slipping back to the lower level.

The changes in language show the influence either as cause or effect of the same forces. Here again the vices or incapacities of the English race have what we may regard as a beneficial effect. Notoriously the Englishman is a bad linguist-it is with difficulty that he learns another language. Furthermore he has no desire to learn other tongues and is inclined to regard them as hardly worth while, if they are not beneath him. In consequence, wherever he goes he refuses or is not able to learn the language, and the other more competent lin- 
guists and more adaptable individuals learn his. The German, on the contrary, is usually better trained in languages, is keen to acquire a new one, and, in consequence, adopts the speech of the new home and gradually loses his own. The American may have more competence than the Englishman in learning the languages of others, but he is certainly as little able to appreciate the beauties or the advantages of the immigrant's tongue. Ordinarily he refuses to learn and in addition he assumes an attitude of superiority to the man who speaks another tongue or at least towards the man who cannot speak English. He is inclined, even, to measure the general intelligence of a man by the accuracy with which he speaks English. One who speaks it brokenly is by the average untutored American at once assigned to an inferior social position.

While language may not be essential to belonging to a nation, the individual who speaks the language of the race is more likely to know and to accept the ideals of the race than the individual who does not. $\mathrm{He}$ is also much more open to the manifold suggestions on all points that serve to mold the mass of newcomers in the unessentials as well as in the essentials. To read the newspapers, to understand political addresses and on occasion to make them one's 
self, are important elements in becoming a member of a nation. To know the literature gives one a point of contact with other members of the same group, stimulates emotions to be shared in common with them, and gradually gives a pleasant tone that will fuse with other feelings aroused by the thought of the nation or of the state. One can become one in spirit with the group only by knowing what the other members are thinking and learning, and this is impossible or at least very difficult unless one knows the language.

The other strong influence is the school. Most of the forces we have mentioned operate much more effectively upon the child than upon the adult. In the school the child feels them all with greatest force. Here he is forced to learn the language, here he receives his instruction in hygiene and becomes aware of the habits and manners of the native more intimately than his parents may ever do unless they become servants in the native homes. Here, too, the influence of race prejudice is felt most fully, even most brutally. The boy has no respect for the feelings of others and has no doubts about the superiority of the ways of his elders. Even in neighborhoods where newcomers from one race are present in large numbers and possess considerable wealth, we find the children 
ashamed to speak the language of their parents and thus gradually forgetting it. In many cases I have heard a college student regretting that he failed to take advantage of the opportunity to learn the speech of his parents because as a child he was ashamed to be heard speaking it. The cruelty with which children enforce the dictates of fashion upon members of their own race is much increased when the victim is an alien. When the foreigners are few in number the effect is overpowering and rapid. Even in schools where, as in many cities, the number of foreign children is large in proportion, the effect is still seen. It is weakest where most of the children are of one foreign nationality. If several nationalities are represented so that the different prejudices nullify each other, the American comes in to tip the beam and dominates all.

The Americanization of the child is effective not only for the next generation, but also works back upon the parents. The old people learn from their children and gradually accept the leading of the children. That this is true is emphasized by the reports of most social workers that the parent often loses his natural control over the child in ways that are unfortunate. The father speaks only the language that the child has learned to disdain, the mother wears 
clothes that mark the "dago" or "wop," the manners of both are uncouth from the child's newly acquired standards. The teaching of the parents on all points is similarly open to suspicion. Where the child is exposed to temptations the parental admonitions on points of morals are regarded as of no more value than their opinions on matters of dress or speech, and morals suffer. The new environment exerts its influence for bad as well as for good. Its strength is undoubted. The assimilation of the parent is frequently accomplished through the child.

In addition to the changes in ideals and other purely emotional respects it seems that even the physical and mental characteristics undergo a change as an individual moves from one country to another. To make an American of an immigrant may mean, if this be true, not merely that he changes his likes and dislikes and his habits of living and thinking, but that he changes his physical characters and his mental capacity. Proof of this statement requires much longer observation and more accurate measurement than has been possible so far. A few bits of evidence are accumulating in its favor. On the physical side we have already mentioned the changes that have taken place in the Germans who settled in the Caucasus. One 
can easily note the changes that are found in the second generation of many races that keep pure in the United States. Men of both German and English stock are taller and in many cases more lithe than were their progenitors. These may easily be ascribed to better food and a more active life, as we find a similar change in the native stock as a family moves from the city to the country or from the east to the west. Most striking evidence for the physical change is Boas's' series of measurements of the shape of the head in immigrant parent and native born child. He finds that the shape of the head tends to approach the average American head, that the child of the broad headed (brachycephalic) Russian Jew becomes markedly longer (more dolichocephalic) in a single generation, while the head of the child of the long-headed Sicilian is broader than that of his parent. Why these changes take place cannot be stated at present. Boas himself makes no explanation. Their main significance is to indicate that even the physical characteristics of the immigrants may be changed. If the process continues there is a possibility that the new will not be distinguishable from the old even in stature and formation of the head.

'F. Boas: "Changes in Bodily Form of Descendants of Immigrants." Government Printing Offiee. 1910. 
The change in the mental status of the immigrant after a few years has often been remarked. Carl Schurz ${ }^{2}$ asserted that the European peasant assumed in America an attitude of independence that he never would have attained in his home environment. The change he ascribed to the practice in self-government acquired here. Miss Balch, in her study of the Slavonic immigration, asserts that the returned immigrant can be easily detected in his European home by his carriage and his greater independence of thought and his interest in education. The returned Greeks who fought in the Balkan war had the reputation of being much better soldiers in every way than their fellows from the same province. They had more initiative, learned much more quickly, were in every way more intelligent. I was struck, as I chanced to be in Athens at the time, to see a Greek I had met on the boat, who had been unusually successful in America, walking with his brother who had come up to the city with him to enlist. The one had all the marks, the bearing, the garments of the better type of American business man. The brother was uncouth, awkward, a typical peasant, obviously what his brother had been a dozen years before.

"Carl Schurz: "Reminiseences," vol. 2, p. 77. 
This is typical of the change that is wrought by a few years' residence in America.

The results of measurements that have been made recently of the mental capacity of groups of immigrants, are in certain respects more definite than these general observations. The Binet tests were applied for three years to the Russian Jews and Italians who entered New York. ${ }^{3}$ These showed that at least 40 per cent of the adults of each race were below normal intelligence, had a mental capacity of no more than the equivalent of the American child of ten. This low state of intelligence is not transmitted to the offspring as measurements of their children in the schools show no such prevalence of mental defectiveness. Nor is it characteristic of the younger members of a first generation after a few years' residence in this country, if one may judge from their success in business and in other pursuits. If low intelligence were an innate character, we would expect it to appear in the children. As it is, we must assume that it is merely an acquired characteristic. One may venture the hypothesis that the narrow life of the peasants or lower grades of laborers in the home country which gives no opportunity for initiative results in

"H. H. Goddard: "Mental Tests and the Immigrant." Journal of Delinquency, vol. 2, p. 243. 
the formation of habits of accepting everything on authority and so of not thinking, and that these habits have an injurious effect upon what seem to be the fundamental mental characteristics.

This fact of the low intelligence of the immigrant would at least eliminate the hypothesis sometimes offered as an explanation that the emigrants are superior individuals, selected by their intelligence and initiative for the venture to the unknown land across the sea. That the best emigrate might be doubted on a priori consideration as well. To be sure, it requires initiative to break home ties and start alone. On the other hand the adventure appeals to the individuals who are not too prosperous and contented with their lot in the home environment. The man who has succeeded is not likely to make the break unless he is the victim of political misfortune or of a wandering, venturesome disposition. It is the man who has not quite found his place and so probably the man of less than the average intelligence or adaptability who is forced to emigrate. In these days of assisted immigration, when the large majority come on funds sent from relatives already established in America, when, too, the steamship agents are soliciting immigrants and supplying through tickets from the village in Eu- 
rope to the destination in America, it frequently requires more strength of character to resist than to yield to their entreaties. These forces would not necessarily select the worst for emigration but they would add to the best a large number of the less intelligent, and make it probable that the emigrants would be not much above the average of their community.

The elements we have been enumerating might be regarded as unessential, in many ways they are symbolic of the fundamental changes rather than themselves important. A woman may be just as good an American when she wears a shawl as when she wears a hat, but when she is sufficiently affected by the new environment to feel uncomfortable in the shawl, she and her family are likely to appreciate the forces of American society in other ways as well. And in associating American life with cleanliness and a high standard of living the immigrant is accepting ideals that may be more effective in creating an allegiance to the country of his new residence than would acceptance of the principles embodied in the Declaration of Independence.

But the work of transformation does not ordinarily stop with a change in the habits of the toilet or in the standards of living. The formal political beliefs of the United States are suffi- 
ciently in harmony with the general likes and beliefs to make them acceptable to all, no matter whence they may come. The questions raised are rather of the sincerity with which they may be applied, than of the principles themselves. Our immigrants may be socialists or belong to other anti-government groups in reaction against the overbearing treatment of their employers or in continuance of home teachings or the preaching of the American agitator, but they are all willing to accept the principles of the Constitution. It may well be questioned whether a larger percentage of them will be found in the socialist group than one would find among native born Americans of the same social and financial standing. As they increase in wealth the number of socialists among them certainly diminishes. The list of leaders among our most radical organization, the I. W. W., contains fewer foreign names than the proportion of the foreign population among the poorest paid groups would lead one to expect.

As one talks casually with the foreigner of the working class, one finds a wealth of political ideas that are in harmony with the best in American political theory. During the first summer of the war, I remember hearing repeated expressions from Scandinavian and southern Slav sheep herders in Wyoming of 
the opinion that the end of the war would bring a United States of Europe. I could not trace the idea to any common source, and individuals who spoke it were sufficiently far apart to make a common source unlikely. In all conversation with men who would be regarded at first sight as still foreigners, one finds an objection to monarchies as such and a preference for republican or democratic institutions which, whether acquired during residence here or in Europe, argues well for respect and affection for our form of government and political ideals. Willingness to count as part of the social or national group is much more important.

How far changes in ideals of a social sort, such as we have been enumerating, indicate or prove a cliange in the fundamental emotional attitude that would have political significance, is a problem of the utmost importance. At present its solution requires detailed knowledge of motives that neither the individuals themselves nor careful observers can supply. Opinions differ widely. Pessimists insist that the much vaunted "melting pot" has proved incapable of fusing the different national elements into a homogeneous mixture, a single product that may be called American. Enthusiasts for the effects of life in America, on the other hand, find evidence from approximately 
the same facts for a belief that Americanization is as complete as could be expected, even, as has been said, that the new citizens may be more American than the Americans themselves. The differences seem to depend in part upon the prejudices of the authorities, in part upon the definition of Americanism or of nationality in general, probably in greater part upon the experience of the individual who passes the judgment.

An objective measure of the transfer of affection is difficult to obtain. Naturalization is a legal rite and may be unaccompanied by the change of heart in which we are interested. It is generally accepted, as was said earlier in the chapter, that an alien not infrequently makes application for citizenship for the social or pecuniary rewards that go with it. On the other hand many who are thoroughly American in spirit neglect to take the legal steps and may even be accepted as citizens and vote for many years without realizing that the legal form has not been complied with. No single test is altogether adequate. Between two races or two civilizations likes and dislikes are always of parts and of phases, not of wholes. One may like the national ideals and dislike their application or the failure to realize them in action. One may be fascinated by the man- 
ners of a people and disgusted with their morals. On the other hand one may appreciate the necessity of fulfilling certain property obligations, like paying taxes, without appreciating the political doctrines of the state.

Perhaps the simplest and on the whole the most satisfactory test is willingness to fight for one country against the other. That means a willingness to cut one's self off completely from the land of one's birth and to cause the death of one's own old neighbors and perhaps one's kin. Even this test is met in the present war by many of the citizens of the first generation. Large numbers of the second and third have satisfied it with little or no hesitation, even if there may have been regret. In fact, for the citizens of the third generation who have not lived in a close community, political or religious, one could hardly distinguish the man of German from the man of English or Scandinavian descent in his attitude towards the war. Where the individual has lived in a community where German customs have continued, and the language is still spoken, or where the man is a teacher of German or a preacher in a German church or even the son of such a teacher or preacher, the feelings are likely to be mixed. Even of these a larger percentage than would be expected were loyal. 
The clergyman and the teacher of German have been recognized propagandists of the German spirit as well as of the language and the gospel. It is not strange that they and their children persist as Germans when others have become Americans. A secondary allegiance undoubtedly goes to America and were the enemy other than the fatherland, they would fight as well as another. Put ourselves in their places as residents of the second generation in Germany and one can see how little one would desire to face the ordeal of fighting against the home nation and possibly against relatives and friends.

Of the neutral nationalities one finds on the whole much the same willingness to fight that one does among the natives. Resistance to the draft was found in surprisingly few cases, and then among individuals who did not speak the language well enough to know what it was all about or who were members of sects and parties that on principle did not believe in fighting. When the full statistics of the draft are published, as it is to be hoped that they will be, we shall have an interesting indication of the degree of de- and re-nationalization among the immigrants. Meantime if the accounts of court martials have any value and the names among the casualties overseas have any significance, 
we must admit that the optimist is nearer the truth than the pessimist. The citizens of foreign descent have been converted into real members of the nation to a degree that few could have hoped.

While there are a number of instances of immigrants, who have proved disloyal or less loyal than one could wish, it must also be remembered that much of what has been called disloyalty is based on political theory that would have made the individual disloyal to his own native country as well. Pacifists from conviction, socialists of long standing, and hired spies constituted the great majority of trouble makers and these found almost as many representatives among native and neutral citizens as among the alien enemies. Were one to imagine two million Americans permitted to live freely in Germany with as little police or military surveillance exercised over them as has been exercised here, we would be very much disappointed if there had been no more trouble than the United States experienced in the course of the war. In fact a similar expectation was formed on the part of the less experienced among German commentators. The hope for a revolution among the German-Americans had apparently been one of the stones in the foundation of the German military and 
political theory. Those among the Germans who had a better opportunity to observe the changes that came over the immigrant after a few years or decades of residence in America knew better. The German university professors who saw students of the second generation returned to study have long marveled at the assimilative capacity of the American nation. As one said to me, "Children of German parents come back to us with names no longer German, with no knowledge of the language, apparently even trying to forget that they are German." That assimilation is the rule, persistence in the native tradition, the exception, is fairly evident from observation and from what few statistics we possess. Those who would expect more forget the failures of the native born, and overestimate the possible effect of a few years' residence in a foreign land.

While discussing the influence of change in residence upon nationality one must remember that occasionally at least the American may similarly change his affiliations. One need only mention Caspar Gregory's death in the German trenches and a few less conspicuous examples of men of intelligence who as a result of residence in Germany espoused the German cause, although of definitely American or English descent. 
The attitude of the returned immigrant as he is met upon his native soil is also significant in emphasizing impressions, if it is not to be regarded as furnishing convincing evidence. As a traveler in Greece during the Balkan war, I was much impressed by the enthusiasm of the returned Greek for America. One found them with small American flags on their Greek uniforms, their conversation was always of America and the superiority of things American. They were loyal to Greece, too, and many of them had returned to fight to avoid losing their citizenship. Some, as they spoke of it, regarded it as an anchor to windward in case they should desire to return, some wanted to make secure the freedom of their country out of pure patriotism, in spite of the fact that they did not expect to return. All alike, whether they had been laborers or merchants in America, whether they expected to be permanent residents or only to return to accumulate more wealth to be enjoyed in the home land, were imbued with the American spirit and were inclined to place things American on a pedestal. What they spoke of most often was not the ideals of American political life, but the standards of living, the increased comfort that is possible in America, and the higher wage which makes that possible. Coupled with this was 
the appreciation of an opportunity for advancement. Those who had succeeded were thankful for the chance, those who had not, hoped that their turn might come and were rejoicing in the anticipation. This personal freedom rather more than the abstract political freedom was most frequently mentioned.

The factors which further the change in nationality as an individual lives among a new people are in part identical with those that led to the development of the nation in history. The main difference lies in the fact that the ideals and resentment against oppression or actual hardship are more important in the historical development of a nation, while the formation of habits and the gentler influence of improvement of social conditions are of greater effect in inducing the individual to transfer allegiance. The ideals may cause the individual to emigrate and raise a presumption in favor of the adopted country. The most effective factor of all is the gradual development of new standards of living, the acceptance of the standards of the new home as applicable to himself. The change in ideals is accomplished in part through imitation of the model passively set, but more by the constantly effective pressure of the contempt of the older residents for the costumes and habits of the newcomer. The 
harsh attitude toward the foreigner is coupled with a kindly reception of the man who changes and equal opportunity before the law in business and property relations. This punishment of contempt for the old and the reward of willingness to receive as an equal the man who changes combine to impress the language, the styles, the size and location of the house, and finally political ideals and willingness to die for the new people of which he has become a part.

After the standards have been accepted under the influence of this double process of punishment for remaining alien and reward for assimilation, becoming emotionally and politically a part of the nation follows naturally and unavoidably. The newcomer, who finds himself at first an outcast except among the immediate members of his old race, gradually accepts the customs and learns the language of the new country and as he does, finds that his lot is improved physically and socially. $\mathrm{He}$ is more and more accepted. If he had not decided to remain and become a permanent citizen he seriously considers it at this stage. He finds that his closest associates are with Americans, or at least that the ideals of American life have become his ideals. He in turn begins to look down upon the newcomer with his own old 
standards. With that acceptance of the nation as his nation, a desire for its continuance and prosperity over all other nations develops and with that goes willingness for self-sacrifice to further that end. Then, naturalization or nationalization is complete. Were he to be called upon to justify the changes in affiliation that have developed in this habitual way, the probability is that he would find a reason for it in the phrases of liberty, opportunity, or the superiority of our institutions. That these have had no effect cannot be asserted, but the greater well-being and the formation of habits which make the continuance of the new life an essential to happiness are probably much more important. 


\section{CHAPTER VI}

THE NATION AND THE MOB CONSCIOUSNESS

Modern writers without any important exception unite in believing that nations are held together by mental rather than by physical or hereditary bonds. It is something in the spirit, not anything in the physical constitution or common ancestry that makes them one. Our discussion so far reënforces this belief. Exactly what the nature of the mental or spiritual process may be that unites, what it is that changes when a group of individuals becomes a nation, or what is altered in an individual when he transfers his allegiance from the Emperor of Austria to the United States of America, is not made so clear where any attempt is made to answer the problem at all. In a psychological study, such as we are attempting, it is this phase of the problem which must have the center of the stage. It is our task to decide what the mental processes are which are referred to so vaguely by the writers in history and political science. Zimmern ${ }^{1}$ defines na-

${ }^{2}$ Zimmern: "Nationality and Government," p. 96. 
tionality as "a form of corporate consciousness of peculiar intensity, intimacy, and dignity, related to a definite home country." If we discount the relation to a definite home country now and leave it to be discussed more seriously later, it would seem that all that we have is a corporate consciousness, which probably means a consciousness of belonging to a common body or society. What this is, whether instinct or habit, and whether as consciousness it belongs under feeling, intellect or will, he does not say and probably for the problem he is interested in does not much care. For our purpose, however, it is just this that does matter. We must attempt to discover if we can what this peculiar consciousness is and what its effects may be upon the action of the individuals that feel or experience it.

Of the more definitely psychological theories we may select a few types for more detailed analysis to show what is characteristic of each and what all regard as essential to the nature of nationality. It must be said that some of the theories we are to discuss are almost as vague in their statements as those that we have just quoted. They are more picturesque in their analogies, but are quite as elusive when we attempt to discover what they really mean. Others are sufficiently definite in the compari- 
sons that they make, but the states or processes to which they compare the consciousness are quite as little known as the consciousness itself. Perhaps the most vivid and at the same time most widely known of the modern theories is Le Bon's, which is, in essentials, that a nation approaches a crowd in the nature of its consciousness and that a crowd induces in the individuals who compose it a state peculiar to itself and allied to the hypnotic and other abnormal conditions. Examination of this theory implies an investigation of the nature of the mind of a mob in the first place and then of the question how far the nation resembles the crowd.

Le Bon ${ }^{2}$ insists that the man in the crowd is altogether transformed, that in considerable measure he loses all of his distinguishing characteristics of control, that he is fused with the other individuals to constitute a new mental unit. He speaks more or less pictorially of the process as one of giving over all of the acquired characters and getting back to the instincts which all men have in common just because they are men. In these fundamental instincts they are little different from the beasts; they descend to a lower level of culture and evolution. More definitely he compares the man in the mob to a man hypnotized. He as"G. Le Bon: "The Crowd," p. 11 et passim. 
serts that in both conditions the activity of the cortex is in abeyance and that the individual is controlled only by the action of the medulla. The neurology involved in this statement is archaic, if it were ever accepted, but we are less concerned with the detailed theory than with the description of the state and the conditions of the action. The test of the theory is the closeness of the resemblance between the man hypnotized and the man in the crowd. The stage of hypnosis that offers similarities is the somnambulistic. In this the patient is marked by susceptibility to suggestion in thought and action, and even in perception. The least command is executed, however absurd it may seem. Any statement seems to meet with acceptance, and the patient will even see objects said to be present where nothing resembles them. Thus Binet could make a patient see a picture on a blank card, and when shown the same card when hypnotized on another occasion the patient would again see the picture. The individual hypnotized seems also to have the emotions that are suggested to him. He will weep at command or when it is suggested by word or picture; he becomes angry when his fist is clenched or the command is given. He also will at suggestion assume a part and act it out consistently. An almost invariable symp- 
tom of this stage of hypnosis is that there is when wakened no memory of any of the happenings of the hypnotized period.

When we compare the action of the man in the crowd with this state we find many similarities and a few differences. It should be emphasized that Le Bon would not ascribe this peculiar state to every crowd, but only to those under special conditions. He would say that men might gather without going into this condition, without becoming fused into the unity that submits each to the control of the whole. The existence of the peculiar condition does not depend upon the size of the crowd, but upon other attendant circumstances. At times the group goes into a trance, becomes hypnotized; at times the same group or another group of the same size might gather and the men in it remain normal. Le Bon has in mind the mob in action, as in the French or Russian Revolution or any crowd indulging in riots. It is then that we see the individuals carried away with little thought and less control. There can be no question that under these conditions the individual will commit acts that he would despise when alone. The reduction of control is in the influence of the directive forces of experiences, the forces that constitute what we group under the term reason. In general, the 
instincts dominate, but in neither the hypnotized condition nor in the mob is direction altogether abrogated. The limitations of ordinary morals and good taste are merely reduced. There is a point beyond which neither will go. The hypnotized patient will commit a play murder with a paper dagger, but will not stab with a real dagger. A mob will commit murder, as has happened altogether too often, but it does not do it unless it can find some reason that, in form at least, would satisfy a sane man in a quiet moment. The criminal is lynched because the punishment of the law is not adequate. The bourgeoisie are destroyed for fear: that they may again regain power and oppress the proletariat. Or this rich man deserves death, not that he has done anything himself, but that he belongs to a class that has oppressed and he will himself if occasion arises, or he must have injured some one or he would not have been so wealthy. The crowd acts because it accepts these arguments, but in many cases the arguments are supplied by a leader, and the greater suggestibility of the mob is shown by the fact that they will see but the one side of the case which is presented by the oratorical leader, and that they are not in a condition to resist the tendency to believe an argument of the most fallacious type. 
The suggestibility of the mob extends to the perception processes as well. Innumerable cases are on record in which all of the members of a crowd will see what is suggested in spite of the fact that it has no existence in reality. We can find instances all through history in which armies in the excitement of a conflict or the fatigue of retreat have seen apparitions. St. George appeared to the crusaders on the walls of Jerusalem, and even in the last war there have been several occasions when a whole army has seen an apparition or apparitions. The best attested instance is perhaps the angels seen by the British on the retreat from Mons. The evidence for these hallucinations would easily find acceptance in a court of law unless questioned on a priori grounds. At other times St. George or St. Michael has been seen leading the attack upon the enemy, or strange lights have been seen in the sky by a number of men and the sight has been accepted as a happy omen and inspired a successful charge. All of these visions must be regarded as collective hallucinations, started by some one man and extending to other members of the crowd. They are altogether similar to the collective hallucinations which are supposed to explain the Indian conjuring trick of making a tree grow before the eyes of a crowd or the other of throw- 
ing a rope into the air which extends out of sight and is climbed by a sailor or acrobat. All taken together show that on occasion, rather rare occasion, to be sure, an hallucination sufficiently vivid to lead to vigorous action may. be induced in a crowd.

The changes in the emotions are as marked as are the changes in thought and action. In the crowd this is a subordinate phenomenon. The thought or the perception is suggested first and emotion and action follow. If we admit that there are similarities between the condition in the crowd and in hypnotism, we must also admit that there are differences which are quite as striking. The man hypnotized to the state of somnambulism always forgets after waking what he did during the stage of hypnosis. In the crowd there is no such amnesia. The individual remembers all of his acts. The hypnotized man gives definite evidence of being in an abnormal state. He shows signs of the advent of the condition by groans, change in breathing, and sometimes muscular contractions that may approach slight convulsions. These are lacking in the development of the crowd consciousness. While the most skeptical critic would be compelled to admit that there are similarities between the crowd state and the hypnotic, the differences are quite 
as marked. One is justified in the statement that a man in the crowd is somewhat similar in his acts to the man hypnotized, not that he is hypnotized. The similarity is in the action, not in the state itself.

It has also been asserted that in the mob the individual is highly suggestible or that he is controlled altogether by imitation. The first of these theories states what is true of the hypnotic theory. Not to make the man in the mob too different from the man in his ordinary life, it is well to emphasize the fact that in one sense all that we do is done through suggestion. Reduced to its simplest terms suggestion is nothing more than habit on the one hand and association of ideas on the other. Give any man a stimulus that has been connected with a certain movement and he will make that movement at once. Ask him a question and the answer that has been most frequently given will come to his mind and in most cases to his lips. Suggestion is nothing more. We use the term suggestion for the instances in which the response is more mechanical, when the suggested movements or ideas are opposed to rational interests or are more than usually uncontrolled. This statement that the individual is subject to suggestion is about all that is true in Le Bon's statement that a man in a mob is a man hypno- 
tized. It is only necessary to add that a man is always subject to suggestion and is more subject to it in the crowd than when alone.

The same may be said of imitation which has been made a law of social action by Tarde and many of his followers. The movement that is imitated furmishes a stimulus to action, suggests it, if we use the term discussed above. Imitation is only another form of suggestion. Of both it should be said that they attract attention only when the act or thought that they initiate is in some way different from the ordinary. Usually the movements and ideas are controlled by wider experiences, by what we ordinarily know as will. In the crowd this control is reduced. But the control is not altogether relinquished in favor either of imitation or of suggestion. The movement that shall be imitated is determined by the instinct of the individual and by his reason and all other factors that control experience. Experiments on monkeys, supposed to be the most imitative of animals, show that they will not imitate every movement that they see, in fact the experiments so far made have never been able to show that a monkey can be taught to make a new movement by imitation. He may be shown a movement a great many times and make but slight effort to repeat and when he does try to. 


\section{THE PSYCHOLOGY OF NATIONALITY}

repeat it is necessary for him to go through an elaborate try, try again process before he will succeed in doing what he has been shown. In the monkey and in man as well, imitation is successful only when the movement to be imitated has already been made before and is thoroughly known. Even then only those movements that promise desirable results will be imitated and if the results prove undesirable when obtained, the movement will not be repeated. Imitation is not then really an independent force or condition of action, it is only the name for the result of a number of other forces. The result, not the cause, is emphasized in the term. The only new feature and the only instinctive element in the fact of imitation is the instinct that was emphasized in an earlier chapter, that a man will be attracted by the action of his fellows, and will in consequence attend to their movements, and, secondly, that there is an instinctive tendency to do what all others are doing. Imitation is only suggestion with the added effects of these two instinctive tendencies.

One must insist, then, that the same truth is at the basis of the three theories that describe the man in the mob as hypnotized, as acting under suggestion and as being controlled altogether by imitation. In hypnotism suggestion 
rules, and imitation is only suggestion in which the stimulus is the act of another man. If one object that in hypnotism suggestion is much stronger than it is in the normal state, we may answer that the man in the mob is not so completely open to suggestion as the man hypnotized. The principles of action of the man in the mob are the same as those of the man under ordinary circumstances. The suggestibility of the man in the mob is limited as is that of the normal man by instinct and by ideals or reason. One may even assert that the instincts of the men in the group are the essential forces in determining the character and degree of the action. When a mob is angry because of an act that arouses its sympathy for the victim and hatred of the aggressor, it will go to the greatest excesses at the slightest excuse. In this the responses are merely exaggerated by the presence of the other members of the mob. Should one attempt to induce the mob to rum away at the sight of the atrocity, when no great danger threatened the members, the endeavor would be wasted. Should one at any time suggest to the mob some act that was in itself ridiculous or was not in harmony with some one of the instinctive tendencies of the individuals there would be complete failure. More than likely all would break out in laugh- 
ter or in jeers and the mob would dissolve into its elements. Where the crowd has been trained by one man and accustomed to one set of acts, no matter how ridiculous, as happens in the ritual of certain religious or pseudo-religious sects, the ridiculous may become an accepted sign of unity, and be repeated without question. On the whole, however, only acts that are adapted to the situation and to the instincts of the crowd will be made. All that the leader can do in the most docile mob is to select one from among the possible instinctive responses. If a mob wavers between flight and aggression when each is in some degree appropriate, the act of a leader or of a part of the crowd will decide which course shall be adopted.

Again, these theories all assume that a mob is absolutely under the control of a leader, and some seem to believe that the leader works with full consciousness of what he is doing and even that he malevolently uses the crowd for his own purposes. This is at most only one side of the problem. The leader not merely exercises his will upon the crowd, but the crowd also works its will with him. One could quite as readily sustain the thesis that the leader has been hypnotized by the mob as that the mob has been hypnotized by the leader. If the statement can be made with some plausibil- 
ity that the members of the mob evidence an unwonted submissiveness to the leader, it may also be said that the leader exercises an abnormal aggressiveness. Any one who has even temporarily and in minor matters assumed the leadership of a crowd is in some degree aware of a change in his attitude or character. Even in addressing an audience, one feels at times an exaltation which one may imagine leaders to feel in a crisis. A practised speaker has an assurance before a sympathetic audience that $\mathrm{L}$ ? does not feel in his study, and will not infrequently make statements that he would not make in writing. For many men the presence of an audience acts very much like wine, and in some the effects are deplorable. The permanent or temporary leader of a crowd is affected even more strongly. He becomes more important in his own eyes because of the position he holds. After he has overcome the first instinctive fear of the crowd that is felt by all of its members, he goes to the other extreme and takes courage from the group to attempt deeds that he would not dare alone, and would not plan for the crowd in a quiet moment. For good or for ill he rises to heights of which he is not ordinarily capable. He feels in himself the strength of the men he is leading and acts correspondingly. 
The leader also takes many of his beliefs and opinions from the crowd. He hears a cry of "lynch him," repeats the cry as if it were his own opinion, and takes the first step towards putting the man to death. Should he hear a plea for clemency he would be equally willing to lead a rescue. There is no weighing of evidence on his part, no real decision, only one side of the case presents itself and only one set of instincts has a chance for action. $\mathrm{He}$ is the embodiment, not merely of the executive force of the crowd but in large measure of its opinion, of its reason, and of its emotion as well. It is here that the ordinary fear of the crowd asserts itself. While the leader is bold when he represents it against the opinion of the victim, particularly when it is expressed against a weak individual, he is a coward against the demand of the crowd itself. He does what it demands or what he thinks it demands with little or no question. Even Napoleon always feared to oppose or thwart a mob. It is this curious interdependence between the leader and the crowd that contributes most to making the mob irresponsible. Each relies upon the other and makes the other take the blame for failure, while each is willing to ascribe any success to the leader. A member of a crowd may advo- 
cate a course of action or unite with the others in doing something of whose advisability he may be in doubt. The leader may be just as doubtful, but afraid to protest for fear of the mob. It is this that makes the action of the mob so irrational. Each suggestion is made more recklessly than it would be in private, it is also only slightly weighed, for each throws the responsibility for the act upon some one else or upon the crowd as a whole.

The activity of the crowd and of the leader in the crowd is primarily an expression of the social instincts, particularly of the instinct that makes the individual subordinate himself to the opinions and beliefs of the whole. It is this that makes the crowd act as if hypnotized and also makes suggestion and imitation so important. What makes the crowd different in its action from the action of a society in its quieter moods of comparative isolation is the fact that the ideals and conventions do not exercise their ordinary restraints. As has been emphasized in earlier chapters, instinct is usually subordinated to formulated rules of conduct which have been developed in various ways and tested by long experience. These decide between the simple instincts, where they are in conflict, and select those which have proved most adequate to similar situations in the past. At the same 
time these ideals of conduct have the impelling effect of instincts because of the general instinctive respect for the opinions of society when formulated in convention as well as when expressed in words or in acts of the group immediately present to sight and hearing. In brief, then, these theories which would explain the acts of the crowd by hypnosis, imitation, or suggestion, are but expressions of our earlier described general principles of instinct and ideals. It is only that in the crowd the effects of the social instincts induced by the bodily presence of the crowd dominate over the slowly acquired and tested ideals and so produce what we call uncontrolled action.

Finally, admitting what there is left that is peculiar to the action of the crowd, how far is a nation as a whole similar in its action to the crowd? Le Bon and Tarde make certain assertions with reference to the action of the crowd and then without more ado apply the same laws to the action of a nation or of a people. If this were altogether fair, either there is nothing really peculiar about the crowd, or the nation is in itself an abnormal social entity or organization. A little consideration will show that it is only on rare occasions, if at all, that the laws of the crowd are also the laws of action of the nation. Le Bon guards himself at the 
beginning of his discussion by the statement that it is only infrequently that the mob really fuses into a new entity, only when its cerebral action is in abeyance and the action of the medulla obtains prominence. This happens only at moments of great excitement. These moments must be very rare in the life of the nation. The means of communication are not sufficiently rapid for the whole of a great state to be fused into one and to be dominated by a single impulse, except on rare occasions. When the Maine was sunk in Havana harbor a wave of emotion spread over the United States, very much as an emotion might spread in a crowd, and the authorities were compelled to declare war against the will of most of the responsible statesmen. Something of the same kind occurred at the time of the sinking of the Lusitania, but the effect was less immediate, probably because it was only one of a series of events of ever increasing atrocity. The nation's decision in favor of war was made more deliberately and rationally in accordance with the evidence.

For the most part the nation thinks as a sane individual in isolation thinks. The various instinctive responses that would impel to opposed actions neutralize each other, and while it would be an optimist or a blind man who would assert 
that the decisions have close approximation to perfection even in the best organized of national states, the final decisions usually attain the level of the average intelligence of the men who compose the group. This hesitation is due partly to the slow means of communication and the balancing of different reactions to the same situation by men in different parts of the country, partly to the action of established convention, and partly, in the modern state, to the effects of party government. Nearly every situation tends to arouse more than one instinctive response. In our lynching mob, sympathy for the victim or anger at his deed are both possible reactions, but the mob as a whole will make but one of these reactions and will be but little affected by the other possibility. In the nation that hears of the event only by rumor or reads of it in the papers, one emotion is aroused in one group, another in another. By the time a decision has been reached through reconciling opposed opinions there is a balanced judgment which neutralizes strong suggestions.

Conventional ideals also have the same effect. They are to be deprecated as preventing rapid advance and frequently preventing advance altogether, but at the same time they do prevent excesses that result from immediate uncontrolled instinctive responses. They may be the 
result of experience at a relatively low stage of development, but the instinctive responses for the most part represent responses in the prehuman period, are remnants of a still more rudimentary condition. The conventional methods of procedure in reaching decisions of a social type compel delay, and while they prevent rising to a possible best, they also save society from the possible worst. The influence of party government, even more than the local differences of opinion prevents the domination of the nation by one set of instincts, or by one form of impulses. Each party is skeptical of the opinions of the other and questions on principle any statement made and any action advocated by the other. This means that the opposing considerations are sure to be heard, and decision will follow upon consideration of more than one aspect. A nation will be carried away by impulse only on some question that has not been a party matter. Even new questions are likely either to be similar to familiar issues, or are made party measures because the men who suggest them belong to a party and so arouse opposition and discussion. ${ }^{3}$

The only place where national affairs might be settled as the mob settles them is in the na-

Cf. A. Lawrence Lowell: "Public Opinion and Popular Government," p. 96. 
tional assembly. Even here the mob spirit is seldom in evidence. The member is in the first place really representative. He knows that what he does must be passed upon by his constituency, and that reëlection depends upon doing what they will accept, even if one decision has not yet been advocated by them. The mass of his partisans at home restricts his freedom of judgment and prevents him from being led away by the suggestions of his colleagues, the members of the immediately present crowd. The rules of procedure with their requirements of votes at different times and by different houses also make impossible or unlikely an unthinking decision. While at times one sees in the assembly evidence of the effect of the crowd, that is only on unimportant matters or at the most only in periods of crisis, when the legislature consciously defers to the individuals who are responsible for decisions. Again the party system is active in checking too hasty action, sometimes even in delaying desirable action. The presumption that any suggestion from the opposing party must be wrong inhibits any too sudden influence that it might have and, if no other factor were at work, would prevent the assembly from becoming a mob in Le Bon's sense of the term.

While, then, we must do justice to the im- 
portance of Le Bon's discussion upon many modern theories and accept some of his conclusions regarding the influences that are active in the control of crowds and even of peoples, we cannot accept his views as they are stated. The crowd is not made up of hypnotized individuals, nor is suggestion alone the explanation of its acts. Suggestion in one sense explains all human acts, but it is not the machine-like form of suggestion that Le Bon attributes to the mob. All action is due to suggestion, but to suggestion controlled by ideals and conventionalized wider experience. Due to the instinctive effect of the other men present, this control is less when the man is in the mob than when he is in isolation. We must insist, too, that what slight difference really exists between the isolated individual and the man in the crowd is not in evidence in the collective activity of the nation, or can be observed only on rare occasions of great excitement. The nation is not a mob, even when we grant much less of the abnormal to the action of the mob than Le Bon insists that it has. We shall attempt in the next chapter to discover how the nation really does think and feel and act. 


\section{CHAPTER VII}

THE NATIONAL MIND AND HOW IT THINKS, FEELS, AND ACTS

IN the last chapter we reached the negative conclusion that while the nation has many of the characteristics of the mob it is not a mob, nor is the mob so instinctive in its acts as Le Bon and others assert. Still there are laws that control the activities of the nation and there are theories that would assign to the nation a mind very much as mind is assigned to the individual. These theories have something in common with the doctrines of Le Bon. They differ from it mainly in that they regard the mind of the nation as a more highly developed mind, more like the mind of a sane, normal individual than of a man hypnotized. We may examine this theory and in connection with it attempt to discover how the nation thinks, even if we cannot accept the theory that we are examining.

The analogy on which many of these theories are based is the somewhat mystical one that the nation possesses a super-individual mind, 
that by living together the members of a nation in some way develop an actual new mind that is related to the bodies of the individuals in very much the same way that the mind of the individual is to the cells of which his body is composed. This is a perfectly good analogy. One frequently speaks of the body as a colony of cells, each of which is an independent unit save for its dependence upon the whole for its nutrition, and for certain of its stimuli. Similarly, one might argue, the individuals are independent when apart, but when they come together there is in some way developed or generated a group of phenomena that is common to all of them. The voluntary and emotional processes are more prominent in this complex, the rational and sensory components are little in evidence if they are not altogether lacking. The will of the group dominates the will of the individual, if the latter has any place in the action of the group at all.

Many facts can undoubtedly be made to harmonize with this assumption. Yet it suffers from two defects if it is intended as more than a vague analogy. In the first place the relation of the individual consciousness or mind to the separate cells is by no means so clearly known or understood as one would like to have it. All that we know is that in some way the in- 
dividual is conscious, and that the physical organism on which that consciousness depends is a mass of separate cells. We know nothing, however, of any consciousness in the cells and we have only indirect evidence of the way in which the consciousness of the whole individual depends upon the activities of the different cells. To explain the consciousness of the social whole in terms of the relation of the individual consciousness to separate elements is to attempt an explanation by means of something that is itself far from fully known.

If one may assert that we have no direct knowledge of the consciousness of the separate elements in the organism of the individuals, it must also be asserted that we have no immediate evidence for the existence of a super-consciousness or over-soul in the group or in society. Each individual is aware of his own consciousness, may be aware that his own consciousness or his behavior is modified when he is in a crowd or is acting in a group, but no one knows immediately the consciousness of the crowd apart from this modification of the minds of the individuals who compose it. The crowd has no means of expression apart from the language of its members. One knows what a nation believes only from the assent of its members to general propositions; one knows of the 
emotions of the crowd only from the emotional expression of the individuals. There is no possibility of communicating with the soul of a nation other than by way of the souls of its elements and these can never be sure that they are accurately representing the over-soul. One can go beyond only by means of the plebiscite and that seldom speaks with unanimity in detail, however close may be the community of sentiment as regards general principles. That, too, gives only the opinions of the separate elements, not the belief of the over-soul as such.

One might abandon the attempt to discover a super-consciousness directly, as has been done by one school of psychologists for the individual consciousness, and endeavor to discover similarities between the action of the group and the action of the individual. This would not give any evidence of a super-consciousness because the theory denies the existence even of the individual consciousness, but it does permit one to speak of a social organism, or of a social entity, in a way that is free from many of the objections raised above. One can admit that the mob or the nation intensifies the instincts of the individuals, that the group behaves as if it had a guiding intelligence above and in addition to the intelligences of the separate individuals. This would permit the use of the term national 
spirit. It would not, however, justify its use as a warrant for acts that would not be permitted of themselves. The German philosophers since Hegel have spoken as if a nation, particularly the German nation, were the embodiment of a special spirit of divine or mysterious origin and as if the advancement of this spirit were demanded for the improvement not only of themselves but of the world. The Germans are to be regarded like the Jews of the Old Testament as a peculiar people, with a national spirit that is in an unusual if not exclusive degree the embodiment of the divine influence, and which must be advanced at the expense of doing violence to all human instincts. What matters a series of murders or debaucheries of the Belgian population! God has decreed that the spirit of the German people must spread over and dominate the world. What boots the suffering of the uncultured provided only that all makes for the attainment of this divine end! Such deductions as this would have no standing. The national spirit is not an entity which may be assumed to exist independently of its expression; on the contrary, it is merely an analogy by which certain acts and beliefs of the group have been expressed or explained. The existence of the spirit is justified only in so far as it explains observed facts. It may not be used 
as an established principle to prove assumptions or to justify courses of conduct in themselves made reprehensible.

If we make the tentative assumption that the social whole may be regarded as an entity apart from or added to the individuals who compose it, it is interesting to enumerate the qualities or forms of behavior that distinguish it. If we are to write a psychology of nations, it may be well to discuss our phenomena under the heads used in the traditional individual psychology. First, we have no chapter to write on sensation and little on perception. The social whole has no new means of acquiring knowledge. The sense organs of the group are the sense organs of the members. All that the group may add is a readiness to interpret the contributions of the senses in harmony with the suggestions received from the others. As was said in the last chapter, a group is more easily deceived than the individual, since each tends to accept the statement of another. The first man, if misled, passes the mistake on to the others. Of course, if a sceptic or accurate observer be the first to announce his opinion, the group will see clearly and will be less open to mistake than the average individual. The mistakes of the group are more striking if not more frequent than the mistakes of the indi- 
vidual. Perhaps they are more striking because shared by so many, and for that reason are so likely to be accepted as fundamentally true. Certain it is that, on occasion, individuals in a crowd will be subject to illusions that they would not have fallen into if alone.

Much the same may be said of the thinking of the nation. The thinking is always of the individual but the acceptance is determined by the group. In a popular assembly it may truly be said that the final arbiter of thought is the group, not the individual. Suggestions are made by the speaker or writer. These are passed upon by all hearers or readers and as they are accepted or rejected, the group decides upon their truth. For practical purposes it makes them true until actual test may confirm or disprove them. In many cases, test is long delayed or the results of tests are not correctly interpreted so that the decision of the group stands as the truth in the face of fact. Most thinking is limited by the accuracy of major premises and, as the premises are not open to careful, unprejudiced examination, acceptance depends upon universal agreement or popular acclaim. Belief in the right to domination of the German state could never be disproved to a German by argument. It is an accepted major premise and can be eliminated only by misfor- 
tune to the government or the death of the people. A good Republican in the United States is not open to argument on the subject of protection. Even facts have no effect upon him. The superiority of a protective system is a major premise established by generations of popular speakers and probably by the self-interest of the dominant elements. The good Democrat has similar major premises, equally irrefutable. Facts have no effect upon the loyal partisan. Similarly, the true socialist believes in the existence as a conscious group of a capitalistic class and in the essential malevolence of that class towards all labor.

Study of the process by which these premises are developed and the use made of them shows that the process is in most respects the same for the group or class as for the individual. The premises are partly the expression of prejudices accepted from parents. In many cases these were essential to the existence of the group in the past and have survived in spite of changing conditions. The continuance for so long of autocratic government is an instance in point. Possibly the dominance of the lord or chief was essential to the satisfactory leading of the men of the tribe, and continuance of the leadership through heredity was more certain than any form of election when the machinery 


\section{THE PSYCHOLOGY OF NATIONALITY}

of selection had not been developed and accepted. Any unitary leadership was better than none and because of the tendency to transmission of capacities from father to son hereditary continuance of the leadership was on the whole advantageous. Confidence in the leadership of old families continues to the present on the continent at least and it is only with difficulty that proved ability in a new family will be recognized. Many major premises in politics, in religion, and even in science can be traced in a similar way to general statements that harmonized with the practices and could not be refuted by the experience of earlier times and which now continue of their own inertia or through the mental inertia of mankind.

Major premises that are established anew in a generation owe their appearance at times to the initiative of experimental workers. Now that science is given a free hand much, if not most, of the advance comes from that source. Premises established by science are always welcomed and need no defense. Society is con-' vinced by the successful invention and the comforts that come as a result of the success. Yet not all of the most fully established results of scientific investigation can establish or maintain themselves against prejudice. This is perhaps most striking in medicine where there is great- 
est difficulty in distinguishing between the effect upon a single individual and the general results as determined by statistics. The prevalence of the use of patent medicines, of the use of concoctions handed down from grandparents and long shown to have no value, and the prevalence of Christian Science and other healing cults is striking evidence of this tendency for old beliefs to stand against scientific knowledge. Laws established in physics and chemistry, where each test gives the same result, are less affected by popular prejudice. What any one can try is accepted. Statements resting upon collection of statistics or determined by conditions that act irregularly are more open to popular doubt.

Study of the way major premises in the fields of religion or health or in politics come to be established affords the best evidence of the methods of affecting the beliefs of a nation. One of the most important in its effects is the desire to believe, the instinctive pleasure given by the belief. The complete acceptance of the Tolstoian and Marxian doctrines by the proletariat of Russia and the consequent belief in the designing cruelty of the capitalist offers one of the best instances of this effect. The men who were convinced are for the most part relatively uneducated, although education probably 
has little effect upon the spread of doctrines or the reasoning of the populace, and also were undoubtedly suffering from lack of many necessities of life, probably the most essential circumstances. The doctrine of Tolstoi was promulgated by a man of the upper class, who had the prestige of social position and accepted intelligence. His doctrines were based upon a first-hand knowledge of the facts. Where he described the actual situation his statements could be checked by individual experience and seen to be accurate. The scheme promised relief, was based upon a conception of human nature highly flattering to the common man. In short, it was a doctrine that he desired to believe, and to arouse the desire to believe takes the hearer a long way on the road to belief.

The rest was done by iteration and reiteration of the relatively simple principles until they became familiar to every man in Russia, however ignorant. It corresponded to the instinctive desires of every peasant in his mud hut to think that he might have the power of the lord at the manor, and that when he had it he would use it to the benefit of himself and of all mankind. Every time his sympathy was excited by a hungry child he would think that when he and his kind were in power there would be food for every one. He could satisfy his 
sympathies by a thought, by a dream, at no expense to himself. Each time he saw himself imposed upon by a wealthier or more powerful man he took his vengeance in the thought that when the revolution came that man would no longer have more than he had himself. He satisfied his vengeful instincts as he did his sympathetic by the imagination of the good time to come when the theory was realized. No wonder that the doctrines were accepted. As a result of the propaganda the name of Tolstoi as well as his doctrines were familiar to all. Since the doctrines were themselves pleasant, even if out of harmony with the best results of their reasoning, the were inclined to idealize Tolstoi, the author, that they might be the more certain of his conclusions. Talk even with an intelligent Russian of the proletariat and he will quote Tolstoi as a final authority in political economy as the old Puritan did his Bible. What he says is not open to question. If an observation does not harmonize with his statement, something must be wrong with the observation. The doctrines of socialism, particularly as stated by Tolstoi, had become a major premise for all social and political thinking in Russia. One is always inclined to glorify the men whose opinions one desires to believe, that one may be spared the trouble of coming 
to a conclusion for one's self or the unpleasantness of doubt.

All reasoning of the nation is limited to the acceptance or rejection of suggestions made by individuals. As a mind, the nation as a whole originates nothing, it can do no more than accept or reject. In this the unintelligent mob or the nation as a whole is not so very different from the self-selected body of learned individuals who pursue any science. The theories are all worked out by individuals, but the conclusions are accepted and become part of the science only in so far as they are accepted by the somewhat vaguely limited body. of men recognized as authorities in that field. One could probably cite instances in which the conclusions were accepted because one desired to believe them, or because there was no other statement on the point and any opinion or decision was better than none. One might even allege with some semblance of truth that scientists incline to vaunt the prowess and genius of the men who hold views that they desire to believe and thereby establish the reputation of the man at the same time that they give vogue to a doctrine or theory. Certainly the advance of thought in the most abstruse and accurate sciences and in philosophy is like the growth of the opinions of the populace in that the theory is always 
first outlined by some one man, is then accepted by the skilled group and becomes the orthodox theory or belief.

The difference between the mob and the individual lies in the more critical attitude of the latter. The individual believes what he desires to believe, but only within limits. The limits are set by the experience of the individual. A statement directly contrary to the individual's experience will be rejected. In the social group if its members can find the vaguest analogy for the statement in the facts of experience, the pleasant will be accepted as true. The healing cults take advantage of the well-known fact that fear of a disease predisposes to it in certain cases, or at least may make recovery slower or more difficult, to generalize in the form that disease is an illusion and pain a product of a diseased mind. All advocates of a political utopia find analogies in present facts for their beneficent state. If they can find no analogy they will at least put their promises on a plane where no practical test is possible.

While in general the nation tests the theories presented to it in the same way that the separate individuals do, and the conditions of belief are the same for the rabble as for the select group of scholars, the nation is more credulous towards the desired conclusions. This is true, 
first, because the credulity of the group tends to become that of the weakest member. When one believes and announces his belief he adds to the authority of the statement. While one man does not necessarily count for as much as another in the opinion of the multitude, each counts for something and each convert is a new argument with the propagandist and an added bit of evidence to the man trembling on the brink of conviction. Second, society, because of this acceptance of the opinion of the others, goes more quickly and thoroughly either by its reason or its instinct or experience as the case may be. If the populace finds a syllogism that will suit its purpose, experiences will not turn it from its deductive conclusion. When the Russian revolutionists decreed that all officers were brutal and must perish, they killed the kindly with the known despots; the odd habits of discipline, once broken, seemed to exaggerate the license rather than to restrain it. When it was decided that the aristocrats should be robbed, no cessation of robbery occurred when they had been reduced to a state below that of the robbing peasants. All was taken. In this way the mob, and the nation, in less degree, is single minded. On the other hand, when isolated experiences favor the conclusion that has been suggested and is desired, no heed is taken of 
general principles. The Christian Scientist or the devotee of Peruna is content with the fact that a relative has recovered under the treatment and is little concerned to know what general principles would make the recovery possible. In this sense the nation or the group is more likely to accept the evidence of a single observation or relatively few experiences in the face of lack of general principles, or even in opposition to general principles, and also to accept a syllogism when its conclusion is in conflict with observations, than is the average of the individuals who compose it. One takes courage for the satisfaction of his desires from the reasoning of others. He excuses his carelessness by reference to the general acceptance.

But one can find instances of the same tendency in the most scholarly and refined works. When an author is hard put to discover a major premise that will justify a conclusion, he almost invariably falls back upon the phrase "it is universally agreed among the most eminent scientists or philosophers," or in a more popular gathering he will assert "we all know this" or "it is generally agreed." Where he can prove his point by particular evidence he does; where he cannot, he pretends to rely upon the proofs of others. Such an argument is always suspect, but you find it in nearly every popular speech, 
in every political address, in almost every sermon, in most theological treatises, and in nearly all abstruse metaphysical arguments. One must admit also that it is occasionally made use of in scientific treatises, when the writer departs from experimentally verified fact.

One must admit that the nation thinks in this loose way for the most part only in moments of excitement and even then there are always some who are not misled. Each nation or at least each party in a nation has certain major premises that are not open to argument for which the laws of reasoning outlined above will hold. On other subjects the same groups will be perfectly rational, or as nearly rational as human limitations permit. During national crises the mass becomes organized as a mob and the domination by the majority is nearly complete. During a war, the Great War at least, doubt of the final success is not permitted, nor is any question of the justness of the national position. Aside from these repressions of opinion demanded by the practical necessities, many abstract principles thoroughly accepted before the war cannot obtain a hearing. One who questions the universality of cruelty among the enemy is not granted a hearing. The hopes for a lasting peace and the believers in a possible abolition of war by universal agreement are 
laughed to scorn. The individuals who have kept an eye on economy of expenditure lose all of their influence, and any recognition of the usual sympathy for the foe is taken as a sign of weakness or of hostility to the nation's ends and desires. This is partly, no doubt, an expression of the necessity for unity in action against the foe. When there is no outside danger, internal differences seem important and can be pushed to the extreme; when war comes and the external dangers are great, lesser diffculties recede into the background. It is the greater hate which conquers the less. This willingness to give over the lesser belief for the greater in moments of crisis constitutes the characteristic of the Anglo-Saxon that makes it possible for them to maintain themselves as a free people. The Poles, on the other hand, have always shown when free, that the internal hatreds, hatred of opposing political parties, are more important than the external. Even in a crisis they persist in fighting the other party in the state more than the common foe. In consequence they divide and are conquered. The same is said of the Slavic communities in this country. They can seldom keep up social or religious organizations because of the frequency of the internal feuds.

In any nation, even in emergencies, a mi- 
nority will continue to exist and if it does not express itself it is from fear of the consequences or from a belief that to do the wrong thing is better than to do nothing. The Irish question was recognized as unsettled during the Great War, even if the division which threatened before the war to lead to a revolution was not permitted to influence the policy of the great parties. Similarly the jealousy between Prussia and Bavaria was quieted apparently and all worked together for the common cause. There is a latent minority ready in all countries to advocate disarmament and some form of international agreement for settling conflicts which will undoubtedly find expression now that the treaty of peace is actually signed.

In the ordinary life of the nation, political doctrines are discussed much as they are in a club. The alternatives suggest themselves and are weighed by the individual. On many questions there is never agreement, and on few is there complete agreement. One aspect appeals to one group and is reiterated by that group on all occasions. Each different aspect has its adherents, and action depends upon counting votes, not by attaining even approximate unanimity. The reasons that control belief are approximately those that would appeal to the individuals, that do in fact appeal to the indi- 
viduals. These are first, the instincts, which determine primarily what one desires to believe; second, tradition in the community, which not only influences desire but also determines what one shall believe to be true; and, finally, the experience of the individual, including the results of personal observation and reports from others on experiments and observations. In the process of development of belief, new observations are brought in by written contributions or by the speaker on the platform or in the political assembly, and the possible interpretations of the facts and their most probable bearing upon the course of future action are considered. All these influences serve to modify the conclusion of the individuals and of the group as the sum of individuals. In all of this the nation thinks only as the individuals that compose it think. To be sure the individual would not think as he does were he not a member of the nation, just as he would not think as he does did he not possess the instincts that he does. But the suggestions all come from individuals, the acceptance of the suggestion is by the individuals. As Cooley has said, all thinking, even the most individual, is a social process, but it is social as a coöperation of individuals not as a process in a super-individual mind. Only in moments of great excitement is 
the thought of the individual in a nation profoundly different from what the thinking would be of a man in a medium as little social as possible, the thinking of the traditional hermit, e. $g$., whose society is the written communications of past generations. Even then, the process is the same as ever, the only difference is in the greater prominence of the instinctive elements, and the tendency for the loudly proclaimed conclusions of the few to dominate the belief of the many.

It is in the field of action and feeling that the group most nearly approaches an individual entity in its organization. If we return to our analogy with the individual, it is the voluntary processes and the closely interrelated emotional processes that may be most easily studied by the objective method. In fact, even in the individual, aside from a little more definite knowledge of motives, one knows about as much about acts and emotions in another as in one's self. Even the motives are not always more clear to the actor than to the observer. The action of the crowd is merely the action of the individuals that compose it. The individual movement depends upon the reception of a stimulus. This stimulus arouses the movement most frequently connected with it, its habitual response, or an instinctive response. When several responses 
compete, as when the most frequent response would produce an effect obviously undesirable, selection must be made between them. It is here alone that conscious guidance is of value or is effective in any degree. Even in the individual this guidance is exerted first by other stimuli which are also affecting the man at the moment, or by consideration of the desirability of the probable effects of the acts. These effects are desirable either because they have a direct instinctive appeal, or have an appeal that is indirectly instinctive, because they are approved by the society in which the man lives. To act in a way to meet social approval is instinctively agreeable.

The acts of a nation are controlled by the same laws. The difference is to be found, first, in the belief that a nation may make right what would be wrong for an individual. This can be seen in the mere fact of war. A nation may kill by the wholesale, although killing is forbidden to the individual under other circumstances. This is, of course, in part a survival, in part it seems to be a matter of necessity. In connection with war a nation will justify what the individual without casuistry would not. The atrocities in Belgium were based on the deliberate theory that terrorism was the easiest way to conquer and to repress revolt. Coupled with 
this there seems to have been a belief that all tortures inflicted upon women or children, upon prisoners and defenseless men were done to the glory of the fatherland and so were to be excused if not glorified. The looting and rape were a suitable reward for men who were sacrificing everything for the fatherland. The peculiar conditions and the general approval of the country excused the most revolting exhibition of primitive instincts.

The nation, like the mob, may by the common approval of what would ordinarily be condemned, make possible acts that would not be possible to the single man. The belief that the survival of the nation is more important than the survival of any individual has been used not infrequently to justify acts for which the individual could find no warrant. This exaltation of the nation makes a matter of pride what otherwise would be most reprehensible. The soldier is esteemed for an act no more essential than that for which the hangman is held in contempt. In this sense, the will of the nation enforced by slowly developed ideals and ambitions controls the acts-may at times be said pictorially to constitute the will of the individual. In this sense will means no more than the system of ideals that impel or justify 
the action. The real execution is by relatively few members.

The nearest approach in modern times to the actual movement of the nation as a whole is seen in the registration for the draft in Great Britain and America. Both of these countries had abhorred any interference with the will of the individual. Only when the crisis came that could be met in no other way, was compulsory. service resorted to in Great Britain. America profited by the experience of Great Britain at once on entering the war. In both countries the response was direct and immediate, with practically no necessity for resort to compulsion. Individuals as a whole appreciated the fairness of a selection on the basis of capacity for service, and obeyed the first summons with pride. Here again national ideals may be said to have provided the motives and impelling force, while the acts were performed by numerous individuals. After all, the motives are the essential elements in the initiation of any action. They constitute what is essentially the will of the individual. When they are shared by a nation as a whole and result in action by a large proportion of the members, it might be said that they constitute action of the whole as truly as some central idea, which excites the 
motion of certain muscles of the body, constitutes the will of the single man.

In moments of excitement the individual in the nation is like the individual in the crowd in so far as he is more likely to accept the ideals and aims as his own than he would be were he alone. But it is inconceivable that he ever should be alone, and all that we have as an outcome of the discussion of the will of the nation is that the will is a result of the action of common ideals upon the separate individuals who compose the nation, that, while the individual accepts these ideals because they appeal to his judgment, they appeal to his judgment because he is part of the nation, and both judgment and action are an expression of the social instincts and of the fact that the man has been reared and been trained in a nation.

In the acts of the nation in ordinary times when the individuals are not in sight of each other, even this exaggeration of normal laws is not present. The opinion of the nation is enforced through the papers, but these present urgings to opposed actions as often as proclaim the unanimous decision of the whole. It is only in the popular assemblies that there is any opportunity for the action of the forces peculiar to the mob, and in well ordered democracies, these assemblies are seldom controlled by the 
acts of their fellows. They constantly remember the fact that they are responsible for reelection to their distant constituencies, and they try rather to formulate in their speeches what they believe to be the opinions of those distant and scattered individuals than to act on the spur of the moment under the influence of their fellows exerted either in speeches or in the quiet conversation of the committee room or lobby. Even the French Assembly in the Revolutionary period was affected only by the physical presence of the mob, rarely by the eloquence of its own members. The acts of the nation show no greater evidence of a common mind or common will than do the acts of the individual. The acts all start with some individual, are taken up and executed by other individuals. There is no more a common will in the specific sense than there is a common arm or a common trunk.

In the metaphorical sense most of the acts of individuals whether in the crowd or separately are determined by social influences. The ideals that determine the individual are the ideals of the nation or the community. This means on strict analysis that they are ideals that have been stated by some one man, accepted by many others, and now pass practically unquestioned. They are enforced by the approval of 
acts that conform to them by the majority of individuals. Failure to live up to them and, more definitely, action in opposition to them is punished by disapproval. Approval and disapproval again are often expressed in very indefinite ways. It may be no more than the shrug of the shoulders as a friend tells what he has done. In the crowd the offender may be hooted at or cheered. In most cases the individual is influenced more by what he thinks other individuals are thinking or might be thinking than by what is said or done. This control is the more effective in that it works in advance of action. All that the nation does is to express more clearly the ideals that are latent in all. Again only in moments of excitement will the whole completely dominate the units and then only through the force of the social instincts acting in greater strength because of the visible presence of the members of the group.

The emotions of the crowd, too, are the emotions of the individuals. True again that the emotions of a man are easily aroused when he becomes part of a gathering. When the audience is fully under control a speaker can arouse laughter by a story or remark that would seem in none too good taste when spoken by an individual of the group. The enthusiasm of a crowd in a good cause and the anger or venge- 
ful spirit of the crowd in a bad cause are likewise aroused more easily than are similar emotions in a small group or tête-à-tête. If we accept the modern notion that emotion is fundamentally only a slight movement, and a movement instinctively determined, it would follow that emotion, too, is always an individual process, but an individual process that would be particularly susceptible to exaggeration by the presence of the crowd. This we find in practice. As applied to the nation, the emotions are obvious expressions of the instinctive responses to the common appeals of ideals, and of all the endeavors of the group. One thrills at the story of the attainments of one's fellow-countrymen, as one does not for similar deeds of foreigners; one feels the glow of exhilaration as one is called to increased endeavor for the nation, whether in the armed conflict, in better citizenship, or in self-denial for the benefit of the common cause. While the glow is due to the changes in the body of each individual, the cause of the response is to be found in the community of ideals and in the inherited nervous connections of each individual. The emotions in the nation are an expression of the social instincts, a direct indication of the tendencies to act induced by the sight and thought of the group. They are not new phenomena of the social life, but mere- 
ly the way in which the individual becomes directly conscious of the fact that he is a social being-is descended from a race that has acted with his fellows and is now likely to respond in certain ways in common with them.

In one other sense does the nation become an emotional unit. It becomes the center of reference for many common emotions. The modern psychologist, since James wrote in 1884, has emphasized the fact that emotions are instincts regarded from within, that as the observer sees a man respond in certain ways under the influence of inherited tendencies, the man himself feels these responses and many others too slight to be noticed by the observer as masses of slight movements. If we group these instincts as those which come with furtherance of activity and those which arise from the thwarting of activity, the one pleasant, and the other painful, we find that in the individual the helpful or hindering character comes to be associated not with the benefit to the physical being, but with the expansion or contraction of one's notion of one's self, a pure ideal. One is hurt when one does not obtain the expected end, one is pleased when one develops more than this anticipated amount. It is one's notion of one's self as a whole which is furthered or checked. Most emotions are aroused in the 
modern individual by factors which affect this imaginary entity.

With the development of the nation it comes to constitute a similar center of emotional reference. The individuals who compose a nation suffer real pain when it is in any way injured, when an outsider even speaks disparagingly of it, and are correspondingly elated when it thrives, when it grows in any way. A true Britisher feels a thrill of pride when he hears that the sun never sets upon British soil, that the sun is followed in its course by the roll of the morning drum of British garrisons. The American, however humble, is never left unmoved by the statistics of billions of imports and exports, particularly when the balance is in favor of America. Neither may be in any degree better off for the fact, neither thinks of the expense that may rest upon him for the attainment of these glories. He thrills as he does at his own success. As the ideal source or occasion of emotion, the nation is as real an entity as a person.

It is one form of this emotional reaction towards the nation, what we call the national honor, that is at the bottom of many of the international difficulties, as Perla ${ }^{1}$ has recently emphasized. The American is not concerned

'Perla: “What is National Honor?" 1918. 
about a fisheries dispute or any trade dispute bocause the outcome may affect him. He feels an emotion merely because his nation may suffer in its prestige if the decision goes against him. The extension of national territory in a modern state is seldom of any value to the separate individuals who constitute that state. They never can take any part of it for their own without the same compensation to the owners that they would have had to pay if it remained under the original flag, but they feel a pride if it is expanded, just as they feel aggrieved if the territory is in any way diminished. It is the same pride that the excessively wealthy feel when they add to their property even if it is already more than sufficient for any possible need. The additional acquisition may mean only new cares with no possible increase in comfort, but they nevertheless feel pride in the acquisition and would be chagrined were they beaten in the struggle for it.

It is probably this development of an entity which serves as a point of reference for the emotions that is the most characteristic and the most important phase of the development of the nation. When you band a hundred million men together who will be elated whenever a few square miles are added to the territory of that nation, or when it gains any prestige in the 
financial, intellectual, or moral world and will grow angry when it is slighted or suffers loss or even insult in any form, you have a force that must be reckoned with for good or for ill. The emotions have an enormous effect upon the actions of the state as a whole and of the individuals that compose it. You can argue as did the pacifist before America entered the war that each individual would be just as well off if a German army were occupying New York and competent German civil servants administering our national and state affairs. But even if the loyal American accepts your statements of the effects as true he will reply "a thousand times better to be inefficiently administered as we are or even to be destroyed altogether than to have the best German or any foreign official prescribing in detail the private or political affairs of the smallest portion of our territory." It is the fact that the nation is a center about which develop such emotions as these which constitutes it a real force, perhaps the strongest force in the modern world.

What really counts in naturalization is having the individual accept the new nation as the center for him of these emotions. When he can share them he is in truth a member of the new nation. It is the development of a common ideal in a mass of individuals that constitutes 
the appearance of a new nation. All of the other effects of nationality may be regarded either as springing from this or contributing to it. The acceptance of the general ideal carries with it willingness to strive for the minor ideals that are accepted by other members of the nation-the respect for freedom, for the standard of morality and cleanliness that is held by the other individuals in the nation. On the active side it implies willingness to make sacrifices that the nation may be maintained in all of its phases and in all of its mental and physical characteristics.

The existence of this ideal in so strong a form has also disadvantages when nations come into conflict. One can no more see one's nation give up to another what seems to be an advantage than give it up for one's self. Many modern wars and most dangers of war have arisen over questions that affected the pride or the honor of nations rather than their interests. It is not so much the loss of territory for the value of the territory as it is the loss of national prestige involved in the abandonment of territory that galls and arouses the anger of nations. It was the insult to the flag in the blowing up of the Maine rather than sympathy for the suffering Cubans that started the SpanishAmerican war. It was the demand for an abro- 
gation of sovereignty on the part of Serbia that the German and Austrian used to start the world war. It was quite as much the fact that the Boers refused to accept the demands of Great Britain and the consequent apparent contempt for her that was as important as any desire for territory or sympathy for the owners of Transvaal mines in really causing the Boer war. The instances may be multiplied until it seems that material damage, no matter how great, would seldom start a war were it not for the purely emotional reactions that are produced by injury to national pride and national honor. Rationally regarded, a war always costs more than it is worth. Once started on a course of aggression, the same pride will never permit either nation in the controversy to draw back. Many wars, no doubt, arise from unsuccessful bluffing. When a threat has once been made it is almost invariably carried through for fear of loss of national respect if it be withdrawn. Millions in men and billions in money will be lost before this national pride will be permitted to suffer.

It may be objected that, after all, the national entity has no existence outside of the minds that create and accept it, that no physical pain or material harm would come to any one if this ideal should be permitted to disappear. This 
must be granted. At the same time, since it does exist and men are willing to make sacrifices to maintain it, it is a real force. The same objection might be made to the existence of the individual personality. That, too, most modern psychologists regard as largely a concept, an ideal that has no definite relation to physical existence. A man's notion of himself is in large part merely the man's idea of what others think of him. He might be just as well off without many of the ideal characteristics or possessions that he ascribes to himself. James asserted that many Bostonians would be much happier if they gave up believing that they were musical experts and stayed away from the operas that they pretend to enjoy, if, $i$. e., they cut off from their idea of themselves the pretence that they were musical. Most of one's emotions are connected with ideal elements that have nothing to do with real suffering or real, i. e., bodily, pain. The self of which we are proud is as much a mental construction as is the nation, yet most of our endeavors are devoted to furthering this notion of ourselves, to increasing a reputation for wealth, for charity, for accomplishment in some line. When some slight is cast upon a capability which we believe that we have, but really do not have, we are as much disturbed emotionally as if we were 
robbed of a real possession. Personal honor and prestige are all of a piece with national honor. In many respects the nation is as real as is the self. Both are in large measure ideal constructions, but when constructed, much of thought and action and practically all of emotion both in the individual and in society are controlled by or derived from them.

Altogether, then, it is clear that the social mind is merely a metaphor and has no real existence. Nevertheless the phenomena that it is used to designate are real. The nation is in a sense a mental aggregate, and ability to develop and be controlled by common ideals and to carry out acts in common is the prime criterion of the existence of a nation. In many ways the products of the individuals who compose the nation may be regarded as the products of the nation. The nation certainly provides a medium in which the ideal of the individual may develop to the fullest extent, the nation spurs him to accomplishments that he would not otherwise be capable of, and restrains divergent tendencies that he would be liable to in another environment. The thought is, however, always the thought of an individual, the acts are the acts of individuals, the emotions are reverberations in the bodies of individuals. Even the nation that is regarded as providing the ideals is a 
mass of individuals, and the ideals have no existence except as they are expressed by individuals, or as they are pictured by individuals as present in the mind's eye of other individuals. Even the social instincts that give force to the ideals, and make possible social discipline, and the common thought and action in the nation are embodied in the nervous systems of individuals. They are individual possessions and exist only in the individuals. What makes the group behave as a nation is the qualities of the individuals that compose it, not a single superindividual entity.

True, nationality is an affair of the spirit, not of the body; it is an ideal rather than a material inheritance of certain races of men; it is a spirit incarnated in individuals. Again, it grows with experience, gains force with success, is dispirited or weakened by failure, even though it may be strong in adversity, but the experiences are the experiences of individuals, known and appreciated by individuals, and effective only in so far as these individuals make them appeal to others.

While, then, the nation is not a single individual or a mind in the literal sense of the word, there is one sense in which the nation does assume many of the aspects of a person. This is as an ideal center of reference for emotions. 
The nation, as a concept, is a reality. About it the emotions of the members cluster. Increasing or improving it in any way gives them emotions of joy, impairing its existence or efficiency in any way gives sorrow or anger very much as does the waxing or waning of the individual's own ideal self. In fact, as ideals for emotional reference, the self and the nation are very much on a par. Both are largely social products, are developed through experience in harmony with social standards, and while neither can be said to have material existence, they are both more effective in controlling the action of the individuals than any material forces. In this and in this alone does the nation resemble a mind. It is or has a self in much the same sense that the man is or has a self. 


\section{CHAPTER VIII}

\section{THE NATION AS IDEAL}

WE have come to the conclusion whenever we have examined any theory of the nation that it is a number of individuals held together first by the common social instincts of mankind; gregariousness, sympathy, and fear of the group on the one hand, and by the acceptance of a common group of ideals on the other. Of these the instincts would explain why there is a grouping at all, but they would not explain why a man accepted one group rather than another. It is the existence of the common group of ideals that determines the differences between groups. That a crowd should gather and follow a leader to the end he suggests may be due to the instinct of gregariousness for the gathering; to fear, by the individual of the mass as a whole for the acceptance of the leader's suggestions, and for the tendencies to follow the crowd. But such a temporary gathering leaves no after grouping, no tendency to gather again, no sense of belonging to a common body. There may be a beginning in a desire to recall the com- 
mon experiences, but one single common action would give relatively little even of that. There is no persisting unity.

What is characteristic of the nation is the existence of common ideals in all of its members. The group must have been united for some time if the ideals are to have a chance to develop or even to be accepted by the great mass. Ideals develop gradually. For a nation they require either a long period of life in working together, or a short period of intense endeavor and strong emotion, if they are to reach any intensity sufficient to produce marked effect. The possession of ideals and willingness to act to maintain them are what constitute the common consciousness or spirit of the nation that we find referred to so frequently by the different writers and which is so little or so loosely defined.

In the last chapter we saw that the sense in which a nation could be assigned a corporate existence, or something incorporeal that corresponded in some degree to a mind, or to a self, was the existence in the different individuals of a common ideal. The most striking effect of an ideal is that it serves to give to an individual an end or aim that he could not acquire by virtue of his own knowledge, by his own devices. In this sense most of the directing 
forces in society are the results of ideals. I have called their effect social pressure in other volumes. They constitute the ideal of attainment for the members of the group in every possible respect. In the ordinary study of a school boy, we find that he tries to excel because he respects the ideals set by his teachers and by his family for standing well in the subjects of instruction. In a school in which the ideal develops of slighting work and obtaining honors in athletics or in social activities only, all attempts to keep students up to the mark in studies will fail. In a wider sphere the youth chooses his calling because of the esteem in which the different callings are held in the community in which he lives, or in his immediate family. Much of the incentive to work comes, from the desire to reach distinction in the chosen profession, and the subjects in which he shall work are selected because they are prescribed for the profession or are assumed to be necessary to the members of that profession.

The ideals of attainment in every field of social life show the same laws and tendencies. We have pointed out that what shall constitute wealth depends upon the ideals of the community. It may be the ability to live on nothing of the anchorite, it may be the mere possession of a billion dollars, reputed to be the ideal of 
one ultra-wealthy American, it may be the acquisition of the largest number of rare books or rare stamps, or paintings, or it may be the shell money of the South Sea Islander. It is wealth, primarily because it has been fixed upon as desirable by the men who constitute the particular society, and secondarily because it has value in exchange, because others are willing to give other desirable and necessary things for it. Both depend upon the existence of common ideals.

In the ethical and legal relations very much the same rule holds. What shall be proper for a society is fundamentally a matter of the existence of ideals, in spite of the apparent fixity of most of these prescriptions. Many of the things fixed seem important for survival or for happiness, but many others are absolutely indifferent to both and may even be uneomfortable if not positively harmful or painful. It is quite as improper and meets quite as much social disapproval for a woman to smoke a cigarette as to lie; in fact, unless the lie is particularly flagrant or on a matter of great importance, most women in an American small town or outside of the wealthiest or more debauched classes would much rather lie than smoke, although the difference from any rational consideration between the smoking of 
man and woman cannot be discovered. Similarly, many a man of the educated class would much prefer to be detected in a minor dishonesty than in saying "ain't," which has no essential value other than as a sign of belonging to a social class. Many of the compulsions that are grouped as moral in opposition to mere social conventions are enforced in the same way. In fact, the difference between a social convention and morals is a finely graded one. Many of my readers would agree that smoking a cigarette is a matter of morals rather than of manners. The prescriptions are effective and the punishment of social disapprobation is real. One may even say social disapproval is the most severe punishment and probably constitutes the really effective element in all punishment. Any society is held together and most of the individual acts are in some degree determined by the force of these ideals.

The ideals that exert an influence within a nation are in part common to society everywhere, and in part are peculiar. The common effects represented in the nation are those that enforce the ordinary standards of decency and morality (decency and morality being words that indicate the accepted standards of mankind as a whole). Some of these are common to the same class in all nations although they may not 
be binding upon the nation as a whole. Such, for example, would be dressing for dinner, the avoidance of inelegancies in language, certain standards of personal hygiene. Others, such as the ten commandments or the modern substitutes for them, would be fairly generally accepted and they are regarded as applicable to all classes. The punishments are the same forms of disapproval.

One might enumerate the peculiarities of the ideals of different nations. Some of these are important, as, e. g., the attitude towards liberty. It has been pointed out in an earlier chapter that there are minor variations even between the most similar modern democratic nations. Liberty is essentially freedom from governmental interference with the personal conduct to the Briton; to the American, it is more nearly freedom to express himself on political questions and a willingness to submit to almost any detailed control, provided he may impose it on himself through the polls; to the Frenchman freedom has more of an element of equality with others in a personal way and less of the political equality. One could undoubtedly find other shades of difference in each modern nation, even where all alike were enjoying political freedom, and were equally impressed with the ideal of freedom. 
The definite political ideals also vary in some degree. This can be most readily shown by the difference in the organic law, or at least in the fundamental phases of that law which corresponds to the constitution. On the whole, it is probably safe to say that in part the different systems of law and government accomplish the same ends by different means; in part they accomplish different ends by the same means. Here again some of the ends are set by the fundamental human instincts common to all men, others depend upon ideals that have gradually spread from the countries or peoples who first developed them to others because they have an instinctive appeal even if they are not themselves instinctive in character. The different methods used in the attainment of the same ends, as differences in the procedure of the courts, are to be explained historically in large measure. Most go back to the acceptance of the Roman or the English Law. The changes are to be regarded as due to the attempt to adjust the accepted system to changing conditions in modern developments in industry and the accessories of life. They express what we call the genius of the people, which in its turn is largely dependent upon the ideals that have developed because of their peculiar characteristics and the environment in which they lived 
and of the experiences to which they have been subjected.

To attempt to describe these ideals for the different nations would require a treatise on comparative constitutional law as the outgrowth of the history and native endowment of the peoples, a subject that would take volumes. Granted the existence of these varying ideals, it is more within our province to consider their effects. These we can divide into two groups; one which corresponds to, if it is not in part identical with, the will of the individual, the other which is more closely analogous to what we call the self of the individual, the ideal of the state as a corporate entity, which embodies the hopes of the people, and is the source and object of their common emotions. 'The two in a measure coincide, for unless one had some notion of the nation as a corporate entity, as something which was to be respected and even loved, the compelling and controlling effect would be inappreciable.

In so far as the ideals determine the will of the members of the nation, they act because of the instinctive respect felt for the desires and accepted aims of the larger group. The state is the personification of public opinion with reference to the affairs of the nation. What these aims are cannot always be stated, but 
there is always an appeal to them to decide all questions of state, and one can nearly always decide when they are infringed upon. Thase ideals of the nation are best typified by the British constitution, which is definite enough to serve as a guide for government in all of its essential general lines although it has never been formulated in words. The opposing members at least always know when it has been violated even if there is no agreement as to what it is. It controls the action of statesmen in no small degree, it is the incentive to many of the actions of the ordinary voter, it is the conscience and might be regarded as the will of the British nation in the same sense that the ideals and accepted aims of the individual constitute his will. It is the director and still more the gauge of all actions.

These ideals may change with time and under the influence of special stress. We have seen evidence of these changes over long periods in the history of the development of nationalities. We can see the same sort of change working over short periods under the influence of special strains in the change or temporary abrogation of the British constitution when the power of the House of Lords to prevent legislation was given up recently, or in the numerous changes that were made by common consent during the 
war. In the American constitution, the same changes are wrought more slowly by the adoption of amendments and, a still better instance, by the immediate effect of the social ideals or the social conscience, express themselves directly in the changes in judicial decisions. The constitution, like every written document, is - susceptible of many interpretations, and the change in interpretation has amounted in many cases to a rewriting of the instrument. It is a question whether the writers of the constitution would have recognized it when it had been interpreted by Marshall, and certainly Marshall would not recognize it as it stands in the present interpretations made necessary to conform to the changed social conditions and the more humane attitude that man takes towards the less fortunate members of society. Still more striking are the effects of decisions made during the war when the lower courts and, on some points, the highest have held to be constitutional acts that are, to the lay mind, against the spirit of all earlier interpretations made on similar questions. With the greater development of the corporate consciousness then comes the acceptance of the common ideals and aims as law for all of the separate members-the courts recognize as constitutional many acts of the central government that would have been denied 
a quarter of a century ago. Some of these changes are made consciously, as when the court decides that it may take cognizance of social changes and the advances made in scientific knowledge; others are the imperceptible effect of the experiences that come to the judge as a man and a citizen, which change him with the rest of the nation. $\mathrm{He}$ is bound to think and act in the light of his knowledge, and to accept the ideals that have developed in the community.

In this way the ideals of a nation enforce action in political and social matters. They compel each individual to act up to or at least towards the ideal of conduct in the selection of candidates for office, in enforcing upon the legislators the measures that shall represent the standards of the community and make possible the realization of them. In emergencies they impel citizens to go forth to fight that the nation and its ideals may be maintained. They compel the officers of the state to attain a certain standard in the performance of their duties and, as we have seen in the case. of the courts, may determine the standards and in part at least take the place of specific laws in determining what their duties shall be and that they shall be performed.

Connected with this, the ideal of nationality 
becomes associated with many incidental standards which are not at all essential to the maintenance of the state and have only the vaguest relation to the political ideals. We have seen the effect of these on the naturalization of the immigrant in America. There are standards of dress, of wages, of food and hygiene, even of entertainment, which come to be accepted here as American, although there is nothing that would prevent them from being regarded as a symbol of occidental civilization in general. These vary in many respects from nation to nation and become associated like a flag or national anthem with the nation itself. They may be regarded as an expression of the national solidarity, even if the nation would not be significantly changed without them.

As closely connected with this directing effect of the national ideals which may be regarded as their dynamic phase, we must also reckon with the existence of a static aspect, the existence of the nation as an imagined corporeal or personified existence. It is this aspect that has been likened in the last chapter to the individual self as ideal. It is a notion or concept of the nation as something existing as a unified thing which is apart from the individuals but nevertheless in which they may be regarded as participating and whose glories they may share. 
This entity is what gives especial solidarity to the nation. To the member of the nation it has a real existence and the development of its prestige is a real end towards the accomplishment of which he is willing to exert effort. Its existence depends in part upon the history of the nation and the accomplishments of the glorious past. A nation like Great Britain with a continuous history of successful endeavor has a fuller sense of real existence than a newly developed group like the Ukraine, although it must be granted that, when a nation develops quickly through great peril and much conflict, the ideal of a national entity acquires great strength in a comparatively short time. An element in the development of the spiritual unity and of national pride is undoubtedly the sense of past successes.

The existence of a common literature and hence of a common language is also of great importance. We have seen that this was all that held the Italian nationality together for half a dozen centuries, and it undoubtedly was largely responsible for the community of feeling among the German states before the development of the German Empire and in the reconstruction of that empire. But this is not altogether essential as is seen from the fact that Switzerland was one of the first modern nations 
to develop a sense of nationality and that it is among the states that have a very strong nationality, although it has four languages in accepted use in different parts of the nation. On the other hand the United States and Great Britain have a common language and largely a common literature, although they are definitely different nationalities. A people's literature gives a sense of community, partly because it praises the nation and the deeds of its heroes, partly because it is itself a source of pride and furnishes a center about which the emotionally toned associates may cluster.

Zimmern ${ }^{1}$ insists that a nation demands for existence a home land with which the ideals may be associated. It is not necessary that the people live in this home land in any great numbers, it is not even necessary that people who inhabit the physical territory shall be free, but he asserts that each nation must have a country of its own if it is to be a real nation. There is no discussion of the point, although it is asserted each time that he defines nationality. He illustrates by the Irishman in New York who has never seen the old country but nevertheless has an aspiration for nationality because he can picture to himself the actual physical contours of the beloved old home. If

"Zimmern: "Nationality and the State," pp. 52 and 96. 
we examine the statement by the methods of similarities and differences, it is hard to find opportunity of reaching a conclusion. Every nation has a home land with one exception, the Jew, and possibly the Gypsy. One may be said to be so thoroughly a part of the nation in which he lives that there is little chance for the notion of a separate nationality to develop; the other probably has no sense of nationality, although there may be a consciousness of race. The Jews would seem to an outsider to have a sense of nationality that has persisted marvelously, considering the fact that they have not only no independent home country but also have been scattered over the earth for centuries. Zimmern might argue that the bond was race or: religion rather than nationality. If this is granted one must add that race and religion are hard to separate from nationality where the three go together and in any case there is much in common between them in their psychological laws and characteristics.

Whether Irishmen would retain so full a consciousness of nationality after two thousand years away from a home country even if that country continued to have its present degree of physical distinctness is a question. Certainly the Irishman in America shows more of a tendency to be lost in the general population than 
does the Jew, and if amalgamation continues at the present rate, an Irishman with a distinct consciousness of nationality will soon be very much more rare than a Jew. The Irishman, too, is much more likely to remain conscious of the land of his origin if he retain his religion than if he change. For him, too, it might be argued that nation and religion are in part, at least, one.

While we may doubt whether a native land is absolutely necessary for the existence of a consciousness of nationality, there is no doubt that the possession of a common land is an important element in the notion of nationality, that the concept has as part of its content the picture of the home country, and that part of the longing of the exile is for the ancient seat. It matters little whether the land be beautiful as Switzerland or as unpleasant as the deserts of Arabia, the native acquires a fondness for it that aids his pride while at home and makes him long for it when at a distance. This pride may be aroused by the natural beauties, as in Switzerland, or by the architecture and other works of man as in France or Italy. Whatever it is, it gives a body to his ideal and a point of attachment for the other more spiritual or mental elements. Whether the strength of the national feeling depends upon the size of the 
country may be doubted, but certainly an American and probably a Russian is influenced by a knowledge of the vast extent of his land.

What is most important in the ideal is the sense of the mental achievements, the civilization, the education and technical skill, together with the physical power that goes with it all. These combine in different proportions with a notion of political freedom. All fuse in the general notion or symbol, but the proportions differ in different individuals and at different times in the same individual. The ideal reveals itself in consciousness in the emotional thrills that come whin one thinks of the achievements, the feeling of bitter resentment when the nation is maligned, and the sorrow with which one hears of any harm or deterioration that may affect the nation or any part of it. The true nationalist identifies himself with his nation and rejoices or mourns with it as he would at similar changes in his own physical or social status.

This ideal as a social entity is in part essential to and identical with the ideals that enforce the dictates of society. If one did not have the pride in the national entity, one would not feel impelled to strive to meet the approval of the nation in many political and related ways. One would not accept the standards of the nation and rise to them. The emotional reaction de- 
pends directly upon the ideals; the success of the nation or its failure arouses the emotion of the individual, just as does his own success or failure. The same influences that give rise to the emotion also serve to impel to action. The voluntary action of the individual is determined by very many of the same forces as these which control the action of the nation. What appears as the symbol of the nation and is reverenced as a real thing is also in part identical with the factor or force which drives the members of the nation to obey the mandates of common opinion. It is also a very large element in the individual will.

It must be said that the nation is only one of the many partial systems of ideals and idealized organizations into which each individual enters. Each group that forms within the nation has approximately the same general characteristics as the nation as a whole. The church or churches, political parties, in lesser degree, the occupations and professions, and even the orders of society come to constitute similar entities with a distinct group of ideals that are enforced upon their members and an ideal representation that constitutes the end of endeavor. A good party man is only less concerned that his party shall win than that his nation shall not be defeated. Some of the 
members of the socialist party are less concerned about their nation than about the party or the principles for which the party stands. In fact, for one branch the nation ceases to be of any value and should be dissolved to enter into an international organization of those that produce, to destroy the power of the capitalists. Socialism is distinctly anti-national, although in the late war the international allegiance was not strong enough to conquer the national and prevent war. In many cases a man's union or his class may assume a similar ideal existense as a definite unit. Still smaller units about which one's emotions cluster and which take on the character of real entities are found in one's factory or business where the employees are really interested, or in a school, or, in fact, in any organization with which one comes into close contact. Some, as the relation between the classes, are more marked by hatred of the other than by pride or liking of one's own. This holds definitely of the attitude of the lower towards the higher, although in the upper, particularly in the older countries where the caste system is more in evidence, there is pride in the group as such that holds its members to certain conventional acts, that enforces definite standards of action in essentials as well as in 
incidentals. To be worthy of the name "gentleman" is a conscious ideal.

Some of these different group consciousnesses overlap, some as we have seen are antagonistic. The religiously inclined nationalist regards any disparagement of the nation as irreligious, as opposed to the laws of God as well as of man, while he may also regard assumption of the national attitude towards religion as a patriotic duty. This holds particularly where there is a state religion, as in England, or where the church is closely connected with a national protest as in Ireland. In Italy and in France, to a slighter degree, we find nationalism in some classes connected with opposition to the church, so that religious belief becomes in some degree unpatriotic. Others are largely indifferent to the national ideals, and may be strong or weak with no reference to its strength. We find that any individual in the nation is always a member of numerous groups, is always possessed of a number of group consciousnesses. Some of these will exert a control at one time, others at another. Most of them tend to become organized so that there shall be little or no conflict between them. When a man is in one environment he will be dominated by one consciousness, in another he will be under the influence of 
another. Many of these may fuse into a single consciousness, or into a single one with many phases. In every case one may have a number of different loyalties more or less equally well developed. Man's social consciousness is not single but is a complex of many with control by a number of different groups of ideals, and pride in a number of different organizations.

One may well ask whether the existence of these minor allegiances will affect the nature of the national allegiance. On the whole the answer is no. They tend to strengthen it. Belonging to a nation is not a matter that can be daily contemplated and regularly emphasized. It is possible on the other hand to become immediately aware of the smaller group in the school and of such larger groups as the political parties. These with their frequent meetings serve as centers of real interests and so increase the warmth of the sense of community. All of these lesser groups with their allegiances naturally keep alive the loyalty to the larger whole. The meetings of the party all involve references to the solidarity and welfare of the nation even if it is only to accuse the other party of threatening that welfare or solidarity. The school, the church, the lodge, and all other local meetings recognize the existence of the larger, while they give specific emphasis to 
loyalty to the lesser whole; all aid rather than hinder the development of a national loyalty, even when there is nothing of patriotism in their specific teachings.

We may, as we look back over the various considerations so far mentioned, see that nationality is dependent in varying degree upon race, upon a common language, a common history with the inspiration of the great deeds of common ancestors, and upon a home country. Each of these is important, but its importance lies primarily in its effect upon the consciousness of the individuals who make the nation, rather than in its immediate effect. Belonging to a common race is of value not because it gives an instinctive pleasant reaction, or because, let us say, that the odor of another race gives an instinctively unpleasant reaction, but because it is a source of pride to the members of the nation to believe that they are all descendants of the same progenitors. It may not correspond to the facts; a belief in belonging to the race in question is all that is necessary. This is well illustrated by the story, perhaps apocryphal, of the negro soldier who spoke of the effect upon the Germans of "us Angrysaxums." Each of the nations of Europe, no matter how mongrel, glories in its assumed race, even if a very small proportion of the 
population really belongs to that race. The larger stock to which the nation is assigned varies according to the prestige of the race in question. The Englishman a quarter of a century ago gloried in being Teuton, but now makes little mention of that mixture in the population. The race as we use it is largely an artifact developed to give an explanation from heredity of the national consciousness. A common language is of importance as a medium for the communication of ideas and so to provide for the spread of ideals. A common history is of value in the enthusiasm it may excite for ancient deeds and attainments. The "native land" has the same function. It provides a physical center about which fond associations may cluster. Each of these factors is important in so far as the nation believes in them. The nation is what it believes itself to be. The nation is founded in ideals, and these are effective in so far as they inspire loyalty. Loyalty in its turn is pride in what the members of the nation believe that nation to be and a willingness to strive for the ends which have been accepted by the group as a whole.

If, in conclusion, we attempt to define the consciousness of nationality we may assert that it is an awareness of belonging to a group, with pride in the ideal notion of that group as a 
separate entity, a willingness to be controlled by the ideals of that group and to serve its ends. The nation exists only in the minds of the separate members, but when it does exist it unites them for action in a way that makes the nation a force without an equal in the accomplishment of common tasks. The members of the group may change but the ideals persist in the members who continue and in those who replace those who fall out. The nation is immortal if its ideals are suited to survive, in spite of the fact that the men who created the ideals and those in whom they have been propagated have died and are constantly dying. The nation is an entity that changes and grows and still persists. It is a force in the world in spite of the fact that it is always an ideal in the minds of changing groups of men, and an ideal which controls the acts of an ever shifting multitude. Considerations like this tempt one to adopt the notion of the Hegelians that the nation is a super-personality of divine origin and guided by superhuman knowledge. There is no objection to this if one is content to take it as metaphor merely, and if one is permitted to question whether the force that shapes the destiny of all nations but one's own is satanic or divine. It must also be remembered that 
248 THE PSYCHOLOGY OF NATIONALITY

the nation always exists merely in the individuals who compose it, even when they regard it as an independent entity, and furthermore, that it exists for the individuals, not the individuals for it. 


\section{CHAPTER IX}

\section{NATIONALITY AND THE STATE}

We have been discussing the nation as if it were an entirely informal organization of a group of people whose action was always determined by the instincts and ideals of the different groups. We have entirely neglected to consider the organization of the state, or its relation to the spirit of nationality. The details of the organization fall well without our province, but it will not be out of our field to consider a few of the general bearings of one upon the other. One might assume with the philosophical anarchists that a government was unnecessary, that the human instincts were in themselves all good and that, were all restraints removed, man would act for the best and all individuals would be happy. An assumption of this type presupposes that instincts are perfectly adapted to the environment and that they alone wculd suffice to meet situations in the best possible way. This assumption is true neither for the higher animals nor for the sim- 
pler instincts in man. Instincts as developed care only for the more general situations and for those only in the crudest, most general way. They suffice to keep the individual alive during the period of learning and to determine the more general form of response to the new situations. All else must be learned and then established as habits. Even the pecking of a chick, fundamental as that process seems, is partly learned and only partly instinctive. At first the chick pecks awkwardly and at any small object; it is only with practice that it learns to discriminate edible from inedible substances and to make accurate movements.

In the more complicated responses of social intercourse the instincts are still less adequate to serve as a complete guide. This is seen very clearly in the historical cases in which government has disappeared and only instincts were left to trust to for the control of the group or society. Even the Russian mob which, if one may believe Lincoln Steffens, started the revolution with a passive doctrine of non-resistance that promised ideal relations based on brotherly love alone, quickly gave way to bloodthirsty acts and exhibited the lowest instincts in the most unrestrained way. Whether this is to be attributed to falling under the sway of leaders in whom hate of the wealthy dominated, and 
who came to feel the necessity for executing all possible successors that their own rule might be continued and their lives saved, or whether it is the natural outcome of control by instincts when all rule of ideal and convention is relaxed, is not altogether clear. Certain it is that in the two conspicuous instances in modern times in which an attempt has been made to return to a natural existence with guidance by instincts alone, the Russian Revolution and the French Revolution, not to mention the lesser experiment of the French Commune in 1872, the results have been a dominance of the worst rather than the best in man. The excuse that in all of these cases the condition has developed through reaction against tyranny, when the hates of the old order would naturally encourage excesses, does not seem entirely adequate. Even in the communities which have been drawn together by desire of gain, the unorganized mining and oil camps of the American frontier or of Australia and Alaska, freedom from restraint nearly always gives free sway to the worst instincts.

If one attempt to delimit the rôle of instinct and ideal or law in the control of man's action in society, it would seem that the two are related very much as are instinct and habit in the control of the acts of the individual man 
or animal. The fundamentals are prescribed by instincts, the refinements must be added by learning. Instincts may be pictured as a rough hewing of the acts to make sure that they will be performed somehow, but as leaving much room for improvement by knowledge. In the social arrangements, man is provided with a set of vigorous reactions which are to be applied when he is the subject of oppression, when a fight is necessary; with another set of responses that are called into action when faced by overpowering force; with another, still, that is to be applied when one of his own species or of any species which may even by personification be brought into the same class with himself is suffering; but which of these responses shall be evoked in any particular connection is not absolutely determined. One may classify the situations or stimuli in terms of experience, and in the contemplative human type of action, response waits upon this classification. It therefore becomes the deciding factor in determining what reaction shall be made. The selection from among the possible responses to a given situation is determined by this classification. One can see the operation of this selection best in the action of the human emotions. In a given situation one may frequently either become angry, be frightened, or amused 
according to the interpretation that one puts upon the various circumstances. A remark, for example, will be a pleasantry or an insult according to the tone in which it is uttered or the previous relations to the man who makes the remark. It depends upon a rather delicate estimate of personal strength and the strength of an opponent, whether one becomes angry or afraid, and whether in consequence one attacks or runs, when, let us say, one is forced to deal with a drunken bully, an infuriated horse, or bull.

Where the estimates must be made by a crowd in a moment of excitement or when much is at stake, all may turn upon some chance circumstance. A mob will vary in its action from the extremes of sympathy and helpfulness to the most fiendish brutality with little change in the circumstances. Whether a prisoner is to be classed by a revolutionary mob as a pleasant, inoffensive old man or one of the hated. oppressors will depend upon such a slight factor as a remark of one of the crowd who remembers a kind deed, or upon the remembrance by another of some time when he has applied for work in desperation to another member of the employing class and been refused, perhaps by a man who resembles this one in dress or stature. The old emotion is re- 
aroused and the victim perishes through his denunciation or by his overt act. In the actual contact with problems, instinctive reactions are determined by such slight factors and the character of the reaction is so vital that alone they are a very unsatisfactory guide. The psychological justification of government, if one is needed, is to be found in the method that it affords of standardizing these responses and freeing them so far as is possible from control by chance and arbitrary elements.

In essentials, ideals have been seen to furnish rules of conduct based upon a determination of what is most satisfactory in the light, not of crude instinct, but of instinct guided and controlled by experience which has been summed up in what we call intelligence or reason. As opposed to instincts, this means action on rational grounds. In common sense terms the opposition is between doing what one pleases and doing what is right. This opposition is not absolute, because where right is taken to mean harmony with the most enlightened experience, right is what one would choose did one take all of the circumstances and all of the effects of action into consideration, rather than the few circumstances and few effects that influence instinct. Informally these results of experience are embodied in conventions, stand- 
ard forms of response or acts that are tacitly accepted as norms of conduct by all of the members of society. Their growth has been shown to be through trial and error, the acceptance of acts which have proved useful and the rejection and reprobation of acts that were found on trial to produce disagreeable consequences.

Formal government 'is to be looked upon as the embodiment of these successful conventions and rules of conduct. At first one can make sure that the rules shall be enforced by giving them a divine origin. It was ordained by the gods that reparation should be made for life taken wilfully; later they prescribed that there should be no killing, etc., as in the commandments given to Moses on stone tablets. All through the earlier stages the enforcement of the conventional rules even when they were given a divine origin was in the hands of the individual and was always subject to the whim of the stronger, and open to contest by the man upon whom it was inflicted. Gradually the conventional law, which has been accepted informally, is expressed in definite statutes and some one is given or assumes the authority of seeing that it shall be enforced. We need not run through the various stages in the development of government. As all else in evolution it was at first crude and the means used were or seem 


\section{THE PSYCHOLOGY OF NATIONALITY}

to us to-day unnecessarily harsh for the end to be accomplished. The chief or king would enforce the penalties of the law with the purpose of making sure that he maintained his authority rather than to prevent the suffering of others. It was only after much experience and much knowledge of human nature under many different conditions that it was possible to consider the rights or the comfort of the offender.

If we look at the fundamental question of the control and the source of authority for government in general that has been so important in all of the theories of political science, we must find it in the agreement of its methods and effects with the ideals of the people who are governed. Each of the theories of the origin of authority probably can be supported as an explanation or partial explanation through reason for the particular form that government took. The patriarch probably received his first authority from the fact that he was the oldest member of the group and stood to the others in the relation of father to son. It was natural that his authority should be accepted. His development into a king was again natural with the increase in the kin over whom he ruled and the additions to the tribe by conquest and assimilation. As the king became inefficient, natural leaders would tend to take his place 
with the development of aristocracies, or, if the selfish interests of the king overcame his tendency to care for the good of the whole, he would be overthrown. In all forms of government one finds that the accepted good of the governed and harmony with the ideals of the social mass determine the form of the government. If one form gives good results and the community is pleased, the government is continued and arguments from religion, from the greatness and success of the ruler, from the glory gained for the nation by the acts of the leader and of the whole nation are used to justify the continuance of the power. When the form of government is unsuccessful, there will be grumbling, but it will nearly always be continued for a time because of the arguments that have been accepted to enforce the rule of the good government. They will be too strong to yield at once to the evidence of facts. After a particular ruler has been unsuccessful, or a particular administration has failed, the form of government will persist for a time in the hope that the personnel of the ruler or of the rulers may change for the better and the good old time return. Habit is always strong with the mass. All through the early ages, save for a period in Greece and Rome emphasis was put upon the maintenance of the particular form 
of government, upon the right of the king to rule, rather than upon the real source of power.

When it became evident that the government must derive its authority from the consent of the governed as it did first in modern times in England, France, and America, attempts were again made to develop a theory that should give a rational warrant for government. This we see in Rousseau's famous theory of natural rights and the social contract in which it is asserted that man is born with a right to do as he pleases and that he early consented to part with some of his rights for the good of himself and his fellows. Each limited his rights on condition that others would limit theirs for the mutual benefit of all, a suggestion in which he had been partly anticipated by Locke. History and what knowledge we have of primitive peoples afford no warrant for the belief that the process of developing a govermment had any of the self and other conscious bargaining that Rousseau suggests. Probably before man had a knowledge of the needs for government and any such concept as right, he was already part of some community or other, through the action of his social instincts, and group ideals had begun to develop. Rousseau's and similar theories are interesting in so far as they emphasize the modern tendency to derive the 
authority of government from the community as such, rather than from a divine warrant or from mere tradition or from respect for elders.

Viewed in the large, governments may be thought of as means of subordinating immediate instincts to the control by knowledge and experience-to guide acts towards others by the results of earlier results of such acts and to properly classify them for instinctive reaction. The forms of government developed from the conditions of life, modified by trial and error. One might assume that all forms go back to the patriarchal, but if so they would be modified in various ways by the exigencies of different peoples living under divergent conditions. When a modification comes that gives satisfactory results, it persists; when unpleasant or undesirable results appear, the government is either overthrown or modified to give greater satisfaction. One may think of the development of government as a process of trial and error. The various suggestions grow out of antecedent forms of control, the family, the more extended chieftainship, the priest, or what not. Success or failure is measured by the survival of the group, in the final analysis, and before that by the satisfaction or happiness of the individuals in the state. One must not think of the origin of government as altogether ra- 
tional and voluntary on the part of the individuals who are involved in the government, either as ruler or ruled. Occasionally, particularly in modern times, a scheme of govemment has been worked out theoretically and applied in practice, sometimes successfully, at times unsuccessfully. Locke suggested a form of government for the colony of Carolina which seems to have been moderately successful. More often a suggestion as to a desirable method of government or change in government has been obtained from a neighboring state. Maitland ${ }^{2}$ instances the transfer of the jury system from England to the continent in the eighteenth century. It was adopted at first in minute detail, although later was changed to suit the new conditions. Much less successful were the attempts to borrow other forms of government by the leaders of the French Revolution. They modeled their form of government upon England and the old Greeks. Although both had been successful in the land of their origin, the attempt to transfer resulted in a disastrous failure. It must be said that Napoleon's code, made equally out of hand, was on the whole successful. One can see similar instances of successful and unsuccessful borrowing of forms and methods of government

2Maitland: "Collected Papers," vol. 3, pp. 298f. 
in the different states of America. After all, the development of government has its closest anclogue in the trial and error and natural selection of the biological evolution, rather than in the conscious planning of a rational being. The suggestions for improvement may be given by the other forms of government already developed, or by the imagination of some man of visior. However the suggestions arise, they must always be tried in practice, and gradually modifed to meet the demands of a nation, before they can be assured.

The specific prescriptions and laws as well as the form of government that enforces them are constantly being tested by their agreement with the ideals of the community as well as by their effects in practice. If a law is promulgated that seems to work injustice to a large proportion of the members of a community, they, at least, will work for its revocation and if it proves to have bad results it will either be repealed or ignored. In a democratic state where the laws are made by the votes of the people or by their representatives, the initiation of the law will be due to a belief on the part of some considerable portion of the community that it will improve the existing condition. This anticipation will be checked by its effects in practice, and thus the laws become an embodi- 
ment of the ideals of the nation. As opposed to the control by instinct, this means that each act will be tested not by the instinctive appeal of the moment with the uncertainty of interpretation of the situation that results from that, but by instincts checked by ideals, and by experience. Then, too, each individual who reads the law will pass upon it in part by instinct as well as by knowledge and reason, so that the final test is by man's original nature plus experience instead of by his instinct alone.

After the action has been decided upon in the light of the prescription of the law, the act itself will have all of the characteristics of instincts and will arouse all of the emotions that attach to instinctive acts. If the law or convention prescribes charitable care, the emotion of pity and the joy of helpfulness will be aroused as completely as if the act were done without forethought, $i$. e., on mere impulse. If, on the contrary, punishment is prescribed, the act of punishment arouses the emotions connected with vengeance. True, the execution of the law may and probably should become impersonal and unemotional, but the attitude of the public that impels to the enforcement will be accompanied by emotion, and this in part gives force to the public opinion. One may think of the law as a process of restraining 
action until the situation has been properly classified and the plan of action determined in the light of the best knowledge of the community. After the classification has been made, the action is carried out in accordance with the instinct in whose class it belongs, and the corresponding emotion will be aroused in the natural way. This statement does not take into account the fact that the individual may be aided in executing the act by other members of the state upon whom the duty has been imposed, but considers only the individual's part in the act. One can see in the numerous added tests and safeguards of the correctness of action that this process of law throws around it, why action in accordance with law should be more suited to its ends than purely instinctive responses such as are made by the mob when it attempts to enforce its authority.

In general, the relation of the state to the nation is that the state embodies and provides a means for realizing the ideals of the nation. The rulers will be guided by those ideals in their acts even when they seem arbitrary, and in the modern state the laws will be an outgrowth of the ideals and will be tested by the sentiment of the nation before passage and their effects will be tested by similar comparison with ideals and with public opinion. So 


\section{THE PSYCHOLOGY OF NATIONALITY}

far as the general rule goes all is smooth sailing. Of course, in practice the relation is not so simple. The interests of all members of the state or nation are not identical. Where they come into conflict, methods must be developed of harmonizing the conflicting interests, or some means of deciding which of the irreconcilable interests shall be permitted to have its way. These methods of making decisions on disputed points have also become conventionalized and reduced to laws. They are probably more important in the function of the modern state than are the means of enforcing generally accepted ideals where such exist. A large part of the modern development of states has been made possible by a willingness to abide by the opinions of a majority, to accept apparent or actual loss of personal advantage in the interests of harmony, and even to give over ideals which seem right in the face of a vote in favor of other ideals by the greater number of the community.

Even this process is tempered and modified by the existence of ideals. Most states have laws or principles behind laws which prevent a majority from depriving the minority of rights. One cannot invade the home of the individual except under definitely stated conditions, one cannot prescribe religious beliefs or 
interfere with freedom of speech even if the religion of the few or the opinions expressed by them be distasteful to the many. The state cannot divide the property of the few among the many even if the many vote for the division. These exceptions are made because of a belief, in certain cases based on trial, that the welfare of the state and so of the individual in the long run and on the average will be furthered if the action of the majority be limited in this respect. The man without property hopes to acquire it later and desires to be able to keep it when he gets it, the man with no new theory of government or religion knows that he may have one later and desires to be free to expound it, or he may see and have proved by test that a state or society advances more rapidly and is more contented if each man is left free to think and say or do what he pleases within limits that do not conflict with the freedom of others. This again is a case of adjusting acts to the advantage of the future instead of the present alone and of considering the greatest good of the greatest number for all time rather than the immediate advantage or apparent immediate advantage even of the majority.

How far the ideals of the nation and the formal prescriptions of the state will coincide 
varies with circumstances. In nearly every age there is some lack of harmony from the fact that the ideals grow more rapidly than they can be embodied in laws and also because laws are continued after the ideals have changed. This is a condition that, with the modern mechanisms, tends to right itself, although in the period of lack of harmony the result may be very irritating. More important in many of the modern states is the problem that arises when more than one nationality and more than one set of national ideals chance to be represented in the same state. Here again the attitude of the modern state is to treat the differences in nationality much as one does differences in religion. The essential ideals will be common to all. These may be enforced. The unessential must be permitted to stand freely and each nation be compelled to respect or at least refrain from interfering with the others. Where this course has been followed there has usually resulted an amalgamation of one by the other or the fusion of both into a common new group that offers a permanent solution of all the problems. Where attempts are made to force a people to give up its national language or any of its national peculiarities or ideals, the result is usually to arouse the emotions of hate with the result of intensifying national 
feeling and keeping it more distinct than it would otherwise be. This can be seen with Danes, Poles, and Alsatians in Germany, and with the minor sections in the various regions of Austria. A state is probably strongest when it has but one nationality, but unity cannot be forced upon it. National ideals must be accepted willingly or not at all.

The relation of the state to the nation took a practical form in connection with the drawing of boundaries at the peace conference. There were many places where state lines and national lines did not agree and where it was difficult to make them agree unless one disregarded all economic considerations and all problems of ease of administration. If one assume for the moment that we were to be given authority to adjust these problems and were also given omniscience for the facts, a solution in the light of our principles must follow several different rules. The first is that any division must be made as nearly as possible on the lines of nationality. Nationality is not a matter of inheritance primarily, but of ideals. It is an affair of the mind or spirit, not of length or breadth of head or even of physical relationship. The only way to decide whether an individual belonge to one nation rather than another is to ask him. While his answer is not 
necessarily infallible, since he may not appreciate what his ideals are in every case, it is more likely to be right than any other. It does not necessarily follow that in practice nationality is to be the only consideration in the creation of a new state. After all, nationality is not absolutely fixed. As we have had occasion to see in several connections nationality and the ideals of nationality are subject to change, and on occasion where any possible division will do violence to some principle of nationality one must accept the best solution possible and trust to adjustment of nationality with time.

Other circumstances that must be taken into account are the economic relations and the ease of government. A state should have easy communication with its markets, and the industries of one part of its territory should, if possible, supplement those of another. Also where small colonies of one nationality are interspersed among other nationalities or within a single nation, it would be difficult, if not impossible, to administer a government for each nationality. In such cases any solution will be unfair and have its disadvantages. All that can be suggested is to follow the national lines wherever that will give a unit of homogeneous people of suitable size. Each of these units 
should be sufficiently provided with lines of communication, and with correlated industries to be economically independent. On the borderlands inhabited by mixed races, the wishes of the majority of the inhabitants should be considered first, but where these were too seriously in conflict with economic conditions, the best compromise possible must be made. After an adjustment has been reached it should be open to change in the light of later experience. It will always be tempered by the fact that members of the minority nationality can move to a region where their own people predominate, and also by the fact that under any fair government the individuals after a time are likely to change their ideals to conform to those of the majority - will become naturalized.

These general principles were accepted in principle by the peace conference. Poland is to be given an outlet through Danzig, the claim of the Slavs to an outlet on the Adriatic is recognized at the moment by all but the Italians, who have an adverse claim. The supposed majority of inhabitants decided the boundary between Roumania and Hungary and between Germany and Denmark, although any division would necessarily leave Roumanians in Hungary and Magyars in Roumania. After a decision has been made, each state, new and old, 
must exercise toleration if the lot of the minority is to be bearable. In an enlightened state this should not be difficult. There are always differences of opinion, many times on matters that are as important and as much a source of irritation as nationality. Some we have already mentioned in this chapter; religion, economic theories and the resulting political beliefs, race prejudices, apart from differences of nationality, are all as keen and as difficult to overcome as national differences. Nevertheless they are subjects on which all modern states recognize the right of individual opinion and even of individual expression, and in most states working agreements have been reached which permit amicable relations between opposing parties. Development of a habit of forbearance on these matters will no doubt prepare the way for a similar toleration with reference to nationality.

On the whole, the national boundaries would follow linguistic lines as well. The common means of communication implies the development of common ideals, and a common history will give at once common language and common ideals. Exceptions will occur to any one. The most prominent at present is probably in $\mathrm{Al}$ sace and Lorraine where French sentiments are found in people who speak the German lan- 
guage. It was true under the French rule that the language was German and under the attempted suppression of the French language in all places, use of French actually increased. Even where the language did not become French, French ideals and the French nationality dominated. While the language spoken by a people is probably the safest objective index of nationality, it is only an index and cannot be trusted against the expressed desires of the inhabitants. In considering the subsidiary factors in rearranging state lines, however, language might well be taken account of as well as the economic factors. Other things equal, a state that speaks but one language is much easier to govern than one of polyglot races. Where nationality fails to follow linguistio lines, and the feeling of nationality is accentuated, nationality must be given right of way. It is more important than anything else.

It must be said that where for any reason language, economic interests, or ease of administration tends to require the erection of a state or a division of sovereignty along other than national lines, there is always danger. Whatever solution is reached is certain to be more or less unsatisfactory; one is presented with a choice of evils. In a situation such as that in Ireland, where national aspirations are at 
variance with both the economic interests and the convenience of government and where in addition it seems that there is no particular desire for a solution, any decision is sure to be unfortunate. Here the south of Ireland cannot and is not willing to exist without Ulster, and Ulster cannot and will not be prosperous without connection with England. Furthermore any division that may be attempted is bound to leave territory with a bitterly resentful minority under the dominion of both sides, a strong minority whose national alignments and business interests lie with the other group. Even a plebiscite would probably give no complete satisfaction, for all might be impoverished with the destruction or impairment of business relations. In any case as much would be determined by choice of the districts within which the votes should be taken as by the results of the balloting itself. Where there is no spirit of compromise or toleration on either side as seems to be the case in Ireland, no arbitrary selection of a principle to use in solving the problem is of value. Nor can one trust to the influence of time to soften the opposition. The more one nationality asserts itself, the stronger is the opposition from the other. Should one side give up, which is unlikely, the other might 
become tolerant. No solution proposed holds any great promise of success.

It is evident that the nation derives its authority and entire raison d'être from the nation. The nation is cause, the state effect. Government is the agency by which the nation as a mental entity expresses its ideals and compels its members to live in accordance with them. The ideals that develop in the nation find expression in the form of government first and then in the specific laws and in the acts of executives and the judiciary. We need not assume that the ideals become fully conscious before they are formulated or embodied in government; rather, the state develops by a tentative process. Some form of government appears by chance, if it is successful-if it works-it is continued; if not, a new form is tried. The results are constantly tested by the instincts and ideals. The government must pass the test of permitting the individual to satisfy his fundamental instinctive needs and must also harmonize with his developed social standards and ideals of right. These, too, grow with life in the state, and with the development of new ways of living. As the ideals of the nation grow they must find expression in new laws or the old laws must be interpreted and executed in a new spirit. That the change in 


\section{THE PSYCHOLOGY OF NATIONALITY}

social order frequently shows itself in a change in the interpretation of the laws rather than in the passage of new laws is one of the best evidences of the dominant influence of ideals. We can find evidence of this in the gradual elimination of the king from all but a formal part in the government of England and in the development of such a legal fiction as the "benefit of clergy" which made endurable the severe penalties of the criminal law long after people in general had forgotten what the legal definition of clergy or clerk really was.

The laws are formulated ideals. They are of value primarily because they anticipate situations which the individual would not know how to classify in the light of instinct alone or of his own experience. When tested they give the individual an approved standard of conduct that represents the experience of the community, even of civilized society everywhere, rather than his own instincts. As an instrument of enforcing the laws, the state may be regarded as a means of providing physical backing to the force of ideals. Even here the authority of the executive rests both ultimately and immediately upon the ideals of the nation or of the smaller group and the instinctive fear of the group or respect for public opinion. An important element is respect for the law and 
for the officers of the law in and of themselves. There is something even in the most sophisticated adult citizen of the small boy's fear of the policeman which is one phase of respect for law as law and for the officers of the state, irrespective of their personal character. This is partly habit, partly perhaps derived from theoretical considerations that the law should have weight so long as it is law. Both are ultimately expressions of the instinctive dislike of disapproval of the mass. The officer becomes the embodiment of the law as the law is the formulation of the ideals of society. Where the law is out of harmony with the ideals it will be nullified or disregarded by mere popular consent as has happened with the blue laws of New England.

It may be again emphasized in summary that the nation develops first, the state later or pari passu with it. Last of all comes the theoretical or rational justification. Whether it be the assertion of the divine origin which was made to support the older autocratic forms or the social contract theory, or theory of the rights of man which were adduced to sanction the modern democratic state, they are arguments developed after the fact to explain or justify the established order rather than statements of the way in which the state or nation really arose. After 
a state has existed long enough for the habits of acting in accordance with its rules to be firmly established, it seems that no other condition is possible. Then many men are ready with theories and arguments to prove that it must have been. These arguments do not state the real reasons for the existence of the state; rather they are devised to prove what needs no proof and to give formal justification for the existence of a condition long accepted and developed, no man knows how.

In short, the state in all of its phases and characteristics can be understood only in its relations to the nation. It grows out of the national ideals, derives its final authority from public opinion, and is merely an instrument by which the nation as an organized mental unity may express itself and control the acts of its members. It takes form slowly by a tentative process of trial, for ideals are not clearly conscious in the minds of the individuals that constitute the nation, the only consciousness that it has, but are frequently merely vague strivings for a better condition. As each change in law or form of government is made, it is tested by its results and accepted, if satisfactory. While the state never is in complete harmony with the ideals of the nation, either because the state has not yet grown to the nation, or the 


\section{NATIONALITY AND THE STATE 277}

state persists as the embodiment of older ideals, nevertheless the ideals of the nation set the standard towards which the state must strive, and where the two come into conflict the nation will always emerge supreme. 


\section{CHAPTER $\mathrm{X}$}

NATIONALITY AND SUPER-NATIONALITY AS EXPRESSED IN A LEAGUE OF NATIONS

THE principles of social psychology upon which nationality depends are fundamentally two: the common instincts and the ideals which develop through these instincts acting in and upon the experience of peoples. The instincts are fixed and the same for all individuals in whatever society found; the ideals are an expression of the experience of the individual group and of the conditions under which it has developed. The instincts constitute what we are accustomed to call the immutable laws of human nature, while the ideals may change as experience dictates. Fortunately the more important elements in the development of nationality are the ideals and so may be made over to suit the changing conditions and give room for growth in the general organization or in the detailed character of the different states. The instincts force some sort of living together, they make possible coöperation through sympathy, and they enforce ideals by 


\section{NATIONALITY IN LEAGUE OF NATIONS 279}

the instinctive respect for the opinions of others and by the fear of the disapproval of the group, expressed either in the immediate presence of a crowd or by public opinion in tradition or in the press. The latter instincts give the ideals and conventions of a nation the impelling force of instincts at the same time that they permit adaptability to the changing conditions.

This distinction is of great importance when we approach the questions, "Is nationality the last word in political organization," and "Is it possible to go beyond and find a larger unity in a community of states?" Were the national organization dependent upon instinct alone, the problem could not be asked. A nation once formed would be a closed unit, its members would be bound together by natural ties-all outside the group would be forever distasteful to all within and there would be no hope for a change of any sort. As nationality is largely dependent upon the development of ideals and a new ideal, when developed, has the force of instinct, it is always possible to make progress. New organizations may arise in the midst of old and old organizations may be extended to include outside elements. These changes in the old nations have always characterized the history of peoples, just as changes in allegiance 
are important phenomena in the modern shifting of populations.

When we face the pressing problem, whether the psychology of nationality involves any principles that would make impossible the development of the wider international state or league of nations, we naturally ask how many of the instincts and ideals effective in the nation are compatible with the development of a wider union. It may be said at once that all of the true instincts are quite as much suited to the international or super-national organization as to the national. One may confidently assert that the development of the national spirit has come about by a restriction of the natural range of the social instincts by training rather than by any unnatural extension of them. Sympathy and fear naturally are not respectors of persons and recognize no limits of race or language. With the setting off of smaller groups through associations they are perhaps unequally distributed, more keenly aroused by the members of the narrower circles and vary in strength inversely in proportion to the distance from the center. It is only artificially that these instincts have been restricted in their application to members of one nation.

What has made the nations, as may be seen clearly in history, is the development of common 
ideals. These are based on instincts but the form that they shall take is due to the experience of the nations and of the individuals that compose it. They change as conditions change. Just as they have been expanded from the tribe or similar small group, to the city, and from the city to the empire, so they may readily spread to include many or all of the civilized nations. Of the ideals that at present guide the nations many are common to all. There is no nation in which there is not at least lip worship for the principles of human liberty and democracy. All at least approve the same general principles of ethics and it would be hard to find a sufficiently unprejudiced observer to say where these principles are least respected in practice.

One might object that the dislikes between nations are too strong ever to be overcome. If one grant the strength of the national prejudices, it must also be remembered that they are conquered or forgotten daily with reference to individuals. The national differences are by no means so marked as many others that are permitted to exist within each nation. There are many antipathies between geographically distinct groups, or between different social strata or even political parties and religions that are stronger than those between nations. Every nation has at times had differences in religion 
that have either threatened or have actually brought on physical conflicts. It is quite as easy to arouse a Protestant native to the fighting point by stating that a Catholic church is bringing in boxes of rifles as it would be by telling him that a Polish society had conducted the same campaign. Just now more excitement would be aroused if it were a German society that was suspected, but that may be regarded as a temporary condition. The readers of the Menace have much more bitterness towards the Pope and the local clergy than they have for Austria, and certainly more than they had for Germany five years ago. On the whole, religious differences have been overcome. No intelligent man in any civilized country would think seriously of stamping out a religious belief or preventing religious practices that were not abhorrent to his humanitarian or moral ideals.

The conflicts between political parties, even when they have ceased to stand for any important differences in principle, are stronger, often, than the dislikes of nations. We have seldom had a war in which the members of an opposite political party would subordinate its interests completely to the interests of the country as a whole. The New England Federalists in the War of 1812 would smash the coun- 
try rather than give over their political and business practices; some of them would rather see the war lost than have the Democrats obtain the credit of winning it. The northern Democrats in the Civil War gave only grudging adherence to Lincoln, and it is not unfair to say that the debates in this war have had almost as much reference to what party should have the credit for saving the country or civilization as to how and whether it should be saved. This is in part pure selfishness on the part of the leaders who see themselves out of a job if party differences should disappear, but in part it is shared by their followers who would regard the dissolution of the Republican or of the Democratic party as a real calamity, commensurate in importance with the disintegration of the nation. At any given point in the controversy they would secretly prefer to see the nation go, but consideration of the consequences, the fact that the party would go with the nation and their interests with the party, restrains them.

Even more prominent and decidedly more vital are the commercial and business disputes. But these are quite as strong between individuals and classes of the same nation as between nations. There is no more logic in a citizen of the United States becoming excited 
because an American company is debarred from transacting business in China or should have difficulty in collecting a debt in Africa than that a citizen of Chicago should be disturbed because another man in the same city has lost money by the repudiation of a debt by one of the southern states. It is to the interest of all that good laws should exist everywhere. These arrangements have little or nothing to do with the wider groupings of nations or super-nations. Wherever one sees wrong done one resents it and where that wrong is done to one of one's own political group the resentment is increased and may lead to revenge or punishment. The impulse is common to all humanity in varying degree, irrespective of the closeness of relation to aggressor or victim. The practical dangers can be avoided either by making sure that no harm is done or by providing a way of righting the wrong that shall not depend upon the separate national organization.

The strongest antagonisms are those that arise between the supporters of different theories of government, not between political groups. A Socialist, a Bolshevist, or an I. W. W. might conceivably object when a wealthy corporation obtained a decree that should enable it to collect a debt, even a just debt, from a member of the proletariat, but there is no 
reason why he should object more if the corporation have its home office in Tokio than in London or New York. So long as disputes are being settled every day within the nations that offer very much more cause for friction and dispute than many or most that would arise between nations, there is no occasion for regarding the solution of the problems of practical organization of international judicial machinery as impossible. In these alone can we see any real danger to the development of a wider union of peoples.

The existence of national rivalries, even of national hates, need offer no more difficulty in practice than do the individual and local rivalries to the working of the present political institutions. After all, just as sympathy is greater, the rivalry between neighbors is keener than that between individuals on the opposite sides of the ocean or the opposite sides of the earth. The hates between men of different social positions in the same town or nation are stronger and can be less easily obviated than the hatred between men of different civilizations. It is much more of a problem to find an equitable, or at least a universally acceptable means of dividing the proceeds of industry between capital and labor than to devise a scheme by which Russian and Australian, or Englishman and 
Hottentot may live together upon the earth without interfering with each other. The problems that do arise between the different races are the same as those that arise within the races and are less acute in form because the contacts are less frequent. On the negative side, then, there is no more reason why there should not be an international organization than a national one. In each case the bond has grown far beyond the range of personal acquaintance and in one case not so much farther than the other as to make a difference in kind. Granting that there will never be a disappearance of national rivalries, we should recognize also that these are no more inimical to the existence of international community of spirit than are the more local rivalries, even the individual rivalries, to the narrower state or national consciousness. These local rivalries, at present, certainly aid as much as they hinder the development of the wider bond.

Ii the jealousies between nations are not sharper than those between individuals and groups within the nations, there is every hope that an international organization may be successful. No one thinks of restricting the belief of the citizens of a state in religious matters, nor in the field of political theory, two systems that have in the past been as fruitful of 
conflict, even of wars, as have the national attachments. In an international state, if the machinery of an international state were to be developed, one would expect the national spirit of each nation to persist, one would even expect the conflicts of these aspirations to continue, but to have them settled in some rational way. Just as the rivalries of individuals in any state constitute an element of strength to the nation as a whole or the rivalries of cities and of larger subdivisions constitute a factor that makes for the progress of the nation, so the rivalries of the nations might very well be an element in inciting to progress in the international community. In our American cities one of the incentives to improvements of all kinds is the desire to be better or not more backward than others that claim to be rivals. A similar rivalry between what are now separate nations need not interfere with the proper coördination of all in the efforts for peace.

Only where questions of boundary or of business dealings enter need there be any difficulty in the adjustment, and, after all, these are just the problems that the courts of our present states settle. The issues between states nearly always go back to issues between individuals with only the additional complication of deciding who shall settle them. There was, for ex- 
ample, no question as to the punishment that should be given to the assassin of the Crown Prince of Austria. The war came, ostensibly, at least, over deciding who should investigate and the insistence of the Austrians that the Serbian state should be subordinated to the Austrian in the investigations on Serbian soil. Provided only that some tribunal exists which is recognized as fair and as having authority to settle disputes, there need be no serious controversies even over these questions. This is all the more probable if, with the habit of appeal, national honor becomes less touchy, as would be the natural tendency. After all, the individual has no vital direct interest in the aggrandizement of the national territory. His interest in the expansion of the nation is an indirect and acquired one, and while it will probably never be lost no matter how completely an international organization may be developed, it can be expected to become more rational, more restricted, to shrink to something like the rivalry between the states in the United States of America. A century ago, still more at the time of the formation of the Union, the states had each its own honor and pride that threatened war on several occasions over the adjustment of boundaries. To-day, we see new divisions made as of the Dakotas and recti- 
fications of boundaries suggested with no feeling at all except on the part of a few people who see some direct effect upon their financial prosperity. An instance of such a friendly adjustment of a national ambition was recently given when Norway was established as an independent state.

What we must hope to develop in an international state is a condition in which competitions and the emotions that grow out of competition shall be between the individuals and classes of individuals rather than between nations,- that the competition of nations shall be restricted to matters directly connected with nationality, and that a national matter shall not be made of purely individual business affairs. Most of the dangerous rivalries of the modern industrial state arise from conflicts in competition for trade. A firm of one country fails to make a sale in competition with a firm of another country. It believes that it is due to prejudice or to undue activity of the officials of the successful country, and bad blood arises. An international agreement should insure equality of treatment so completely that there is no room for suspicion and no necessity for the interference of the national government outside of its own territory. Then competition would be between individuals and there would 
be no occasion for raising questions of national honor over any trade matters. An international tribunal might be necessary to adjust disputes between citizens of different countries, but they would soon come to be adjusted as differences between individuals and not between nations. Then national rivalries might well be confined to competitions in advancing general order and welfare and not to quarrels over the minor advantages of citizens.

If we find that rivalries and sources of disagreement are no sharper between nations than between groups within nations, we may also say that many of the ties which unite men most strongly do not stop at the national boundaries. We all have scientific friends of other nations who are in closer sympathy with our views than some of our own citizens. The same may be said of political theories, of religious belief, and certainly of literature and art. The best illustration is the international socialist movement. To be sure, this very fortunately or unfortunately, as one thinks of our own socialists or of the enemy's, was not strong enough to stand the feeling or emotion of nationalism in war time. But the sentiment of solidarity between members of the proletariat is growing faster than the similar feeling between the members of the employing group. 
The fundamental sympathies are by no means restricted by national boundaries. While one may close one's eyes or ears against knowledge of distant atrocities when they are brought to our attention, one is impressed if not overcome by stories of massacres of Armenians or of the Africans in the Congo, almost as much as by the atrocities in Belgium. In case the event is striking and a large number of individuals are involved, a distant event attracts more attention and more sympathy than the ordinary mishaps even if in the total they result in more suffering than the single tragedy. Deaths from influenza arouse less emotion than do the battle casualties of half the amount. An air raid that causes fifty deaths in Paris or London excites the populace even of New York or Chicago much more than the motor vehicles that kill ten times the number in the streets of the home city. This is, of course, partly because the blame may be definitely attached in one case and not in the other, partly because the latter is a series of incidents far enough apart so that one is forgotten, if heard of at all, before the next appears.

Making all allowances for incidental differences, it is clear that the sympathetic emotions may be sufficiently aroused by events that injure distant men and even men of the lower 
races to back up a judicial and executive authority in the infliction of punishment upon international criminals. That, after all, is the essential factor in the development of a practical internationalism. While the sympathetic emotions may weaken with distance, the disagreeable emotions of hate and resentment also show a similar, probably even a greater, reduction so that the balance is not far from equal. One cannot expect the enthusiasm for man in general to attain the strength of the emotion aroused by an appeal for the Stars and Stripes or for La France or the King. On the other hand, the whole world or mankind in general will not arouse the same hatred as that we now see exhibited towards the German or the Turk.

It might be objected that the distances which separate the different parts of the world in space and still more in ideals are so great that one can never hope to bring them into the unified attitude towards problems that are essential for the proper control of the actions of each by a common ideal. Two answers may be made to that. In the first place, it is certain that the modern inventions bring the world as a whole into closer communication than was thought possible within many of the single states of antiquity in which the national spirit developed. For the purpose of obtaining news 
and the diffusion of ideas all parts of the world are mechanically one through the agency of the press and the telegraph. The general spread of literacy has increased the possibility of a common understanding, and furthered the development of common ideals and the resulting common control, so that there is more of unity between America and Australia to-day than between neighboring parts of the Roman Empire of old or between different provinces of the Chinese Empire to-day. Probably the intelligent classes of Russia and America are also more closely one than were Egypt and Gaul at the time of Christ. At the other social extreme, the I. W. W. and the Russian Bolshevist are equally moved by the same ideals and active in a common cause as is seen by the protest of the Bolshevists against the execution of Mooney, however little we may grant that they understood the circumstances and the motives of that conviction. Taking ease of communication, degree of intelligence, and possibility of mutual confidence into consideration, we car safely say that the most remote parts of the civilized world are to-day more nearly united and more capable of constituting a single social group than were many of the smaller states even of the medieval and early modern period. 
The only one of the fundamental instincts which has been important in the formation of nations which would be lacking in the international organization is hate, and its similars, jealousy and suspicion. In Chapter III we traced the importance of hate in uniting the nation against an outside force or other nations. If all the nations were gathered into one there would be no one to hate; at least, the hatreds would always lead to the disruption of the wider union rather than to its unification. The only substitute for this would be hatred of disruption itself, and of the wars and bad feelings that result. This would not give the same thrills and enthusiasms of hate that are provided by the hatred of persons and groups. The supernational state might and must be content with the coöperative instincts as a basis for its formation, together with these colorless emotions of opposition to abstractions and dread of the condition before the universal state was formed. Religions seems to get on fairly well since heretic hunting went out of fashion and they were restricted to hatred of evil in the abstract. The supernationality must trust to similar motives. For a generation or two, it is safe to prophesy, the human race will be sufficiently impressed with the horrors of war under modern conditions to be united by opposition to 
that alone, and by the time that lesson has been forgotten it is to be hoped that the habit of settling disputes by rational methods may have become sufficiently well established to be continued.

Some have argued not merely that an external enemy is necessary to hold a nation together, but that fighting itself is essential to the welfare of mankind. Two arguments have been advanced for this, one that elimination of the unfit is necessary to the process of evolution and that war is the one method of elimination that is left to mankind; another that fighting arouses emotions that are essential to the development of the individual, or that it alone can produce the highest character. A little examination of each of these assumptions shows that all rest on fallacious analogies. First, it is probably true that part of the selection that acted in eliminating the unfit in earlier times was conflict between tribes and individuals. When fighting was with fists and teeth or even with bludgeons and swords, the strong man, the courageous and intelligent would survive and the weak and unintelligent would be eliminated. Now that fighting is with instruments of precision at great distances and between those self-selected for bravery, or selected after physical examination that shall 
send only the best to fight while the unfit are safe at home, the condition is reversed. In modern war the fit are eliminated and the unfit. survive. Even the German contention that struggle between states will select the stronger states for survival might well be questioned, or at least it may be questioned whether the state that survives in a struggle will be of the type that is most desirable. One may indeed doubt whether the world would be better or human happiness greater in a world dominated by the Germany of William the Second, than in one in which there was only the weak and divided Germany of Goethe, Schiller, and Hegel. The state fitted to survive in a struggle is apparently the one under an autocratic government, that shall emphasize the crass material forces and subordinate the intellectual and artistic. It must subject the wills of the many to the one and permit initiative only in the development of implements of war and of the many material resources that add to the effectiveness of the nation in war. This may include almost everything that improves effectiveness in physical ways, but at the expense of intellectual and artistic values and individual independence. In spite of the efficiency of the latter, most civilized individuals would prefer to live in the England rather than in the Germany of pre-war 
times, and it were better for the world to multiply states like England, America, and France than like Germany.

It is also by no means assured that war is necessary to develop the best in man's physical and mental nature. Some have asserted that there are changes in internal secretion necessary to the full development and health of the individual that can be induced only by fighting. Cannon $^{1}$ finds that an emotion of hate or anger and even the pleasanter forms of excitement stimulate an increased secretion of the adrenal glands which increases the strength of the individual temporarily. These and stimulation of other similar glands are the most important effects upon the organism that would be produced by fighting and not by the more routine forms of bodily activity. That war is not worth while for the stimulation of these glands alone is evident from the fact that they may be stimulated by athletic contests and even by the excitement of hard mental work and mental contests. One might well question whether their stimulation in any great amount is necessary; in fact, there is some evidence that the effect of overstimulation is harmful rather than beneficial. All that is really needed is that the organs should not be

${ }^{1}$ W. B. Cannon: "Bodily Changes in Pain, Hunger, Fear and Rage." 
permitted to atrophy through complete disuse and present evidence is that there is no great danger of that until life becomes much less exciting than is even peaceful civilized existence.

The other argument for war lies in the improvement that it is supposed to work in the moral nature of man. It is held that it is essential to man's full development that he should be able on occasion to stand pain, to undergo every hardship for a disinterested end, and presumably that war alone offers the occasion and sufficient incentive for the degree of self-sacrifice needed to develop this character. That war does develop these qualities in many is undoubted. Whether this alone would be a sufficient justification for war even if the qualities could be developed in no other way is very much open to question. That a nation should sacrifice fifty per cent of its youth between twenty and thirty, as did France in the last war, that great virtues might be shown by the other elements of its population does not appeal to the rational mind. If the price must be paid at short intervals, the men of virtue developed would be too few in number to compensate for the increase in quality. One must not forget in the reckoning the disagreeable and injurious effects upon men's character. If some men develop unsuspected virtues, others develop 
equally unexpected vices. Opposed to courage and self-sacrifice is the increase in cruelty and in bloodthirstiness, which seems equally unavoidable in the conduct of war, modern as well as ancient. Opposed to the self-denial of the soldier and of the patriotic civilian who stints himself that the Allies may be fed, is the profiteering of many who like vultures treat a war. as a time for feeding fat at the public expense. Of the returning soldiers, some seem to have risen to new heights, these probably are the majority; others can find little satisfaction in the monotony of peace after the excitement of war, and suffer moral shipwreck; still others are relatively little affected. While the virtues of a nation at war are impressive, it is questionable whether the final benefit to character is worth what it cost the world in the last war. And as James has pointed out in his Moral Equivalents of War, almost if not quite the same effects may be wrought by the conflicts of peace. It is probable that the moral sacrifices made under the more natural incentives of peace are much more valuable than those forced by a great war. A sufficient training can be had from the constant conflicts with evil, with selfishness, and ignorance, offered in the most civilized and peaceful of states, to bring the race to a high standard of moral health. 
On the positive side much may be said even from the psychological point of view for the development of a League of Nations. The need is readily apparent. The present relation of the individual states is similar to that of individuals when social organization was first developing. While the instincts of the individual in his social dealings have long been subordinated, whether he will or no, to rational guidance, to a course prescribed by the best knowledge of the group, the action of the state is still uncontrolled action on impulse. True, ideals of international relationship have developed, rules that are recognized as honorable for the declaration of war and for the conduct of war when it has been declared, but these are followed only when it suits the convenience of the nation in question. The Germans had a theory and system of ideals of warfare at variance with those of the rest of the world, a theory that any act however frightful which produced results was right, and there was no one to interfere. A specious argument sufficed to strengthen them in their course in spite of the indignation of the world. Within the realm of international relationships there is only a gentleman's agreement on the rules that shall temper the cruelty of natural instincts. When a nation ceases to act like a gentleman there 
is no force that governs it, and there is always great likelihood that the desire to be considered honorable may break down under pressure. No means have been devised for enforcing ideals when the nation in question refuses to accept or live up to them.

While one might argue that the decisions of a nation are so slow that they can be subject to none of the precipitateness of the individual acts, that decisions of a nation should be made in the light of the ideals and experience of the race rather than in terms of mere instinct, this seems in practice not to be the case. There is all too frequently action under the influence of a widespread emotion. Not infrequently selfish motives control the rulers, and at other times the rulers are carried away by the emotion of the group. The problem is complicated for the worse, too, by the tendency to exaggerated ego on the part of the state or nation as a whole. The reverence which individuals have come to give the state prevents its interests from being considered calmly and with due reference to the rights of individuals and of other nations. The emphasis upon the welfare of the whole, which was necessary to develop in the individual a willingness to sacrifice his own interests and to subordinate his own instincts to the law, has resulted in raising the nation as a personi- 


\section{THE PSYCHOLOGY OF NATIONALITY}

fied entity upon so high a pinnacle that we all incline to believe that whatever it does is right, and that anything which will advance its interests is a sacred duty, no matter how much suffering may be inflicted upon other individuals or states in the process. This belief that national need or even national pleasure or desire is above all law is so strong that it makes some curb upon international action quite as necessary as was control of the individual in the savage stage. As it is, claims are made by nations that would not stand for a moment in a civil court in a suit between individuals.

To be sure, there is what is known as international law, but this is little more than a series of precedents for international action. Its only cogency is in the force of international pubric opinion. Where the common decency is sufficiently outraged by the action of one nation in peace or in war, other nations may interfere, but there is no recognized duty or even right of other states to do so, and no force which can be called in to prevent intended or threatened breaches of accepted international rules. That all nations feel keenly the approval or disapproval of others is shown by the propaganda carried on in neutral countries by both sides engaged in the Great War. Each step 
was argued at length, after it had been taken, in pamphlet and newspaper to influence the opinion of the citizens of the world or of the soldiers engaged. The Germans, in spite of their apparent callousness to moral or conventional ideals, were evidently alarmed at times by the universal condemnation of their acts, even when they did not accept the standards of those who condemned them or change their course. To be sure, the United States was driven into the war in the spirit of an international policeman, by resentment at the treatment of others as well as by the injuries to her own citizens, but she delayed two years before the leaders could sufficiently arouse the populace to favor intervention. At present the world is like a primitive community without a police force. One can expect that when an innocent pedestrian is attacked by a footpad a good citizen if near will come to his rescue and perhaps punish the offender. All the world will approve such action, unless the motives are misrepresented, but there is no organized force for the protection of the weak or the punishment of the guilty or even for deciding who is guilty.

From historical analogies the world seems ready for a wider organization. We saw in the discussion of the development of nationality 
that a nation was likely to develop when an ideal or set of ideals had been prepared in the mass of people that were to constitute the nation, and some great incentive came which impelled to a realization of those ideals. The ideal of a League of Nations has been growing and becoming ever more specific for centuries. The cynic might object that the centuries of development are so long that there is no more hope now than ever-that Christ preached the brotherhood of man nearly two thousand years ago and that at short intervals ever since some one has repeated the plea and suggested means for its realization. While wars have perhaps been less frequent recently they have more than made up in ferocity. To this we must answer that the ideal of community of interests has been growing more definite and less exaggerated. We have not merely the utopian schemes of Kant and the general practical plan of Metternich, but we have a widespread belief in their efficacy on the part of the common people, and we have seen some of them realized in a small way in The Hague conventions. Lack of confidence in any regulation on the part of the practical statesman or politician limited the effectiveness of these agreements, but they did provide a standard of judgment, even when violated, which was 
not without its effects in guiding the action of neutral governments. Talk with any one of the common people, in America at least, and if we may believe the reporters, in almost any one of the civilized countries, and one discovers a widespread belief in the necessity for an international or supernational organization. The ideal is prepared and generally accepted.

The immediate incentive of escape from a particular danger or obtaining relief from injustice or peculiar suffering, is perhaps not so strong as it has usually been where nations have developed. There was sufficient suffering in the war just past on the part of the soldiers who participated, and perhaps still more keen anguish felt by the relatives of those who fought and died or were severely injured to make them willing to do anything to avoid a repetition. The great lack is that there is no one in particular to blame for a war, there is as cause only an impersonal condition of lack of organization; while in the case of the oppressed peoples who have risen to form a new nation some ruler or some other nation was to blame and could be hated and fought. Whether the resentment against a condition of society and desire for greater security from suffering, without any reaction against an external force or individual, will suffice to hold the world 
together is the question. That it was sufficient to organize the separate states on a principle of justice is assured. We may only hope that with the increase in intelligence and imagination, hatred of war and injustice in the abstract may be enough to induce a general trial of a new system, and that habits will develop after it has been tried that will make possible for all time a rule of right in international relations.

In no single respect does the psychology of nationality offer any reasonable objection to the formation of an international society. or League of Nations. It is an obvious next step in the development of a social organization, and the social instincts and the social ideals and habits offer sufficient basis for its development and for its proper functioning when it has been developed. The one instinctive 'or emotional element that is lacking to it which has been effective in the development of the present nations is the fear of outside force and the hatred of a common oppressor. Even this may be supplied in the same way that fear of the violence and injustice of an unorganized society may be said to provide an incentive for the formation of the local political organization. The disorders and outrages of a Bolshevist régime serve as an irrefutable argument in favor of any political organization, however imperfect it 
may be in any of its details. Similarly, the horrors of the most civilized of wars make insistent demand for the development of any form of international organization that promises the least chance of success.

It cannot be supposed that the international organization will greatly diminish the importance of nationality in the world relations. Nations will always exist as next to the largest unit of organization. It is essential that they should; no wider state is conceivable except as an organization of the present national states. It is even questionable whether the national pride will ever suffer serious diminution, however thoroughly the larger unit should be organized, and however completely it may be accepted by the world at large. The most that can be anticipated, and all that is desirable is that the excess of national assertiveness should be subordinated to the good of the common whole, that national egotism should be restrained sufficiently to respect the rights of others. All that is good in nationality, all its enthusiasms for the common weal, and all of the international rivalries might well be retained and transformed where necessary into competition for the attainment of mutually beneficial ends. That the sentiment of loyalty to separate nations would ever be greatly re- 


\section{THE PSYCHOLOGY OF NATIONALITY}

duced is not likely and would be a much to be deplored result. It is doubtful if consciousness of belonging to a world league would ever reduce the consciousness of being an American or a Frenchman to the extent even that the Scotchman has been subordinated to the Englishman and still less to the extent that the Yankee or Southerner has been subordinated to the American. One may venture to hope that the remnants of a national consciousness might become less painful in the process of subordination to the wider loyalty than is the national consciousness of the Irishman. One may well question whether the allegiance to an international league would ever take on the personal form of loyalty that is connected with the national consciousness. It would probably always be more like the general sense of decency common to all civilized beings, an extension of the dictates of conscience from the merely personal relations, as they exist at present, to include the acts of nations as well as of individuals. It is not even necessary that the entity should be personified and individualized as the nation has been personified and individualized. But with time and the formation of new habits of thought and ideals of conduct the sense of belonging to a community of mankind might well be strengthened. 
That the first formulation of rules for the guidance of the wider league shall be perfect is not necessary and is not to be expected. As in the development of all governments the first attempt must be tentative, and the instruments must be tested in practice and modified where found defective. If the suggested draft of a constitution shall be sufficient to tide the world over a few crises, and to confirm the desire for a working agreement, it will suffice. Once the world accepts the principle that a better way than war exists for the settlement of international disputes, the best machinery for settling them will be developed by a gradual process of trial and error. After the habit of appealing to right rather than to might has been established, war will be as unthinkable as a private duel. Meantime it is essential that the broader sympathies now wasted in more or less vague sentimentalism shall be crystallized about a definite agreement. When that agreement shall have had the tradition of a century behind it, it will be considered as immutable as the good lawyer now regards the constitution, and with a few centuries of practice it will assume the fixity of the moral law. 



\section{INDEX}

America, Development of nationality in, 110ff.

American constitution, as an embodiment of ideals, $232 \mathrm{ff}$

Anthropometry, 13

Balch, Emily, 149

Baldwin, 45f

Beginnings of nationality, $91 f$

Beliefs, social, 199ff

British constitution as an ideal, 232

Cannon, W. B., 297

Cavell, Edith, 74

Clan system, 7

Commercial disputes as a cause of wars, $283 f$

Condillac, 109

Country, its effects upon nationality, $237 \mathrm{ff}$

Criminal and society, 79

Crowds and the leader, 169

Crowd, Reasoning in, 169

Darwin, 24

Descartes, 109

Dress and nationality, 152
Economic basis of the state, $268 \mathrm{ff}$

Emotions of the crowd, $171 \mathrm{f}$ of the nation, $212 \mathrm{ff}$

Encyclopedists, 109

England, Nationality in, $103 \mathrm{ff}$

Environment and physical characters, 14, 148

Fighting instinets necessary for social development, $53 \mathrm{f}$

France, Nationality in, $105 \mathrm{f}$ French Revolution, Nationality in the, $115 \mathrm{ff}$

French Canadians, Naturalization of, 131ff

Frightfulness as a war weapon, 72

Fryatt, Captain, 74

German unity, Development of, $122 f$

Germany, Nationality in, $106 \mathrm{f}$

Government, developed by trial and error, 259ff Government as embodiment of ideals, $255 \mathrm{f}$ 
Greece, Nationality in, 93ff Gregariousness, Instinct of, 28

Group, Fear of, $32 \mathrm{f}$

Habits, Change of, in naturalization, 141f

Hate in international organization, $294 \mathrm{f}$

in the development of nations, 81ff

and religion, $75 \mathrm{ff}$

and war, 83ff

Honor, national, 215, 220ff Hypnotism, Action of the crowd compared to, $167 \mathrm{ff}$

Hume, 109

Ideals, Effects of, in naturalization, 152 and the nation, 224-228 and the League of $\mathrm{Na}$ tions, $279 \mathrm{ff}$

Imitation, $45 \mathrm{ff}$

in the erowd, $172 \mathrm{ff}$

Instinets, Development of, $25 \mathrm{ff}$

individual and racial, 24 and feeling, $2 S$

Social, 28ff

Crowd controlled by, 166-

175

and ideals, $37 \mathrm{ff}$

Defects of, as a means of government, $249 \mathrm{ff}$

and the League of $\mathrm{Na}$ tions, 278
Intelligence, Increase in, with change of social environment, $149 \mathrm{f}$

International law, $302 \mathrm{f}$ Italy, Nationality in, $119 f$

James, 24, 299

Jennings, 64

$\mathrm{J} \in \mathrm{ws}$, Nationality of, $92 \mathrm{f}$

Keane, 14, 16

Kellogg, Vernon, 73

Kinship, symbolic, 8

Lamettrie, 109

Language and nationality, $17,143,236 f$

Laws as formulated ideals, $274 \mathrm{ff}$

LeBon, 166, 172, 180, 184ff Liberty, ideal of, $41 \mathrm{ff}$

Lichnowsky, 82

Literature and nationality, $236 \mathrm{f}$

Locke, 260

Lowell, A. Lawrence, 183

Loyalty as measured by willingness to fight, $156 \mathbf{f}$

Luther, 76

McDougall, 50

Maitland, 260

Marvin, 96

Mercier, Cardinal, 74

Middle ages, Nationality in, $99 f$ 
Minor groups and the nation, $241 \mathrm{ff}$

Morley, 113

Nation as a social concept, 214, 22:2f, 235

National consciousness, $186 \mathrm{ff}$ pride and the international state, 301, 307f

Nationality, Definition of, 5 and the state, 249-277 Theories of, 23, 164ff, 240 ff

Netherlands, Nationality in the, 101

Paramecium, illustrative of social phenomena, 64

Profession, Choice of, determined by social ideals, 41

Party, Influence of, 183

Party vs. nation, 283

Perceptions of the group, $191 \mathrm{ff}$

Perla, 215

Phillpott, 8

Plato, 6, 109

Political ideals, 229ff

Punishment by social disapproval, 227

Race and family, 6

and nation, $3,245 f$

capacity, 12

Mixtures of, in Europe, 16 prejudice, 128
Religion and nationality, 243

Rivalry of nations a source of progress, $285 \mathrm{ff}$

Rome, Nationality in, 96ff

School and naturalization, $145 f$

Sehurz, Carl, 136, 149

Social alignments determined by hate, $67 \mathrm{f}$ contempt as a force in naturalization, $140 \mathrm{f}$ ideals, $32 \mathrm{ff}$

Conflict of with racial and individual, $44 \mathrm{f}$

Development of, $54 \mathrm{ff}$ instincts, development of, 49

Socialism a doctrine of hate, $80 f$

Stephenson, N. W., 81

Suggestibility of the crowd, 170

Switzerland, Nationality in, $101 \mathrm{ff}$

Sympathy, 29f

developed from maternal instinet, $50 \mathrm{f}$ international, $290 \mathrm{ff}$

Tagore, 12

Tardé, 45f, 173, 180

Thought of the nation, 181, 192 to 206

Totem, 9 
Value as social conventions, Wealth as a social ideal, $38 f$

Voltaire, 109

Wallace, Graham, 51

War essential to progress, 294 to 299 $226 \mathrm{ff}$

Will of a nation, 206 to 209,210

Zimmern, 95, 164, 237 



\section{6}

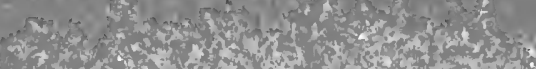

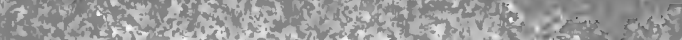

2.

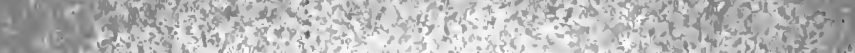

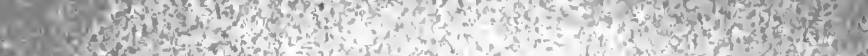

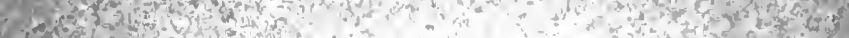

(t)

Sition

6)

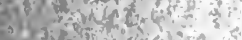

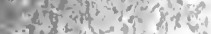

$30+3$ a

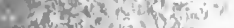

$-99+3413$

asent?

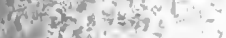

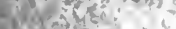

MO ght

- 4 is

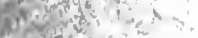

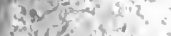

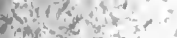

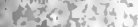

की

is $x^{2}-x^{2}$

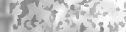

$x y=2 x^{2}+$

$7024=-14$

oif

of

and

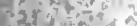

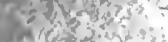

aly 3 inge?

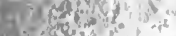

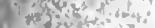

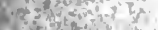

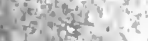

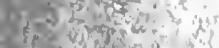

arise

Inom 3 .

स्युक

$2+2 x+4$ ?

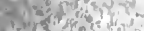

ing $f^{2}, 3 y=$

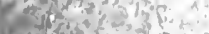

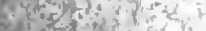

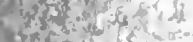

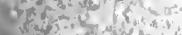

xus on of

-4 is

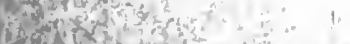

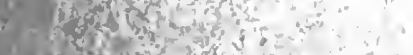

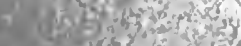

Q3

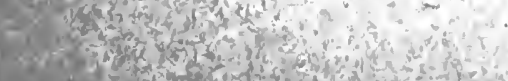

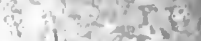

$-1, \operatorname{los}^{2}+2$

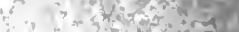

in

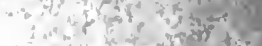

$1=-r^{2}+x^{2}$

$\rightarrow 3 x x^{2} y$

$\therefore$ 年

$x^{2}+y^{2}{ }^{2}=1$

$x_{1} x^{2} x^{2}=$

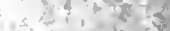

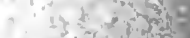

$\because 1$ tet? of

t

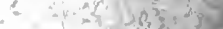

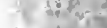

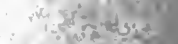

"Ni filct

$r+t^{2}+2$

is is $x^{3}$

$\therefore$.

$\because 7$ in

$\because 4$ ony

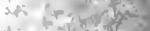

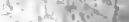

" 1 is $(2)=10$

byil.ma

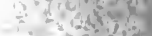

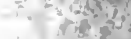

1. extex

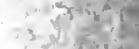

\& 7 y

intons

मीयदि?

a $x^{2}=5(y)$

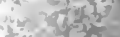

-2 de $a_{2}^{2}$

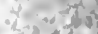

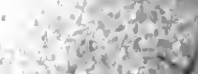

to

it

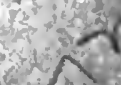

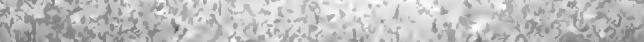


